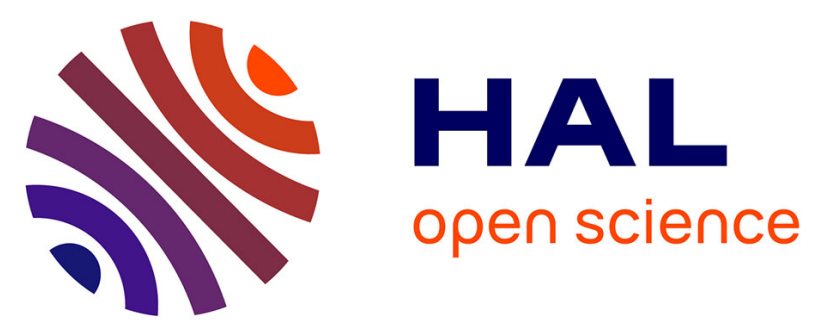

\title{
Rheological and geodynamic controls on the mechanisms of subduction and HP/UHP exhumation of crustal rocks during continental collision: Insights from numerical models
}

Evgenii E.B. Burov, Thomas François, Philippe Agard, Laetitia Le Pourhiet, Bertrand Meyer, Céline Tirel, Sergei Lebedev, Philippe Yamato, Jean-Pierre Brun

\section{- To cite this version:}

Evgenii E.B. Burov, Thomas François, Philippe Agard, Laetitia Le Pourhiet, Bertrand Meyer, et al.. Rheological and geodynamic controls on the mechanisms of subduction and HP/UHP exhumation of crustal rocks during continental collision: Insights from numerical models. Tectonophysics, 2014, 631, pp.212-250. 10.1016/j.tecto.2014.04.033 . insu-01065788

\section{HAL Id: insu-01065788 \\ https://hal-insu.archives-ouvertes.fr/insu-01065788}

Submitted on 18 Sep 2014

HAL is a multi-disciplinary open access archive for the deposit and dissemination of scientific research documents, whether they are published or not. The documents may come from teaching and research institutions in France or abroad, or from public or private research centers.
L'archive ouverte pluridisciplinaire HAL, est destinée au dépôt et à la diffusion de documents scientifiques de niveau recherche, publiés ou non, émanant des établissements d'enseignement et de recherche français ou étrangers, des laboratoires publics ou privés. 


\section{Rheological and geodynamic controls on the mechanisms of subduction and HP/UHP exhumation of crustal rocks during continental collision: insights from numerical models.}

Evgene Burov ${ }^{1,2}$, Thomas Francois ${ }^{1,2}$, Philippe Agard ${ }^{1,2}$, Laetitia Le Pourhiet ${ }^{1,2}$, Bertrandt Meyer ${ }^{1,2}$, Celine Tirel ${ }^{2}$, Sergei Lebedev ${ }^{2}$, Philippe Yamato ${ }^{3}$, Jean-Pierre Brun ${ }^{3}$. ${ }^{1}$ Sorbonne Universités, UPMC Univ Paris 06, UMR 7193, Institut des Sciences de la Terre Paris (iSTeP), F-75005 Paris, France

${ }^{2}$ CNRS, UMR 7193, Institut des Sciences de la Terre Paris (iSTeP), F-75005 Paris, France

${ }^{3}$ Dublin Institute for Advanced Studies, Geophysics Section, 5 Merrion Square, Dublin 2, Ireland.

${ }^{4}$ Géosciences Rennes, CNRS UMR 6118, Université de Rennes 1, F-35042 Rennes, France

\section{ABSTRACT}

While subduction of crustal rocks is increasingly accepted as a common scenario inherent to convergent processes involving continental plates and micro-continents, its occurrence in each particular context, as well as its specific mechanisms and conditions are still debated. The presence of UHP terranes is often interpreted as a strong evidence for continental subduction (subduction of continental crust) since the latter is seen as the most viable mechanism of their burial to UHP depths, yet if one admits nearly lithostatic pressure conditions in the subduction channel. The presumed links of continental subduction to exhumation of high- and ultra-high-pressure (HP/UHP) units also remain a subject of controversy despite the fact that recent physically consistent thermo-mechanical numerical models of convergent processes suggest that subduction can create specific mechanisms for UHP exhumation. We hence review and explore possible scenarios of subduction of continental crust, and their relation to exhumation of HP and UHP rocks as inferred from last generation of thermo-mechanical numerical models accounting for thermo-rheological complexity and structural diversity of the 
continental lithosphere. The inferences from these models are matched with the petrology data, in particular, with P-T-t paths, allowing for better understanding of subtleties of both subduction and burial/exhumation mechanisms. Numerical models suggest that exhumation and continental subduction are widespread but usually transient processes that last for less than 5-10 Myr, while long-lasting (> 10-15 Myr) subduction can take place only in rare cases of fast convergence of cold strong lithospheres (e.g. India). The models also show that tectonic heritage can play a special role in subduction/exhumation processes. In particular, when thicker continental terrains are embedded in subducting oceanic plate, exhumation of UHP terranes results in formation of versatile metamorphic belts and domes and in series of slab rollback and exhumation events with remarkably different P-T-t records.

Keywords: Continental collision; subduction; rheology; orogeny; numerical modeling; metamorphism; HP/UHP exhumation; eclogites.

\section{Introduction}

Continental subduction and the mechanisms of formation and exhumation of UHP rocks are two enigmatic processes that are closely linked together. From geodynamic point of view, the occurrence of HP-UHP rocks raises two types of questions related to the mechanisms of their burial, and to those of their return to the surface. So far the occurrence of HP-UHP rocks in zones of continental convergence is most often interpreted as evidence for subduction (e.g., Smith, 1984; Kylander et al., 2012; Hacker and Gerya, 2013). In most cases it is supposedly linked to subduction of passive margins and early stages of intercontinental collision associated with subduction of continental lithosphere (Burtman and Molnar, 1993; Burov et al., 2001; Yamato et al., 2007). In other cases UHP exhumation is produced at late stages of oceanic subduction, during the transition from oceanic subduction to continental collision (Yamato et al., 2007; Hacker and Gerya, 2013) or when small thick continental terrains (microcontinents) embedded in "normal" lithosphere are forced down together with the subducting plate and exhumed as a consequence of slab roll-back (Brun and Faccenna, 2008; Tirel et al., 2013). More specific mechanisms linked to subduction 
have been also inferred, yet, for the moment, without quantitative match with in-situ PT-paths. These include slab "eduction" (Andersen and Austrheim, 2008; Duretz et al., 2012), "subduction erosion" leading to diapiric rise of UHP terranes (von Huenen et al., 2004; Gerya and Stockhert, 2006), and foundering of orogenic roots (Hacker and Gerya, 2013).

It is worth mentioning that a number of alternative "non-lithostatic" interpretations for the occurrence of UHP terranes (e.g., Mancktelow, 1995; 2008; Petrini and Podladchikov, 2000; Schmalholz and Podladchikov, 2013; Schmalholz et al., this volume) exists, suggesting that non-lithostatic overpressure of different nature may alter pressure levels recorded by the UHP material by up to a factor of 2 , so that the UHP rocks may be formed at about $50 \mathrm{~km}$ depth and hence do not need to be transported to those great "subduction" depths (> 100-200 km) inferred from the lithostatic hypothesis. It is hence argued that the occurrence of UHP material does not present evidence for continental subduction and, by extrapolation, that the latter might not exist, or at least is not needed for explanation of the occurrence of the UHP terranes. The overpressure models inherently imply that P-T-t data are of limited use as markers of dynamic processes. Indeed, if subduction does not take place, then overpressure can be built in the compressed media at levels determined exclusively by the local yield strength and loading conditions, which depend on many uncertain factors such as rheological properties, fluid content, porous pressure, etc., resulting in almost $+100 \%$ error on depth estimations. Alternatively, full-scale subduction models (e.g., Toussaint et al., 2004a, Li et al., 2010) predict no significant non-lithostatic pressures in non-locked subduction channel $(<20 \%$ below $50 \mathrm{~km}$ depth) allowing for reliable interpretation of P-T/P-T-t data.

Therefore, elucidation of the mechanisms of formation and exhumation of the UHP rocks is of utmost importance both for understanding the mechanisms of continental convergence (e.g. subduction versus pure shear or folding) and for evaluation of the degree of utility of the petrology data for constraining geodynamic processes.

Indeed, the incidence of "anti-subduction" models of UHP rock formation (e.g., Petrini and Podladchikov, 2000; Schmalholz and Podladchikov, this volume) can be explained by quite reasonable doubts in physical plausibility of crustal subduction in 
continental settings where slow convergence rates and high buoyancy of continental crust are largely unfavorable to subduction processes. Subduction is only one of four possible mechanisms of accommodation of tectonic shortening (Figure 1): pure-shear thickening; simple shear subduction or underplating; folding (Burg and Podladchikov, 2000; Cloetingh et al., 1999), and gravitational (Raleigh-Taylor (RT)) instabilities in thickened, negatively buoyant lithosphere (e.g., Houseman and Molnar, 1997) dubbed here "unstable subduction." Whereas in oceans subduction is a dominating mode of accommodation of tectonic compression, in continents all of the above scenarios can be superimposed at large proportions. For instance, "megabuckles" created by lithospheric folding (Burg and Podladchikov, 2000) can in theory localize and evolve into mega-thrust zones or result in the development of Rayleigh-Taylor (RT) instabilities. RT and boudinage instabilities leading to slab-break-off may also occur in subducting lithosphere leading to interruption of the subduction process (Pysklywec et al., 2000).

However, it is not only the presence of UHP material but also a host of structural and geo-geomorphological (e.g., Hacker et al., 2006) and geophysical data (e.g., Ford et al., 2006; Zhang et al., 2009; Handy et al., 2010; Tetsuzo and Rehman, 2011) that provide a support for the idea that continental subduction takes place at some stages of continental convergence (e.g., Toussaint et al., 2004a,b). For example, at least $700 \mathrm{~km}$ of Indian continental crust are "missing" from surface since India-Asia collision (e.g., DeCelles et al., 2002), and hence had to be buried in some way at depth. Physical conditions for subduction include (1) presence of sufficient far-field slab-pull/push forces, (2) weak mechanical coupling between the upper and lower plate (i.e., weak subduction interface) and (3) sufficient mechanical strength of the lower plate assuring preservation of its geometric and mechanical integrity during subduction. In oceans, additional strain localization and plate weakening mechanisms are needed for subduction initialization and for downward bending of strong lithosphere when it slides below the upper plate (Cloetingh et al., 1982; McAdoo et al., 1985; Watts, 2001). Enhanced pre-subduction bending of the lithosphere is possible due to inelastic flexural weakening, that is, ductile yielding and "plastic hinging" produced by high flexural stresses near the peripheral bulge (McAdoo et al., 1985; Burov and Diament, 1995; Burov, 2010a;2011). Flexural weakening of oceanic lithosphere is amplified by pressure reduction due to pore fluids and rheological softening due to metamorphic reactions, 
e.g., serpentinization, produced by fluids penetrating in normal faults created by tensional flexural strains in the uppermost parts of the peripheral bulge (e.g., Ranero, 2003; Faccenda et al., 2009a; Hacker et al., 2010; Angiboust et al., 2012; Kylander et al., 2012). In continental settings, subduction initialization is actually less problematic since the continental lithosphere follows the path open by the preceding oceanic subduction.

Since the slab pull/push forces can be directly estimated from gravitational force balance, the most uncertain conditions here refer to the mechanisms of weakening of the subduction interface and to the preservation of slab strength (and integrity) during subduction. The former seem to be influenced by metamorphic processes, at least in two aspects: one concerning the role of the metamorphic materials in enabling subduction processes, and the other concerning the capacity of the lithosphere to transport crustal rocks - future high-pressure metamorphic materials - to a great depth. As mentioned above, it is generally agreed, based both on models and observations, that oceanic subduction is possible due to lubrication of the subduction interface by serpentinized mantle layer formed along crust-mantle interface, and due to mechanical weakening resulting from reactions with free and hydrous fluids released or absorbed during metamorphic phase changes (e.g., Ranero, 2003; Faccenda et al., 2009a; Hacker et al., 2010; Angiboust et al., 2012; Kylander et al., 2012). In continents, the governing weakening mechanisms are not well established but the presence of thick, relatively weak and rheologically stratified crust appear to be of primary importance (e.g., Burov et al., 2001; Yamato et al., 2008). Strength reduction and density changes due to metamorphic transforms in LP-HP range and the associated partial melting should also play a certain role (Yamato et al., 2008), but the impact of UHP transforms on subduction may be of minor importance (Toussaint et al., 2004a), specifically if one remembers that some UHP transforms occur during the exhumation stage only (Peterman et al. , 2009). Preservation of slab integrity is a major problem for continental subduction, since continental convergence occurs at much slower rates than in oceans. In the case of oceanic subduction (at rates of $5-15 \mathrm{~cm} \cdot \mathrm{yr}^{-1}$ ), the slab has no time to heat up due to the thermal diffusion from the surrounding asthenosphere. As a consequence, it loses its strength only at a great depth. In continents, convergence rates are much slower, sometimes not exceeding a few mm.yr ${ }^{-1}$. Under these 
conditions, the lithosphere may heat up, thermally weaken and drip-off before it reaches the UHP depth (e.g., Yamato et al., 2008).

Oceanic subduction has numerous lines of direct evidence such as Benioff zones, straight kinematic inferences from paleomagnetic data, relatively "sharp" tomographic images and gravity anomalies. For continental subduction, on the other hand, the corresponding observational data is much more "blurred", such that probably one of the most straightforward evidences for continental subduction refers to the presence of HP and UHP metamorphic material in convergence zones (e.g., Hacker et al., 2006; Guillot et al., 2000;2001;2009; Li Sanzhong et al., 2009; Ernst, 2010; Maruyama et al., 2010; Lanari et al., 2012). The high- to ultrahigh-pressure (HP/UHP) metamorphic belts are believed to be witnessing subduction processes as the exhumed continental blocks appear to bear an overprint of the subduction record as they return to surface (e.g. Ring et al., 2007; Zhang et al., 2009; Hacker et al., 2010; Diez Fernández et al., 2012). This evidence is generally preserved in small and disconnected lenses (eclogite blocks in blocks in a quartzofeldspathic matrix, see Hacker et al., 2006 for review), as mineral relicts within a dominant low- to medium-pressure metamorphic matrix (e.g., Guillot et al., 2009), and more rarely as relatively large HP/UHP units (e.g., Yamato et al., 2008). If one assumes lithostatic P-T conditions commonly inferred for subduction zones, then UHP material should have been buried to depths of 100-170 km and brought back to the surface. Consequently, if the UHP depth estimates are valid (e.g., Spear, 1993), the HP/UHP rocks can be regarded as passive markers of continental subduction and their P-T-t paths can be used for reconstruction of subduction dynamics and of the conditions at the subduction interface. Under these assumptions, detailed studies of HP/UHP rocks can provide constraints on thermo-mechanical processes in subduction zones (Coleman, 1971; Ernst, 1973; 2010). These data provide insights on exhumation mechanisms as well, since different processes and contexts potentially result in different styles of deformation and, hence, in different exhumation P-T-t paths. In particular, based on the analysis of metamorphic data (Ernst, 2010) it has been suggested that two main types of continental convergence can be distinguished: fast "Pacific underflow", where continental subduction is preceded by that of thousands of $\mathrm{km}$ of oceanic lithosphere, and slow "Alpine closure" of an intervening oceanic basin leading to short-lived continental subduction soon followed by pure shear collision. It 
has been also pointed out that the exhumed HP-UHP complexes display low-aggregate bulk densities (e.g., Ernst, 2010), while the exhumation rates in some cases largely exceed the convergence rates (e.g., Yamato et al., 2008), jointly suggesting a buoyancydriven ascent mechanism.

Large-scale nappes stacking and folding, and other complex deformation processes occurring at subduction interface largely distort kinematic imprint of subduction (e.g. Diez Fernández et al., 2012; Tirel et al., 2013), hence justifying a numerical modeling approach for decrypting and matching structural and metamorphic observations. For this reason, in recent approaches, the data from HP and UHP rocks are treated in conjunction with synthetic P-T-t paths predicted from thermo-mechanical numerical models of convergent processes. This provides validation of the inferred concepts of convergent dynamics and thermo-mechanical properties of oceanic and continental subduction zones (e.g., Yamato et al., 2007; 2008; Li and Gerya, 2009). However, both, the mechanisms of continental convergence and of exhumation of HP/UHP material are still very much in debate, and the ideas on the interpretation of metamorphic data and on the mechanisms of convergence require further investigation. In particular, for each given context it should be demonstrated, in an independent way, that: (1) continental subduction is a viable mechanism of accommodation of tectonic shortening; (2) it is possible to propose a particular mechanism of HP/UHP exhumation compatible both with the P-T-t data and with the proposed subduction dynamics.

According to observations (e.g., Ernst, 2010; Diez Fernandez et al., 2012) and recent modeling results (e.g., Yamato et al., 2008; Burov and Yamato, 2008; Li and Gerya, 2009), exhumation and collision mechanisms are versatile and in general polyphase. However, it comes out from regional-scale numerical experiments that continental subduction provides a physically most consistent background for formation and exhumation of the HP/UHP material. The numerical models also reproduce the observations suggesting that exhumation of the UHP material goes by contextdependent multi-stage mechanisms. In particular, exhumation of the UHP material from depths in excess of typical crustal depths (40-50 km) may occur by Stokes flow mechanism at a high rate controlled by buoyancy and viscosity of the matrix, while, when the UHP material reaches $40-50 \mathrm{~km}$ depth it is more slowly dragged to the surface 
within the accretionary prism, or by simple shear upward sliding of semi-brittle crustal slices and large multi-kilometer scale segments (Burov et al., 2001; Yamato et al., 2008).

Whatever is the mechanism of UHP exhumation, one can conclude that in case of stable subduction, the subduction interface should be devoid of significant deviations from lithostatic pressure conditions (Burov et al., 2001; Burov and Yamato, 2008; Li et al., 2010). In case of stable subduction, only small in-channel under-pressures and overpressures $(20 \%$, or $<0.3 \mathrm{GPa}$ ) may be produced at depths below $40-50 \mathrm{~km}$ (Toussaint et al., 2004n; Burov and Yamato, 2008; Li et al., 2010), even though the surrounding lithosphere constituting the upper and lower wall of the channel may experience pressure deviations of up to $50 \%$ of lithostatic level (e.g., Toussaint et al., 2004a; Li et al., 2010). The in-wall over-and under pressures are basically caused by bending stress concentrations, yet, these zones belong to the channel walls and do not participate in the exhumation turn-over (Burov and Yamato, 2008). Consequently, all studies converge to the point that if subduction takes place, the UHP P-T-t data can be decoded in terms of exhumation depth within 10-20\% accuracy using lithostatic pressure gradients.

By now, a large number of modeling studies have investigated various factors influencing subduction processes (e.g., Doin and Henry, 2001; Pysklywec et al., 2000; Sobouti and Arkani-Hamed, 2002; Chemenda et al., 1995;1996; Gerya et al., 2002; Yamato et al., 2007,2008; Warren et al., 2008a,b; Li and Gerya, 2009; Li et al., 2010; Sizova et al., 2012; Gray and Pysklywec, 2010; 2012). However, not all of the existing models are sufficiently consistent. The analogue models are largely inadequate because of impossibility to incorporate phase changes, rheological simplifications, absent or poorly controlled thermal coupling (not mentioning that it is practically impossible to extract PT paths from these models). The numerical models are often limited by simplified visco-plastic rheologies or by the rigid top/"sticky air" upper-boundary condition, which is widely used instead of the paramount free-surface boundary condition. The use of rigid-top upper-boundary condition forces stable subduction (Doin and Henry, 2001; Sobouti and Arkani-Hamed, 2002), attenuates pure shear, cancels folding and does not allow for consistent prediction of topography evolution. Many models also do not incorporate surface processes which are key forcing factors of 
continental collision (e.g., Avouac and Burov, 1996; Avouac, 2003; Toussaint et al., 2004b; Burov and Toussaint, 2007; Burov, 2010b) and an integral part of the final stages of exhumation. Some studies also force a specific convergence mode, in particular, subduction, via prescription of favoring boundary conditions, for example, by putting an additional boundary condition (e.g., "S-point") inside the model (e.g., Beaumont et al., 1996; Beaumont et al., 2000). Some other models favor pure shear collision by including a weak zone in the plate shortened in the direction opposite to the pre-imposed mantle flow (Pysklywec et al., 2002). Some older codes operating in deviatoric stress formulation (e.g., Navier-Stokes approximation) had specific problems with accurate evaluation of total pressure needed for tracing of P-T-t conditions and correct account for brittle deformation (this problem was fixed in most of the recent codes). Even though some earlier modeling studies (Burov et al., 2001; Toussaint et al., 2004a,b; Burg and Gerya, 2005; Gerya et al., 2002) have considered phase changes, fully coupled models with progressive phase changes directly derived from thermodynamic relations have emerged only few years ago (Stöckhert and Gerya, 2005; Yamato et al., 2007; 2008; Li and Gerya, 2009; Li et al., 2010;2011; Francois et al., 2014).

Summarizing the requirements to the new generation of numerical models of collision and exhumation, we therefore can note that they should:

(1) consider the entire regional context, i.e. encompass lateral spatial scales from $1500 \mathrm{~km}$ and vertical scales from $400 \mathrm{~km}$; (2) allow for all modes of deformation, (3) account for viscous-elastic-plastic rheology and thermal evolution, (4) be thermodynamically coupled, i.e. account for phase changes (and ideally also for fluid circulation), (5) account for surface processes and free-surface boundary condition (or at least incorporate "sticky air" approximation of the free surface), (6) provide an accurate solution for total pressure and report P-T paths based on the dynamic total pressure, rather than based on depth.

It is hence evident that a joint approach considering collision processes in direct relation to exhumation and formation of HP/UHP material is the most promising one for understanding both the mechanisms of continental convergence and of exhumation.

The goal of this paper is therefore multi-fold: we start from discussing different concepts linking continental convergence with formation and exhumation of UHP terranes. We then discuss physical and rheological conditions allowing for subduction in 
continental settings, with a specific focus on the conditions allowing for preservation of slab integrity. We next revise the conditions for HP/UHP exhumation. We finally link all processes together attempting to obtain better insights on the mechanisms of continental convergence, and, by proxy, of formation and exhumation of the HP/UHP material.

\section{Non-lithostatic models of formation and exhumation of UHP rocks during continental collision.}

As mentioned, several alternative mechanisms have been proposed both to explain the mechanics of continental convergence, and formation and exhumation of HP/UHP material. Their common feature refers to the idea that the UHP material comes from shallower depths than is commonly inferred from the assumption of the lithostatic pressure gradient. This implies a presence of static or dynamic overpressure during UHP rock formation which can be created by different mechanisms most of which are incompatible with continental subduction. The major thrust of this models is therefore that (1) continental subduction does not exist or is incapable to bring crust to important depth and (2) that P-T/P-T-t data cannot be directly interpreted in terms of depth at trajectories of the exhumed units.

Some of the suggested mechanisms of convergence are more or less directly associated with the mechanisms of exhumation, some not. For example, in the second case, Petrini and Podladchikov (2000) suggested tectonic overpressure as the mechanism of formation of UHP rocks that, according to the concept, originate from potentially twice smaller depths $(50-75 \mathrm{~km})$ than the usually inferred lithostatic depths of $100-170 \mathrm{~km}$. These authors infer, consequently, that continental subduction does not take place or at least is not the most probable mechanism for UHP rock formation. This conceptually straightforward and formally mechanically consistent conceptual model has, however, a number of narrow places. In particular, it requires that the entire lithosphere reaches the yield state, which needs tectonic forces on the orders of magnitude higher than estimated slab push/pull forces $\left(\sim 10^{12} \mathrm{~N}\right.$ per unit length, Turcotte \& Schubert, 2002). Even though the latter limitation may be bypassed by assuming only localized stress concentrations in 50-80 km depth interval, the maximal over-pressure values may be still limited in nature due to the fact that Byerlee's law is 
relayed by "weaker" Peierl's or GBS creep at mantle lithosphere depths (e.g. Burov, 2011). Another drawback of this concept refers to the fact that it does not provide a particular mechanism for burial and exhumation to-and-from the $50-80 \mathrm{~km}$ depths while the "common" accretionary prism mechanism is limited to $40 \mathrm{~km}$ depth (Platt, 1993) due to the exponential drop of the viscosity of prism material with depth/temperature.

Other workers (e.g., Raimbourg et al., 2007) have chosen another extremity by ultimately linking UHP exhumation to the conventional "subduction channel" concept, in which rocks are dragged down with plate interface by Couette flow, and returned back by Poiseuille flow associated with positive buoyancy of crustal material (Mancktelow, 1995). As mentioned, the "Couette" component of this mechanism cannot work at depths in extent of $40-50 \mathrm{~km}$ due to the exponentially rapid drop of channel viscosity with depth. Therefore it has been suggested (Mancktelow, 1995) that dynamic overpressure builds inside the channel due to a hypothesized decrease of channel width with depth. This is supposed to produce dynamic overpressure by "rocket nozzle" effect (Bernulli's effect) and reduce the depth of the UHP rock formation to $40-50 \mathrm{~km}$. However, Bernull's effect can be persistent only if channel walls are rigid and remain unmovable, while it is widely observed that the lithosphere and hence the subduction channel bends under flexural loads and tectonic forces of less than $10^{12} \mathrm{~N}$ per unit length as well as it locally widens when, for example, a seamount subducts at trench axis (Watts, 2001). Indeed, an overpressure of 2GPa (needed to divide the UHP depth by a factor of 2) in a $50 \mathrm{~km}$ long channel would yield an expansion force on the order of $10^{14} \mathrm{~N}$ per unit length acting on channel walls. Such force is sufficient not only to widen the channel but simply to break apart the entire lithosphere. Even if one considers a much smaller effective channel length of $1 \mathrm{~km}$ (assuming small-scale localized overpressure anomalies), the repulsive force $\left(10^{12} \mathrm{~N}\right.$ per unit length ) will be high enough to push the colliding plates apart, hence widening the channel and automatically cancelling the overpressure. In this relation it is noteworthy that metamorphic terranes often exhibit multi-kilometer scales (Hacker, 2006), which means that UHP conditions should be created at multi-kilometer scales as well. Further numerical thermo-mechanical models of subduction have confirmed these arguments by showing that pressure-driven channel overpressure concepts cannot explain UHP 
burial/exhumation (Burov et al., 2001; Toussaint et al., 2004a; Yamato et al., 2008; Li et al., 2010), even in the oceanic contexts (Yamato et al., 2007; Angiboust et al., 2012). According to these models, underpressure or overspressure in the subduction channel produces its "ballooning", "deflating" or out-of plane flow leading to automatic reestablishement of pressure balance with the environment. As result, intra-channel pressure deviations from lithostatic conditions do not exceed $20 \%$ at depths in excess of 50 km (e.g., Toussaint et al., 2004a; Li et al.; 2010) while significant overpressures (yet not exceeding $50 \%$ of lithostatic pressure) can be indeed created by flexural stresses and fiber forces within the channel walls.

As a matter of fact, most overpressure models remain at conceptual stage and are not really testable against observations. The only exception refers to the work by Schmalholz and Podladchikov (2013) and Schmalholz et al. (this volume), who have presented a thermo-mechanical overpressure numerical model in tectonic-scale shear bands that technically has got all necessary features allowing for prediction of testable PT paths, surface and structural evolution. Yet, this numerically state-of-the-art model is still far from being convincing: it is based on local-scale setup and therefore is not tested in regional tectonic context; the model-predicted PT paths are different from those typically observed; the predicted surface uplift rates (hence, probably intraplate forces) are far too high, with $5 \mathrm{~km}$ of surface uplift in about $2 \mathrm{Myr}$ (Schmalholz et al. , this volume). This model has potential for further development and future will show if it can be finally applied within regional context and match the observations at same extent as the recent subduction models.

Despite the shortcomings of the existing overpressure models, one must agree that strong overpressures are possible in some contexts. For example, volumetric expansion of mineral inclusions in locally stiff rock matrix can result in important overpressures inside the mineral seeds protected by the matrix. Consequently, small and sparse UHP inclusions cannot be considered as evidence for continental subduction.

\section{Preservation of slab integrity as paramount condition of subduction.}

Subduction implies preservation of slab integrity, hence small bulk deformation of the lower plate during convergence: a subducting plate bends without significantly changing its length and thickness. The slab should also provide an efficient stress guide 
for push/pull forces that drive subduction. To meet the above conditions, the lithosphere has to preserve sufficient mechanical strength as it sinks into the asthenosphere. Otherwise it would stretch or thicken, break-off, stagnate or drip-off under the action of the external shear, push-pull forces and viscous gravitational Raleigh-Taylor instabilities. Preservation of slab integrity (= small internal strain rate) is also equivalent to nearly invariable plate-parallel component of plate velocity. Since slab push- pull, shear and body forces acting on the opposite ends of the plate are largely different, this condition can be satisfied only if the slab stays strong even at great depth.

Olivine-rich rocks of lithosphere mantle exhibit important ductile deformation at temperatures above $500-600^{\circ} \mathrm{C}$ in oceans $(P>0.4 \mathrm{GPa})$ and at $700-800^{\circ} \mathrm{C}(P>1.2 \mathrm{GPa})$ in continents (e.g., Goetze and Evans, 1979). The higher yield-strength temperature in continents is related to to higher pressure (depth) at equivalent temperature. Hence, to preserve its strength, slab should remain cold, i.e. rapidly descent in the asthenosphere and have no time to heat up - hence weaken - due to heat diffusion from hot environment $\left(>1330^{\circ} \mathrm{C}\right)$. Therefore, one can characterize minimal thermorheological condition for stable subduction by "subduction Péclet number" $P e_{s}$ :

$$
P e_{s}=u^{2} t_{s} / \kappa
$$

where $t_{s}$ is a characteristic time scale, $u$ is plate-parallel (horizontal at surface) plate velocity and $\kappa$ is thermal diffusivity $\left(\approx\right.$ on the order of $\left.10^{-6} \mathrm{~m}^{2} \mathrm{~s}^{-1}\right)$. The corresponding thermal diffusion length is $I_{d}=\left(t_{s} \kappa\right)^{1 / 2}$. The characteristic time scale $t_{s}$ hence corresponds to the average life span of stable subduction, i.e. to the time interval between the onset of subduction and the moment when simple shear is no more dominant deformation mode, being progressively suppressed by other modes such as pure shear shortening, RT instabilities, or folding (Figure 1). After that, heat advection mechanism is no more directly dependent on the convergence rate, and the equation (1) does not hold anymore. This condition can be also used to characterize the prograde parts of the metamorphic P-T-t paths.

For preservation of considerable slab strength for a time $t_{s}, l_{d}$ should be significantly less than $h_{k}$, where $h_{k}$ is the apparent thickness of strong, nearly elastic mechanical core of the lithosphere when it arrives at the subduction zone. Having a strong core is a condition for transmission of intra-plate stresses with minimal internal 
shortening of the lithosphere, which is equivalent to assuming that heat advection is primarily dependent on the convergence rate $u$, as expressed by the equation (1). Let us assume $I_{\mathrm{d}} \leq 0.25 h_{k}$, that is, a maximum factor of 2 reduction of the thermomechanical thickness of the slab by time $t_{s}$ (slab heats up both from its upper and lower interface, $\left.(0.25 \times 2)^{-1}=(0.5)^{-1}\right)$. Hence, the characteristic time scale of subduction is:

$$
t_{s} \approx l_{d}^{2} / \kappa \approx 0.0625 h_{k}^{2} / \kappa,
$$

and the minimal condition for stable subduction is:

$$
P e_{s} \gg P e_{k}=u h_{k} / \kappa
$$

If $P e_{s}$ is smaller than $P e_{k}$, thermal weakening of the slab, caused by heat diffusion, prohibits stable subduction (Toussaint et al., 2004a). As also follows from eq. 2 , if eq. 3 is satisfied, then the characteristic subduction length $d_{\mathrm{s}}$ (the length of "subductable" lithosphere), can be roughly estimated as:

$$
d_{s} \approx u t_{s} \approx 0.0625 u h_{k}^{2} / \kappa,
$$

which means that maximal stable subduction depth for lower crustal units (initial crustal thickness $h_{\mathrm{c}}$ plus $d_{\mathrm{s}}$ multiplied by tangent of the dip angle) is (1) linearly proportional to subduction rate and (2) quadratically proportional to the mechanical thickness of the lithosphere at the surface. Hence, convergence rate is a secondary factor compared to the initial mechanical strength of the lithosphere, which is thus of major importance for subduction. The above estimations are very approximate. One can complement them by evaluating an additional hard limit on the duration of the subduction, that is, the maximal time $t_{b \max }$ of slab break-off, which will happen no later than when the mechanical core of the lithosphere vanishes, i.e. when $(t \kappa)^{1 / 2} \sim 0.5 h_{k}$.

$$
t_{\text {bmax }}<0.25 h_{k}^{2} / \kappa,
$$

with maximal slab-brak-off depth, $d_{\mathrm{sbmax},}$

$$
d_{\text {sbmax }}<u t_{b \max } .
$$

This yields $t_{b \max }$ of 3-7 Myr for lithosphere with initial $\mathrm{T}_{\mathrm{e}}=20-30 \mathrm{~km} \mathrm{(e.g.,}$ Western Alps), 20Myr for lithosphere with initial $\mathrm{T}_{\mathrm{e}}=50 \mathrm{~km}$ (e.g., Zagros), and up to 39-64Myr for lithosphere with $\mathrm{T}_{e}=70-90 \mathrm{~km}$ (India - Himalaya collision). Surprisingly, these simple estimates match the inferences from observations and thermo-mechanical models for the respective regions (e.g., Yamato et al., 2008; Thomas et al., 2012; Toussant et al., 2004b; Angiboust et al., 2012). Nevertheless, the Eq. 5 may not hold well for slow convergence settings (e.g. $u<2 \mathrm{~cm} . \mathrm{yr}^{-1}$ ) because of strong influence of 
thermo-mechanical instabilities that may develop at similar time scale.

The thickness of the mechanical core of the lithosphere $h_{k}$ can be constrained from observations of plate flexure that reveal significant plate strength in zones of oceanic subduction and in many zones of continental collision (Watts, 2001). The observed equivalent elastic thickness of the lithosphere, $T_{\mathrm{e}} \sim h_{k}$, is a direct proxy for the long-term integrated strength, $B$, of the lithosphere (see Watts, 2001). For example, for a single-layer plate of mechanical thickness $h_{m}$ with $\mathrm{T}_{\mathrm{e}}=\mathrm{T}_{\mathrm{e} \_ \text {ocean }}$ :

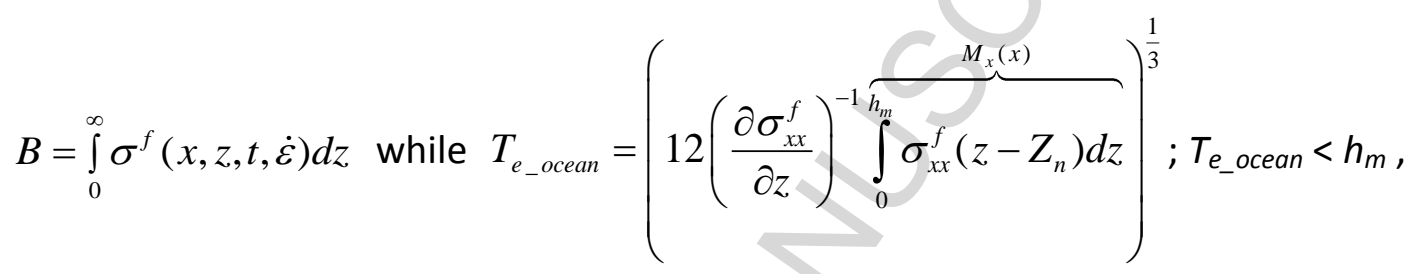

where $x, z, t, \dot{\varepsilon}$ are horizontal and vertical (with respect to local plate coordinates) coordinate, time and strain rate, respectively, $Z_{\mathrm{n}}$ is the position of the neutral fiber within the plate, $\sigma_{x x}^{f}$ is bending stress and $M_{x}$ is bending moment (Burov and Diament, 1995). For inelastic rheology and rheologically stratified lithosphere, $T_{e}$, is smaller than $h_{m}$. In this case $\mathrm{T}_{\mathrm{e}}$ has no geometrical interpretation, and can be identified with our definition for $h_{\mathrm{k}}$ (apparent mechanical thickness of the lithosphere). $T_{e}$ varies spatially due to its dependence on local bending stress that leads to localized plate weakening (called plastic or ductile hinging) in the areas of utmost flexure, e.g. near subduction zones (at the peripheral bulge) or below mountains and islands. As discussed in previous sections, ductile-plastic hinging is important property allowing for subduction.

Typical values of $T_{e}$ of the oceanic lithosphere correlate with the depth of $500^{\circ}$ $600^{\circ} \mathrm{C}$ geotherm and are roughly equal to $30-50 \mathrm{~km}$ near subduction zones (e.g., Burov and Diament, 1995; Watts, 2001). By analogy with oceanic plates, we can assume the same minimal $T_{e}$ value for subduction of continental lithosphere. Continental plates are characterized by $T_{e}$ values varying between 15 to $90 \mathrm{~km}$ (e.g., Burov and Diament, 1995; Cloetingh and Burov, 1996; Pérez-Gussinyé and Watts, 2005). Hence, only some of them are strong enough to develop oceanic-type subduction provided that other conditions (e.g., buoyancy versus shear force balance) are also favorable. For example, consider a convergence rate $u$ of $1 \mathrm{~cm}$. $\mathrm{yr}^{-1}$. Assuming a value for $h_{k}$ of $50 \mathrm{~km}$ we obtain $P e_{k} \sim 16$. Then, from $l_{\mathrm{d}} \leq 0.25 h_{k}$, one obtains $t_{s} \leq 5 \mathrm{Myr}$. For $t_{s}$ greater than $5 \mathrm{Myr}, P e_{s}$ is smaller 
than $P e_{k}$, suggesting that sustainable long-lasting subduction is improbable (characteristic stable subduction length $\sim u t_{s}=50 \mathrm{~km}$; maximal slab-break-off depth $\left.u t_{\text {bmax }}<200 \mathrm{~km}\right)$ at such a slow convergence rate. However, for $u=5 \mathrm{~cm} . \mathrm{yr}^{-1}, P e_{k} \sim 80$ and $P e_{s} \sim 400$ suggesting that stable subduction (characteristic subduction length $u t_{\mathrm{s}}=$ $250 \mathrm{~km}$ ) is possible even for time spans greater than 5Myr. As extreme example, we can consider India-Asia collision ( $h_{\mathrm{k}} \approx 80-90 \mathrm{~km}$ (Watts, 2001), $t_{s} \sim 12-15 \mathrm{Myr}, u=5$ $\mathrm{cm} . \mathrm{yr}^{-1}$ ). For these conditions we obtain minimal $P e_{s}>953$ and minimal $P e_{k}=127$, which implies that subduction is dominating mode and that at least $600 \div 750 \mathrm{~km}$ $\left(=u t_{s}\right)$ of the Himalayan convergence could have been accommodated in subduction regime. The maximal amount of subduction could be even much more important $\left(u t_{\text {bmax }}>2500 \mathrm{~km}\right)$, meaning that slab-break off would never happen if the Indian slab was sinking at a steep angle into the upper mantle (the reality is more complex since Indian plate appears to underplate the Tibetan plateau). These very rough estimates are, however, comparable with interpretations $(500-1000 \mathrm{~km}$ of subduction, up to $1500 \mathrm{~km}$ of total convergence) of geological and paleomagnetic data (Patriat et Achache, 1984 ; Chen et al., 1993; Patzelt et al., 1996; Avouac et al., 2003).

The first-order estimations reasonably comply with the results of recent geodynamic thermo-mechanical models. In particular, Yamato et al (2008) have shown that slow $\left(<1 \mathrm{~cm} \cdot \mathrm{yr}^{-1}\right)$ Alpine subduction could have lasted no more than 5-10 Myr (between $30 \mathrm{Ma}$ and $35 \mathrm{Ma}$ ) and that soon after that the lithosphere had to enter into unstable mode or pure shear collision mode. In this case, the slab was no longer simply descending at the convergence rate but also stretching, and an early slab break-off at about 200-250 km depth resulted in cessation of continental subduction. Slab stretching has actually allowed to bring rocks to $120 \mathrm{~km}$ depth. On the contrary, for the fast (5 $\mathrm{cm} \mathrm{yr}^{-1}$ ) convergence such as the India-Asia collision (Toussaint et al. , 2004a,b; Burov and Yamato, 2008) or past collision between North China and Yangtze craton (Li and Gerya, 2009; Li et al., 2011), it has been shown that sustainable subduction could continue for a very long period of time absorbing considerable amounts of tectonic shortening (e.g., at least 700-800 km for Indian collision). In such settings, slab breakoff either does not occur or has little effect on the collision mode. In particular, slabbreak-off depth increases with increasing subduction rate and strength of the lithosphere, so in cases of fast subduction, slab-break off, if happens, takes place far 
deep from the surface (at distance $l, u t_{s}<I<u t_{\text {bmax }}$ ) and thus has a limited impact on surface evolution (eq. 5).

One can suggest on the base of this discussion that subduction rates are linked to the initial strength of the mantle lithosphere. Fast $\left(>2-3 \mathrm{~cm} . \mathrm{yr}^{-1}\right)$ continental subduction appears to be only possible in the presence of a strong mantle lithosphere.

Numerical models have also shown that the rheological properties of the continental subduction interface and, therefore, of metamorphic reactions transforming host rocks into weaker phases, are of potentially primary importance for the evolution of continental convergence (Warren, 2008a,b; Burov and Yamato, 2008), even though the role of the UHP material in this process may be of no importance in some cases (e.g., Western Gneiss Region in Norway, Peterman et al., 2009) . It has been demonstrated that subduction takes place only when the interface between the colliding plates has a low mechanical strength allowing for sliding of the lower plate below the upper plate. Early studies (Hassani et al , 1997) found that the effective friction angle of the subduction interface has to be as low as $5^{\circ}$ for sustainable subduction to occur. Since real rocks have practically invariable internal friction angle $\left(\sim 30^{\circ}\right)$, it is evident that lubrication of the subduction interface is produced by nonbrittle mechanisms such as ductile flow in weak metamorphosed layers, assisted by shear heating and fluids. In the case of oceanic lithosphere, the lubrication of the subduction interface is provided by very weak serpentine layers that form at the crustmantle interface due to infiltration of fluids through flexurally induced normal faults and fractures (Jolivet et al., 2005; Yamato et al., 2007; Faccenda et al., 2009a; Angiboust et al., 2012). Hydrated serpentinite layers transport fluids to great depths along the subduction interface; these fluids are then released due to dehydration of serpentinite at high pressure/temperature conditions, further weakening the subduction interface and causing partial melting that leads to weakening of the subduction wedge and the back-arc zone (Gerya et al., 2008). In the case of continental subduction, the lithosphere has less ability to transfer fluids to depth, and metamorphic phases, presented such as shists and higher grade facies like eclogites are mechanically stronger than serpentine. Hence, for a given subduction rate, the resistance of the continental subduction interface may be higher than in the case of oceanic subduction. In addition, thick continental crust has a positive buoyancy that creates body forces 
opposing slab pull/push forces (Figure 2). Therefore, in most cases the duration of continental subduction should be limited; at the beginning it is facilitated by the pull of the oceanic slab, which decreases with time, and by initially higher convergence velocity. The latter hypothesis is confirmed for collision zones where paleomagnetic and geological records allow for reconstruction of convergence rates (Patriat and Achache, 1984). Apart of lubrication of the subduction interface and plastic hinging of the plate at the peripheral bulge, several other conditions should be satisfied to allow for the development of continental subduction (e.g., Afonso et al., 2011). In particular, growth rates of the competing modes of deformation (RT instability, folding, pure shear) should be small, and the upward drag (eduction force) due to the buoyant crust and viscous shear must be smaller than tectonic and slab pull forces. The combined effect of these multiple factors can be only assessed through numerical modeling (e.g., Toussaint et al., 2004a, 2004b; Burov and Watts, 2006; Faccenda et al., 2008; 2009a,b; Sizova et al., 2012, Duretz et al., 2011). These parametric studies have shown that continental subduction can occur and remain sustained over tens of million years only if the lithosphere is initially cold, and remains cold during subduction, which, in the case of continental lithosphere (e.g., Toussaint et al., 2004a, 2004b) implies initial Moho temperatures of less than $550^{\circ} \mathrm{C}$, and convergence rates higher than $2-3 \mathrm{~cm} . \mathrm{yr}^{-1}$. It is therefore reasonable to assume that after the onset of collision between, for example, India and Eurasia, when the convergence rate was about $10 \mathrm{~cm} \cdot \mathrm{yr}^{-1}$ (Patriat and Achache, 1984), the oceanic subduction turned into subduction of the Indian continental lithosphere (Avouac et al., 2003; Toussaint et al., 2004b). The critical values of Moho temperature $\left(550^{\circ} \mathrm{C}\right)$ corresponds to the reference rheology profile (e.g. Toussaint et al., 2004b). More dry and more basic crustal compositions will result in stronger crust and hence critical "subduction" temperature may be higher in this case $\left(600^{\circ}-650^{\circ}\right)$ also provided that the lithosphere mantle is controlled by strong dry olivinedominated rheology). Inversely, wet crustal and mantle rheologies may prohibit crustal subduction even for lower Moho temperatures.

Despite these complexities, geologic and geophysical observations suggest that continental subduction took place even under very disfavoring (slow, weak lithosphere) settings such as the Alpine collision (e.g., Chopin, 1984), Western Norway orogen (e.g., Kylander-Clark et al., 2009; Labrousse et al., 2002) or Qinling-Dabie orogen (Central 
Asia, e.g., Hacker et al., 2004) . The key observation here, as well as in many other convergent zones, is the presence of UHP metamorphic rocks (eclogite facies, Figure $3 a,-b)$ of continental origin regurgitated to the surface from the depths of $120-180 \mathrm{~km}$ (assuming lithostatic pressure gradient). In particular, Western Norway (KylanderClark et al., 2009) and Dabie (Central Asia, e.g., Hacker et al., 2004; Li and Gerya, 2009) present a prominent example of fast UHP exhumation in case of hot lithosphere and slow subduction (Kylander-Clark et al., 2009). Some of these orogens (Alps, Yamato et al., 2008) have been successfully modelled using self-consistent thermo-mechanical thermo-dynamically coupled models showing that slow continental subduction of hot lithosphere is actually possible for limited intervals of time and for specific crustal rheological structures. Finally, in some contexts deep exhumation may be also caused by diapiric RT instabilities that can bring a part of the material vertically (Gerya and Stöckhert (2006), resulting in exhumation in the backstop area.

Hence, understanding the mechanisms of continental subduction requires a number of additional considerations. First of all, the negative effect of the positive buoyancy of the lithosphere can be neutralized if a part of low-density crust early separates from the mantle (Cloos, 1993) or if it soon undergoes metamorphic changes and becomes dense and strong (Austrheim, 1991; Le Pichon et al., 1992; Burov et al., 2001). The second factor allowing for continental subduction should refer to the initially higher convergence rates that should favor continental subduction before it is replaced by pure shear, folding or RT instabilities as the convergence rate slows down. Such initially higher continental subduction rates could be a natural consequence of transition from faster oceanic subduction to slower continental collision, which must be a progressive process (e.g., in the above mentioned case of India-Asia collision, the initial oceanic convergence rates of up to $15 \mathrm{~cm} / \mathrm{y}$ have been progressively reduced to $10 \mathrm{~cm} / \mathrm{y}$ at the onset of the continental collision stage to the present $4-5 \mathrm{~cm} / \mathrm{y}$ within many ten Myr (Patriat and Achache, 1984)). On later stages, one can expect that changing the force balance after the first slab break-off might slow down or cancel continental subduction phase.

4. Mechanisms of HP-UHP exhumation and their relation to the mechanisms of continental subduction. 


\subsection{General concepts}

Apart of the role of metamorphic rocks as of markers of subduction processes, it is also expected that metamorphic changes, specifically those leading to the formation of weak and/or denser facies such as schists and eclogites, provide important controls on subduction interface dynamics, largely due to their weakening and lubricating effect, and also, in case of large quantities, due to their high density. The UHP rocks are considerably denser than the surrounding matrix and hence would not flow up on their own. Yet, nearly all UHP terranes are dominated by quartzofeldspathic rock that is buoyant under UHP conditions (e.g., Kylander-Clark et al., 2011); the density of eclogite, as long as it is included in a quartzofeldspathic matrix, is unimportant in terms of the average density of the exhumed bodies. Thus, the positive net buoyancy of the UHP assemblages is generally regarded as major factor of exhumation in the HP-UHP depth interval (e.g., Burov et al., 2001). Yet, to make buoyancy-driven exhumation possible, the matrix viscosity should (1) remain sufficiently high to allow for passive drag of the UHP inclusions back to the surface, and (2) sufficiently low to permit detachment of the exhumed bodies from the subducting lithosphere. (3) In addition, the viscosity of the intra-channel embeddings surrounding the ascending bodies should be sufficiently low to permit their ascent through the channel. Consequently, understanding the mechanisms allowing for the journey of the crustal rocks to the UHP depths and back to the surface is largely equivalent to elucidation of the convergence mechanisms in general.

Without assuming such mechanisms it would be difficult to explain the exhumation of dense UHP rocks (e.g. eclogite density may exceed by $400-800 \mathrm{~kg} / \mathrm{m}^{3}$ the density of the normal crust and by $100 \mathrm{~kg} / \mathrm{m}^{3}$ that of the mantle) within the exhumation models developed for LP and MP rocks, which can be roughly sub-divided onto: (1) shallow, kinematically driven exhumation models (Figure 3c, see also Platt, 1986;1993 and Hacker and Gerya, 2013 for review ) such as the accretion prism model limited to exhumation from depths above the $40 \mathrm{~km}$ limit (e.g., Platt, 1993), (2) shallow overpressure models that can only work if the "subduction channel" walls are undeformable (Mancktellow, 1995,2008, Figure 3c) or in the absence of a dominant simple shear deformation (Petrini and Podladchikov, 2000), and (3) deep basically 
hydrodynamically and buoyancy driven HP-UHP exhumation models (Figure 3c, Chemenda, 1995; Burov et al., 2001; Yamato et al., 2008; Li et al., 2010; Duretz et al., 2012) .

Subduction and exhumation of deep crustal material is more and more considered as result of the competition between the buoyancy of partially metamorphosed crust and downward viscous drag exerted on the subduction interface (Couette flow). A simplistic view of this problem is that the buoyancy forces and the related inverse pressure gradients return the crustal material to the surface within the Poiseuille flow (Figure 3c(c), Platt, 1993), so that the return flow of the exhumed material to the surface results from a trade-off between the downward Couette and upward Poiseuille flow (Raimbourg et al., 2007; Beaumont et al., 2009). Yet, as discussed in Section 2, this mechanism should not work in practice since it required undeformable subduction channel with rigid walls while physical consideration and recent studies show that "subduction channel" walls are deformable so that the channel would rather inflate instead of maintaining any significant over- or underpressure (Burov et al., 2001; Burov and Yamato, 2008). Therefore, in case of simple shear subduction, is more appropriate to consider near-normal pressure conditions and an exhumation mechanism related to Stokes return flow.

If one follows the results of full-scale geodynamic models (Toussaint et al. 2004a; Burov and Yamato ,2008; Li et al. , 2010) that have confirmed nearly lithostatic pressure conditions inside the subduction channel, then the exhumation depth of HP and UHP rocks must exceed 80-120 km. It was demonstrated (e.g., Platt, 1993) that kinematically driven circulation in the critical wedge of an accretion prism (Figure 3c (a), Davis et al., 1983; Dahlen, 1990; Dahlen and Suppe, 1988) cannot bring metamorphic material to the surface from depths exceeding $40 \mathrm{~km}$. This hard limit is established from the fact that the accretion prism mechanism requires, at one side, a relatively high viscosity, needed to drag host rocks to depth and bring their metamorphic facies back to the surface, but on the other side, the viscosity cannot be higher than $10^{19} \mathrm{~Pa}$ s to permit circulation of material and to maintain realistic geometry of the sedimentary prism (Emerman and Turcotte, 1983). At temperatures corresponding to the $40 \mathrm{~km}$ depth, most metamorphic bodies have low viscosity and it becomes impossible to build a sufficiently high viscous force to drag such a weak material up. As a result, large part 
of the material will remain at the bottom of the accretion prism and/or carried down with the subducting mantle. However, despite their presumably low viscosity, a part of exhumed rocks (Norway, Dabie, e.g. Kylander-Clark et al., 2011) show little deformation, which poses additional questions concerning the mechanisms of their exhumation.

Another classical kinematic exhumation model evokes foreland fold-and-thrust mechanisms allowing thrusting (nappe stacking) of one rock unit on top of another (Jolivet et al., 1994, Figure 3c(b)). The kinematic thrust-and-fold and nappes stacking models exploit the possibility of detachment at the base of the accretion prism. In this case the lower accreted units may be folded and thrusted on top of the upper units. This stacking models appear to be consistent with field observations for LP and MP conditions. This mechanism, ultimately linked to simple shear deformation and hence subduction, probably can also work at final stages of HP/UHP exhumation when small volumes of UHP/HP material are included in partly metamorphosed LP/MP matrix. At larger scale, a similar mechanism may work in case of subduction of terrains embedded in the "normal" lithosphere (Tirel et al., 2013).

Finally, a number of concepts of continental collision consider mechanical alternatives to subduction and propose customized mechanisms of HP/UHP rocks formation and exhumation. For example, Thompsons' "tooth paste" model (e.g., Thompson et al., 1997) suggests that rocks may be squeezed up to the surface, for example as a result of closure of the accretion prism. The model of Thompson et al. (1997) can be discarded since it requires quite uncommon rheological properties for the colliding blocks and does not imply realistic structural features. Burg and Podladchikov (2000) have suggested a specific collision model that implies tectonic overpressure (as in Petrini and Podladchikov, 2000) and megabuckling of mechanically coupled strong colliding plates. In this model, there is no upper and lower plate. Instead, crustal rocks are brought down within a gigantic syncline formed as a result of a compressional instability. Due to tectonic overpressure, these rocks are formed at twice smaller depth (than usually inferred for HP/UHP material) and then exhumed to the surface by denudation processes and possibly by squeezing a bit like in Thompson's model. The possibility of megabuckling or, more general, of "symmetric" collision, has been also discussed in a number of studies (e.g., Burov et al. , 1990; Cloetingh et al. , 1999). 
However, this kind of scenario might be limited to some very specific places in the world such as Himalayan syntaxes or Tien-Shan.

\subsection{Most generally considered mechanisms of UHP exhumation}

Chemenda et al (1995) have suggested a highly elaborated and elegant analogue model of continental subduction scenario with a lithostatic UHP mechanism, in which the rigid cold crust is brought down with the subducting mantle because its initial viscosity is high allowing for adherence to the mantle lithosphere. Partly metamorphosed, therefore still buoyant and sufficiently rigid, large crustal blocks return to the surface when they delaminate from the mantle. The delamination is caused by reduction of the ductile strength of the crust as its temperature increases with depth. The UHP units are brought to the surface in solid state with the buoyant low density matrix. Once at the surface, the matrix is eroded exposing less erodible UHP material. As can be seen, the key point of this model relates to the net floatability of the exhumed crustal blocks that are supposed to be only partly converted into metamorphic material. Another condition is that this model requires high erosion rates at final stages of the exhumation processes. The model of Chemenda et al., 1995 has been successfully tested mechanically, but by the time it has been published it still required validation in terms of the P-T conditions because, as most analogue models, it is not thermally coupled and the predicted P-T conditions are out of control. In particular, it was important to demonstrate that the crustal blocks can remain sufficiently rigid at the moment of their decoupling from the mantle. It should be also kept in mind that phase transitions result in reduction of the ductile strength and depend on the presence of fluids, which remain to be a poorly constrained factor of the subduction process. With these reservations, one can suggest that the "rigid block model" may work in particular settings characterized by exhumation of relatively small volumes of non-deformed UHP rock. Recent thermally coupled numerical models (Sizova et al., 2012 ) have demonstrated that Chemenda' model of exhumation is physically viable. Yet, the model is still to be validated with a thermo-mechanical model on a real-life case such as Himalaya collision (in particular, Dabieshan, Hacker et al., 2000), for which it was originally designed for. In particular, it is noteworthy that nappe stacking still occurs under particular conditions in the model by Sizova et al. (2012), i.e. 
in the presence of a rather strong lower crust. So far the only existing thermomechanical model that reproduced UHP exhumation for Dabieshan-Sulu (Li and Gerya, 2009) infers a mechanism that is more close to the multi-phase exhumation mechanism suggested by Burov et al. (2001, Figure 3c(e), see below) than the rigid-block exhumation mechanism of Chemenda et al. (1995).

In difference from the geological contexts considered in the Chemenda' model, there is number of well-studied collision settings such as the Western Alps (Figure 3c(e); Burov et al., 2001; Agard et al., 2001;2009; Yamato et al., 2007; 2008) where the amounts of the exhumed UHP material are relatively important, even though HP volumes of $50 \mathrm{~km}$ wide with $200 \mathrm{~m}$ thick UHP units observed in this area are not exceptionally large (Kylander et al., 2009). To exhume this material, one needs to create sufficient space (e.g. via slab roll-back or by applying strong surface erosion, yet the latter scenario is not applicable to the Alps). This material is also strongly deformed by ductile deformation. These observations reduce the possibility that the metamorphic terranes were exhumed as small inclusions within a rigid matrix. For this reason, Burov et al. (2001) have suggested an alternative model, in which the subduction interface zone breaks into a shallow (1) and mid-depth (2) accretion prism and (3) a deep zone of accumulated crustal material formed near the base of the upper plate (this zone is dubbed "crustal pocket"). For each of these three levels there is a specific mechanism of exhumation. The two accretion prism zones exhume LP and MP pressure rocks and also $\mathrm{HP}$ and UHP rocks that penetrate in the prism with return flow in the subduction interface zone. This return flow is driven both by up-thrusting of the upper plate and small-scale convective movements and gravitational instabilities in the more or less metamorphosed and partially molten subducted crust and in the "crustal pocket" that sometimes may underplate the overriding plate at the 50-120 km depth. At this depth, the weakened subduction interface zone breaks down onto two parts, the upper and the lower one (i.e., "crustal pocket" with potentially partially molten rock), separated from each other by a more or less narrow "neck". Starting from this depth, a large part of the upper and adjacent lower crustal material does not subduct anymore, this material is accumulated below the upper plate and heats up due to direct contact with hot $\left(T=1330^{\circ}\right)$ asthenosphere. Thermal expansion due to heating initiates small-scale convection and RT instabilities in the "crustal pocket". These processes drive the 
metamorphic material, possibly partially molten (in extreme, but not yet observed cases , Little et al., 2011) and mixed up with non-metamorphosed low density crustal units back to crustal depths of $40-50 \mathrm{~km}$. From these depths, the UHP material is exhumed to the surface in the "normal way", by the accretion prism mechanism. Each stage of this poly-phase exhumation process has its characteristic exhumation rate. The exhumation rate characterizing the convection stage may be much more rapid $\left(10-15 \mathrm{~cm} \cdot \mathrm{yr}^{-1}\right)$ than the tectonic convergence and uplift rates because the ascent Stokes velocity, $V_{s}$, is conditioned by the density contrast and the non-Newtonian viscosity $\mu_{\mathrm{eff}}$ of the rocks (Weinberg and Podladchikov, 1994; Burov et al., 2001):

$$
V_{s} \approx 2^{1-n} 3^{1-2 n} r^{n+1} A\left(\alpha \Delta T \rho_{0} g+\Delta \rho_{c} g\right)^{n} e^{-Q / R T}
$$

where $r$ is the approximate half-size of the ascending crustal body, $\Delta \rho_{c}$ is compositional density contrast, $n, A, Q, T$ are the power law exponent (typically $2 \div 3$ ), material constant, activation enthalpy and temperature of the embeddings, respectively, $R$ is the gas constant $\left(8.314 \mathrm{Jmol}^{-1} \mathrm{~K}^{-1}\right), g$ is the acceleration due to gravity $\left(9.8 \mathrm{~m} \cdot \mathrm{s}^{-2}\right), \rho_{0}$ is reference mean density $\left(\right.$ at $\left.0^{\circ} \mathrm{C}\right), \alpha$ is thermal expansion coefficient (typically $3 \cdot 10^{-5}{ }^{\circ} \mathrm{C}^{-1}$ ). It is noteworthy that the eq. 7 holds for a spherical blob in an infinite matrix, and hence provides a maximal estimate for the ascent velocity, because in nature the ascent velocity is progressively reduced as the exhumed body approaches the surface, or, more exactly, the depth of brittle-ductile transition (e.g., Burov et al., 2003). However, since brittle-ductile transition depth in the subduction channel and normal crust is likely to be above $20-30 \mathrm{~km}$ (Yamato et al., 2008), a large part of UHP exhumation may still occur at velocities described by eq. 7 .

Let us consider following typical conditions: background temperatures of about $600^{\circ} \mathrm{C}, \Delta \rho$ ranging from 20 to $200 \mathrm{~kg} \mathrm{~m}^{-3}$ and temperature contrasts between the ascending material and embeddings ranging from $100^{\circ} \mathrm{C}$ to $300^{\circ} \mathrm{C}$. Whatever the embedding is, quartz-rich crust $\left(n=3, H=190 \mathrm{k} \mathrm{Jmol}^{-1}, A=5 \cdot 10^{-12} \mathrm{~Pa}^{-n} \mathrm{~s}^{-1}, \rho_{0}=2600 \div\right.$ $\left.2900 \mathrm{~kg} \mathrm{~m}^{3}\right)$ or mantle olivine $\left(n=3, H=520 \mathrm{k} \mathrm{Jmol}^{-1}, A=7 \cdot 10^{-14} \mathrm{~Pa}^{-n} \mathrm{~s}^{-1}, \rho=3300 \mathrm{~kg} \mathrm{~m}^{-3}\right)$ (Burov et al., 1999,2001), one can find that these conditions would be largely sufficient to drive up a $10-20 \mathrm{~km}$-thick body at $10-20 \mathrm{~cm} \cdot \mathrm{yr}^{-1}$ rate. For larger temperature or density contrasts the estimated values of $v_{y}$ become very high suggesting the possibility of very fast material ascent from great depths, slowing down near the surface due to 
the decreasing temperature. These estimates are highly sensitive to the material parameters, for example in case of a crustal quartzite-rich body ascending through olivine background $\left(\Delta \rho=430 \mathrm{~kg} \mathrm{~m}^{-3}\right)$, the ascent rate may vary from $1^{-4} \mathrm{~m} \cdot \mathrm{yr}^{-1}$ for embedding temperature of $600^{\circ} \mathrm{C}$ to $1 \mathrm{~m} \cdot \mathrm{yr}^{-1}$ for the embedding temperature of 900$1000^{\circ} \mathrm{C}$. In case of much more temperature sensitive quartzite embeddings (hot crust material ascends through cold crustal embeddings), the scatter in possible vertical velocities becomes important, including a possibility of turbulent flow inside and outside the crustal body (Burov et al., 2001).

The velocity contrast between the exhuming material, mantle and crustal material of the upper plate induces formation of a large-scale shear zone, which works as a normal fault with a relative upward motion of the footwall. This is quite similar at a first glance to what Chemenda et al. $(1995 ; 1996)$ have predicted from analogue laboratory experiments. There are, however, some principal differences between the two models. In the Chemenda's model, continental crust is exhumed as a large rigid block, which detaches from the mantle and glides up between the downgoing slab and the upper plate. This ascent is driven by density contrast between the crust and mantle. In the Burov et al. 2001 model, the exhumed body presents a deformed crustal volume included between a thrust zone forming along the Moho boundary of the lower plate and a normal fault zone forming between the lower and upper plate. In this model the exhumed material is not rigid, but ductile due to high temperature. Contrary to that, Chemenda's model is incompatible with long exposure of the subducted crust to high temperatures. The second important difference relates to the geometry of the downgoing slab. In the Burov et al. 2001 model high buoyancy experiment, the downgoing slab has a tendency to rotate upward below the upper plate, due to a positive flexural moment created by cumulative effect of remaining low density crustal layer and of asthenopsheric upflow below the overriding plate. The third principal difference is that in this model there is no important accumulation of crustal material below the upper plate as would be observed in the Chemenda's model in case of weak crustal rheology or hot surroundings. The fourth, less important difference is related to the presence of active extension within the upper plate provoked by the upwelling asthenosphere.

The equation for Stokes velocity of exhumation of buoyant crust does not directly 
consider its capacity to drag heavier metamorphic facies that under some condition can still sink in opposite direction. This additional condition can be roughly defined by "internal" Stokes velocity $V_{\mathrm{i}}$ of these metamorphosed facies within the exhumed crustal body:

$$
V_{\mathrm{i}} \approx \Delta \rho^{\prime} g l^{2} / 3 \mu_{\text {eff_c }}
$$

where $\Delta \rho^{\prime}$ is the density contrast between the metamorphosed part of the exhuming crustal volume and the crust, $l$ is the characteristic size of the metamorphic inclusions and $\mu_{\text {eff_c }}$ is the effective viscosity of the crust. Logically, exhumation of metamorphic inclusions within lighter crustal units is possible under condition that

$$
\left|V_{\mathrm{s}}\right|-a\left|V_{\mathrm{i}}\right|-\left|V_{\text {suv }}\right|>0
$$

where $a \approx z_{e} / s_{b}$ is the ratio of the exhumation depth $z_{e}$ to the characteristic vertical dimension of the body, $s_{b}$, and $V_{\text {suv }}$ is the vertical component of the subduction rate. As long as $/$ is sufficiently small $(I<0.25 r \div 0.5 r)$ the above ratio is positive meaning that large crustal volumes can effectively drag upward smaller metamorphic inclusions. These analytical considerations are largely oversimplified neglecting, for example, the non-linear downward drag due to subduction, which justifies a fully numerical approach. Burov et al (2001) suggest that their mechanism can work for a limited amount of time during the initial stages of continental subduction, but do not preclude the possibility of delayed exhumation of the eventually partially molten UHP material from the "crustal pocket" that underlies the overriding plate in their model. This model has received further development in the models Yamato et al. $(2007 ; 2008)$ and $\mathrm{Li}$ and Gerya (2009), which account for thermo-dynamically consistent metamorphic phase changes, and allow for tracing metamorphic P-T-t paths used for validation of the model-predicted collision dynamics. These models, discussed in full detail in the next sections, belong to the latest generation of thermodynamically coupled collision/subduction models (see also Sizova et al., 2012 ) where material properties are dynamically adjusted in full consistency with thermodynamic conditions.

Recent numerically inspired oceanic and continental UHP exhumation concepts by (Gerya and Stöeckhert, 2006; Stöeckhert and Gerya, 2005; Li and Gerya, 2009; Beaumont et al., 2009; Duretz et al., 2011; Sizova et al., 2012; Li et al., 2013) added new elements to our understanding of exhumation mechanisms, reinforcing, for example, the role of Rayleigh-Taylor instabilities both in the subduction interface zone and the 
hydrated mantle wedge. Rayleigh-Taylor instabilities may develop in the subduction interface zone due to partial hydration and melting and even propel low density "cold plumes" ascending towards the surface (Gerya and Yuen, 2003); back-arc or back-stop exhumation may be partly explained by the formation of rotating rigid "wheels" trapped into the weakened material in the subduction channel (Gorczyk et al., 2006), or by partial melting in the above discussed deep crustal pockets forming as a result of partial underplating (Burov et al., 2001; Li and Gerya, 2009).

The "hot channel" model of continental collision (Gerya et al., 2008) complements the poly-phase model of Burov et al. (2001) by emphasizing the role of the internal heating-weakening mechanism, in which the subducting crustal material may be over-heated by viscous shear heating and radiogenic elements. In this model, heating is also associated with flow of aqueous fluids relieved by rapid dehydration (deserpentinization) of the overriding mantle lithosphere that has been hydrated during previous subduction stages. The channel can penetrate along the plate interface down to the bottom of the lithosphere of the overriding plate $(150-200 \mathrm{~km})$ and is characterized by temperatures reaching 700 to $900^{\circ} \mathrm{C}$. The low effective viscosity of rocks caused by increased temperature, partial melting and fluid infiltration permits profound mixing of hydrated mantle and crustal rocks. The hot channel exists during the early stage of collision only, but rapidly produces large amounts of ultrahigh-pressure, high temperature rocks. Further collision closes the channel through squeezing rheologically weak, partially molten, buoyant rocks between the strong lithospheric mantles of the two colliding plates.

The role of tectonic heritage has been studied by Tirel et al. (2013) , who have suggested, in application to Aegean subduction, that deep stacking of continental terrains inherited from the previous tectonic history can explain deep burial and exhumation in appropriate contexts. In the intensively studied Aegean back-arc domain, HP belts represent small continental blocks buried and exhumed back during subduction and slab roll-back of the African lithospheric plate. Numerical models integrating multidisciplinary observations show that slab buoyancy variations resulting from successive subduction of continental blocks can be responsible for episodic rollback-exhumation cycles. The model of Tirel et al. (2013) succeeds in reproducing major structural patterns and pressure-temperature-time (P-T-t) paths of the HP rocks in the Eastern 
Mediterranean and as such exemplifies a new concept for exhumation of deeply buried continental crust.

The specific features of Burov et al. (2001) and (Gerya et al., 2008; Burg and Gerya, 2005; Yamato et al., 2008; Li and Gerya, 2009) models refer to the presence of several stages or levels of exhumation, with different exhumation rates (and mechanisms) at each stage/level. These models predict high exhumation rates at depth that may be several times higher than the horizontal convergence rates or denudation rates at surface. The predicted rates reach, for example, $10-15 \mathrm{~cm} . \mathrm{yr}^{-1}$ in the Alpine context, where the convergence rates (currently almost negligible) were in average less than $1 \mathrm{~cm} . \mathrm{yr}^{-1}$, with initial values not higher than 3-5 cm. $\mathrm{yr}^{-1}$ (Burov et al., 2001; Yamato et al., 2008).

\section{Successful numerical models of continental subduction and HP/UHP exhumation}

We next discuss the lower and upper bounds on the parameters controlling continental subduction and thus UHP-HP exhumation. We asses various factors controlling continental collision/subduction by using state-of-the art numerical thermomechanical models coupled with thermodynamic processes. In these models, density and other physical properties of the material are computed by minimization of free Gibbs energy as function of P-T conditions (e.g., Connolly, 2005) and re-iterated back to the thermo-mechanical part of the model (see Appendix ).

\subsection{Common modelling approach}

We here discuss the general methodology of subduction/collision models using as representative examples recent modeling studies based on the FLAMAR code (Appendix). This code, originating from Parovoz-FLAC algorithm (Fast Langrangian Analysis of Continua, Cundall ,1989; Polyakov et al., 1993; Appendix), has all major features that are present in consistent models of continental collision. It implements explicit time-marching, large-strain Lagrangian algorithm to locally solve Newtonian equations of motion in continuum mechanics approximation. This code is viscouselastic-plastic and written in full stress formulation, which allows for accurate computation of total pressure, $P$, as a trace of the full stress tensor. Solution of motion equations is coupled with constitutive equations, heat-transfer, fluid circulation, surface 
transport and thermodynamic equations. The algorithm also handles explicit freesurface boundary condition. The metamorphic phase changes are treated using free energy minimization algorithms (De Capitani, 1994; Conolly, 2005). The surface processes (erosion and sedimentation) are incorporated using linear and non-linear diffusion formulation (Avouac and Burov, 1996). The fluid transport algorithm is based on an enhanced variant of Darcy's flow with strain-rate dependent permeability (Angiboust et al., 2012). The Lagrangian grid is supplemented by a denser particle-in-cell sub-grid (9 to 30 particles, or passive markers, per grid element), which allows for diffusion-free interpolation of grid quantities between remeshings, as well as for tracing trajectories of selected particles, allowing, for example, for construction of synthetic $P$ $T$ - $t$ paths.

\subsection{Numerical setup}

\subsubsection{Initial configuration}

To achieve continental subduction phase in "natural" way, without prescribing it from the beginning, recent models of continental collision start from the oceanic phase of subduction (Figure 4; Yamato et al, 2008). Oceanic subduction "prepares" conditions for the continental phase by creating a weak subduction interface and providing initial slab pull on the continental lithosphere. The oceanic accretion prism also provides weak material to start-up lubrication of the continental subduction interface (Figures 4,5). Further lubrication of the subduction interface is provided by the weak rheology of metamorphic and crustal rocks including the supply of sedimentary material produced by erosion of the uplifting topography.

\subsubsection{Mechanical and thermal boundary and initial conditions}

The most appropriate upper boundary condition for geotectonic modeling is a free surface. This condition is explicitly implemented in Flamar, which uses Lagrangian framework. It is noteworthy that many Euleran codes based on Stokes flow formulation use surrogate "sticky air" approximation of the free surface (Sizova et al., 2012). If the required topography precision is not high, the "sticky air" approximation is quite acceptable provided the viscosity of the "air" is sufficiently low and the thickness of the "air" layer is sufficiently large. However, the absolute precision of nodal vertical and 
horizontal displacements in implicit Eulerian Stokes flow codes is typically on the order of half element size (e.g. $0.5 \mathrm{~km}$ for $1 \times 1 \mathrm{~km}$ element size) because they are obtained indirectly, from interpolation of positions of passive markers. In the Lagrangean codes like Flamar, the practical accuracy of nodal positions is about two orders of magnitude better (e.g. $0.01 \mathrm{~km}$ for $1 \times 1 \mathrm{~km}$ element size), because the nodes move with the velocity field (e.g., Francois et al., 2014) and their coordinates are updated directly without interpolation.

In all existing models the lateral boundary conditions are kinematic (horizontal velocities). The Winkler's hydrostatic pliable bottom is often used as the bottom boundary condition. This semi-free condition allows for reduction of the vertical size of the model by up to $25 \%$ compared to the fixed-bottom configuration, allowing the slab to deflect the lower boundary of the model when it approaches the bottom. In subduction zones, the downward translation of a cold slab material produces complex thermal structures (Royden, 1993; Davies, 1999). To account for this complexity, the initial thermal structure (see Appendix) relies on the oceanic plate cooling model for the oceanic part of the model, while the continental part is based on the continental plate cooling model (Parsons and Sclater, 1977; Appendix) with a thermo-tectonic age of $160 \mathrm{Ma}$. The corresponding thermal boundary conditions include zero flux in lateral direction, and fixed temperatures at the upper surface and the bottom of the model. For the entire computational domain, the initial thermal distribution is computed through a combination of plate cooling models (oceanic or continental) for the upper lithospheric part with the adiabatic thermal gradient for the underlying mantle. One first solves the plate cooling problem assuming $\mathrm{T}=0^{\circ} \mathrm{C}$ at the surface and $\mathrm{T}=1330^{\circ} \mathrm{C}$ at the bottom of the lithosphere (Appendix). Then the initial adiabatic temperature gradient in the underlying mantle is computed by equalizing the temperature at its top with the temperature at the bottom of the lithosphere $\left(1330^{\circ} \mathrm{C}\right)$ and by adjustment the mantle heat flux in a way that the temperature at the bottom of the upper mantle (650 $\mathrm{km}$ depth) fits $1700 \pm 100^{\circ} \mathrm{C}$ (e.g., Turcotte and Schubert, 2002). We re-adjust the initial thermal thickness and, if necessary, the thermotectonic age of the plate to satisfy heat fluxes at the mantle-lithosphere boundary. We control both the values of the surface and mantle heat flux to ensure that they fall in the expected range $\left(30-80 \mathrm{~mW} \mathrm{~m}^{-2}\right.$ at the surface and $10-30 \mathrm{~mW} \mathrm{~m}^{-2}$ in the mantle depending on plate age and thickness). 
The bottom and surface temperatures and zero lateral heat flow are fixed during all computations. There is a particular difficulty of thermal computations in the accretion prism that refers to the fact that thermal conductivity of sedimentary materials varies from 1 to $5 \mathrm{~W} \cdot \mathrm{m}^{-1} \cdot \mathrm{K}^{-1}$, with low values for shales and sandstones $\left(\sim 1,2-4,2 \mathrm{~W} \cdot \mathrm{m}^{-1} \cdot \mathrm{K}^{-1}\right)$ and higher values for limestones and dolomites $\left(2-5 \mathrm{~W} \cdot \mathrm{m}^{-1} \cdot \mathrm{K}^{-1}\right)$ (Turcotte and Schubert, 2002). The value used in reference simulation is $2 \mathrm{~W} \cdot \mathrm{m}^{-1} \cdot \mathrm{K}^{-1}$, but a twice higher thermal conductivity was also tested.

\subsubsection{Intermediate conditions for continental subduction}

In the models, continental subduction, or, eventually other collision modes, follows the oceanic subduction. For this reason, the initial continental convergence rate equals the rate of the oceanic subduction (for example, two-sided initial closing rate of $2 \times 1.5 \div 3 \mathrm{~cm} \cdot \mathrm{yr}^{-1}$ during the first 5-10 My). The values tested in this study do not exceed the present-day continental collision rates, which are at maximum $3 \div 6 \mathrm{~cm}$. $\mathrm{yr}^{-1}$. These rates are on the order of smallest present-day oceanic subduction rates, and are also smaller than the past continental convergence rates for some particularly active continental collisions such as the India-Asia collision $(2 \times 4$ to $2 \times 5 \mathrm{~cm}$.yr- 1 during the first 10 m.yr. (Patriat and Achache, 1984).

\subsubsection{Rheological structure}

For continental and oceanic collision models, we assume commonly inferred crustal structure and rheology parameters derived from rock mechanics (Table 1). As in nature, topography growth is strongly affected by surface erosion, which is modeled using diffusion erosion with a diffusion coefficient varied from $50 \mathrm{~m}^{2} \mathrm{yr}^{-1}$ to $11000 \mathrm{~m}^{2}$ $\mathrm{yr}^{-1}$ (the practical range is $100 \mathrm{~m}^{2} \mathrm{yr}^{-1}$ to $3000 \mathrm{~m}^{2} \mathrm{yr}^{-1}$, Avoauc and Burov, 1996; Burov et al., 2001). For continental collision, as for the case of the upper plate in the experiments on oceanic subduction, the initial geotherm is derived from the half-space cooling model modified to take into account internal heat production and structure of the continental lithosphere (e.g., Parsons and Sclater, 1977; Burov and Diament, 1995; Yamato et al., 2008; Appendix).

\subsubsection{Variable model parameters}


One of the universal controlling variable parameters of all experiments is the initial geotherm, which is defined by the thermotectonic age (Burov and Diament, 1995; Toussant et al, 2004a,b) and is largely characterized by the Moho temperature $T_{m}$ (Figure 5). The geotherm controls the major mechanical properties of the system through its strong impact on the rheological strength profile. By varying the geotherm, one can account for the whole possible range of lithospheres, from very old, cold, and strong plates to very young, hot, and weak ones. The second variable parameter for continental models is the composition of the lower crust, which, together with the geotherm, controls the degree of crust-mantle coupling. We generally considered both weak (quartz dominated) and strong (diabase) lower-crustal rheology and also strong and weak (dry versus wet olivine) mantle rheologies (Table 1). In high resolution experiments, intermediate crust has been also included in the models (Yamato et al., 2008).

As discussed in the previous sections, for a given thermo-rheological strength profile, the convergence rate is the main factor defining the mode of continental collision via its impact on the critical Peclet number of the system. In nature, there is a correlation between the convergence rate, the mechanical strength and thermal state of the subducting lithosphere (Mouthreau et al., 2013) such that all major controlling parameters are inter-dependent. We here consider 3 representative cases: (1) very slow collision of weak lithosphere (Alps), (2) intermediate-rate collision (Zagros) of middlestrong lithosphere and (3) fast subduction of very strong Indian lithosphere (Himalaya). The tested convergence velocities vary from $2 \times 3 \mathrm{~mm} \cdot \mathrm{yr}^{-1}$ to $2 \times 3 \mathrm{~cm} \cdot \mathrm{yr}^{-1}$. We then test the influence of most important metamorphic changes such as serpentinisation, schisting and eclogitization (at $P>1.5 \mathrm{GPa}$ and $T>550{ }^{\circ} \mathrm{C}$, see Table 1 ).

\subsection{Results and Discussion}

Figure 6 provides a representative example of continental collision experiments (Francois et al., 2012;2014) in a Zagros collision context that occurs at intermediate convergence rates. The experiments start from an oceanic subduction phase (Figures $4,5)$ and, after several slab break-off episodes arrive at the stage of continental subduction that occurs progressively, as a result of subduction of the continental margin pulled by the oceanic plate. The repetitive character of slab-break off process in case of 
intermediate convergence rates $\left(2 \mathrm{~cm} \cdot \mathrm{yr}^{-1}\right.$ on both sides) is an important feature potentially explaining the possibility of repetitive changes in deformation styles, topography evolution and exhumation events observed at the surface. We will later discuss the results of these experiments in full detail, but at this stage Zagros collision experiments were used as a representative example demonstrating the importance of the oceanic subduction phase in continental collision models.

\subsubsection{Stage I: Pre-continental (oceanic) subduction phase (slow convergence)}

As mentioned, the oceanic subduction phase plays an important role in the development of continental collision, specifically in case of slow convergence rates. We hence start detailed discussion of collision/exhumation models from description of the oceanic phase for particularly slow Alpine convergence settings. Figures 7-9 show experiments on the oceanic phase of Alpine convergence implemented by Yamato et al, 2007 as initial phase of their continental collision model (Yamato et al., 2008, Figure 7). In this model the oceanic plate subducts at a rate of $6 \mathrm{~cm}$. $\mathrm{yr}^{-1}$ below the overriding continental plate. These experiments target the Alpine collision and are aimed, in particular, to test the idea of the possibility of continental subduction as follow-up of the oceanic subduction in slow convergence settings. In these experiments, the thermomechanical model was coupled with a thermo-dynamic model using the thermodynamic algorithm THERIAK (de Capitani et al., 1994, see Appendix) that predicts mineralogical phases and their density by minimizing free Gibbs energy for P-T conditions computed within the thermo-mechanical part of the model. The experiment successfully reproduces the burial and exhumation in a subduction wedge (Figure 8), in terms of correspondence between the predicted synthetic and observed P-T-t trajectories and the structural and exhumation patterns. The model is tested and parameterized on the well constrained Schistes Lustrés complex (SL; Western Alps), which is thought to represent the fossil accretionary wedge of the Liguro-Piemontese ocean. For convergence rates comparable to the oceanic phase of the Alpine subduction ( 3 $\mathrm{cm} . \mathrm{yr}-1$ ), the best fitting results are obtained for high viscosity, low density wedge sediments and/or a strong lower continental crust. After a short transition period of 3-5 My, the modeled accretionary wedges reach a steady state which lasts over $20 \mathrm{My}$. Over this time span, a significant part ( $35 \%)$ of sediments entering the wedge 
undergoes P-T conditions typical of the SL complex ( 15-20 kbar; $\left.350-450^{\circ} \mathrm{C}\right)$ with similar P-T loops. Computed exhumation rates $(<6 \mathrm{~mm} . \mathrm{yr}-1)$ are in the agreement with observations (1-5 mm.yr-1) hence validating the choices of thermo-rheological parameters and conforming the viability of accretion prism concept of LP/MP exhumation. The model confirms the crucial importance of the mechanical weakening due to metamorphic reactions in the subduction interface zone by showing that in presence of a serpentinite layer below the oceanic crust, exhumation of oceanic material takes place at realistic rates approaching $3 \mathrm{~mm} \cdot \mathrm{yr}^{-1}$. The importance of metamorphic reactions was well demonstrated in later follow-up of this study by Angiboust et al (2012) who have developed a two-phase flow model in the oceanic subduction context by coupling the Alpine subduction model with porous-matrix fluid transport equations (Figure 9). In this model, dehydration of serpentinite layers provokes fluid release forming a hydration front in the mantle around the subduction interface. As a result, the mantle wedge is strongly weakened (e.g., Guillot et al., 2000; 2001) allowing for more efficient uncoupling between the lower and overriding plate. A fluid migration algorithm is coupled with thermo-mechanical counterpart so that the fluids are free to migrate through a permeable matrix, driven by rock fluid concentrations, non-lithostatic pressure gradients and deformation. These experiments show that deformation is accommodated along the subduction interface by a lowstrength shear zone parallel to the wall of the subduction thrust interface, and characterized by a weak (10-25\% of serpentinite) and relatively narrow $(5-10 \mathrm{~km})$ serpentinized front. Dehydration associated with eclogitization of the oceanic crust (60$75 \mathrm{~km}$ depth) and serpentinite breakdown (110-130km depth) significantly decreases the mechanical strength of the mantle at these depths, thereby favoring the detachment of large slices of oceanic crust along the plate interface. In these experiments, the resulting morphologies are in good agreement with reconstructions derived from structural field observations from the Alpine eclogite-facies ophiolitic belt (corresponding to, i.e., coherent fragments of oceanic crust detached at $\sim 80 \mathrm{~km}$ depth in the Alpine subduction zone and exhumed along the subduction interface). It can be suggested that overall weakening of the plate contact-zone during oceanic subduction creates necessary conditions for the continental subduction at later stages. 


\subsubsection{Stage II: Subduction of a weak lithosphere $\left(T_{e}<30 \mathrm{~km}\right)$ at slow convergence rate}

(< $1.5 \mathrm{~cm} . \mathrm{yr}^{-1}$ ) showing strong dependence on crustal and lithosphere mantle rheology

The second phase of Alpine convergence corresponds to continental subduction occurring at slow convergence rate and hence at near critical Peclet numbers. Slow convergence settings present a particularly important framework for studying continental convergence due to the extreme dependence, in this case, of the collision mode on thermo-rheological assumptions (Yamato et al., 2008). The well-studied Alps are an excellent example for this that is characterized by both very small convergence rates and by a weak lithosphere, as attested by $T_{e}$ data (Watts, 2001). In the study by Yamato et al. (2008), various crustal compositions have been tested, starting from an "all-granite" (very weak) crust and ending by "all-diabase" (very strong) crust (Table 1). It is difficult to constrain the range of the convergence rates in the Alpine orogeny at the eve of the collision stage, that is, back to 30 myr. The present day convergence rates are at the limit of accuracy of geodetic measurements $\left(<0.5 \mathrm{~mm} . \mathrm{yr}^{-1}\right)$; while the average amount of shortening estimated from structural paleoreconstructions, divided by the duration of the convergence, also yields very small values on the order of 0.8 $\mathrm{mm} . \mathrm{yr}^{-1}$. Exhumation of UHP rocks of continental origin within the first $5 \mathrm{Myr}$ of collision from depths in excess of 100-120 km, suggests, however, that at this stage the convergence rate had to be much faster, on the order of $2 x(0.75 \div 1) \mathrm{cm} . \mathrm{yr}^{-1}$. The UHP exhumation data hence is practically the only observation allowing us to constrain the dynamics of the collision zone during the first 5-15Myr. The most reasonable idea is hence to suggest that during the initial several Myr the continental subduction continued at rates that were comparable to those of the preceding oceanic subduction. This reinforces the idea that the oceanic slab pull is an important component of the initial force balance at the onset of the continental collision phase. It can be also argued that the initial subduction rates were even higher than the estimates obtained from dating exhumed rocks versus the exhumation depth. In particular, some part of UHP rock could be buried deeper without being exhumed (which is probably the case of fast collision zones such as Himalaya). At the agnostic side, we cannot also exclude that the exhumed rocks are not representative of the bulk circulation of the metamorphic material in the subduction wedge. It is however unlikely that the exhumed UHP material 
is formed as a result of local stress concentrations and/or overpressure since the UHP facies are present at a large scale, in vast continuous volumes (Yamato et al., 2008).

The experiments shown in Supplementary Figure 1 illustrate the historically first numerical model of Alpine collision that has been successful in reproducing continental subduction and UHP exhumation in the Alpine context (Burov et al., 2001). This model has been enhanced by (Yamato et al., 2008) who have coupled it with thermodynamic processes while significantly increasing the numerical resolution (Figure 10,11). This model, accounting for multilayered rheological structure of the continental crust, shows that UHP exhumation may occur due to mechanical decoupling of the subducted lower or middle crustal layer from both mantle lithosphere and the upper crustal layer. A large part of the layer tip tears off and flows up at the rear of the accretion wedge, between the subducting and overriding plates, in agreement with the field observations for the Western Alps. The predicted bi-phase exhumation rate and P-T trends match well the observational data thus justifying the model (Figure 11). This high resolution model was first used to parameterize the rheological choices by exploring the impact of the convergence rate and rheology in case of the relatively weak Alpine lithosphere (Figure 12). These experiments demonstrate extremely high sensitivity of the models to the rheological parameters thus allowing for robust elimination of those thermorheological profiles that are mechanically incompatible with the considered convergence scenario. Surprisingly, the models have demonstrated that some rather "classical" rheological choices such as that of all-quartz-rich crust are entirely incompatible with the dynamics of the Alpine collision (Figure 12), hence opening a new way of linking the laboratory derived rheology laws to geological scales. Figures 13,14 also show the impact of convergence velocity for the case of best fitting rheological structure derived for the Alps on the base of the experiments shown in Figure 12. It can be seen that very slow rates $\left(<3 \mathrm{~mm} \cdot \mathrm{yr}^{-1}\right)$ result in Rayleigh-Taylor instabilities and slab-breakoff, while very high velocities, in case of weak lithosphere, $\left(2 \times 3 \mathrm{~cm} . \mathrm{yr}^{-1}\right)$ lead to development of unusual double-sided symmetric subduction. Also, the predicted exhumation rates are directly comparable with the observations thus allowing for elimination of incompatibly high convergence rates. The other remarkable results refer to the prediction that higher convergence rates result in slower UHP exhumation just until its complete disappearance at rates exceeding $30 \mathrm{~mm}$. $\mathrm{yr}^{-1}$. This 
result provides some elements for explanation why UHP rocks of continental origin are rare or absent in faster convergence settings such as Zagros or Himalaya. It can be thus once again concluded that the convergence rates and the integrated strength of the lithosphere are interlinked, probably because that higher convergence rate requires higher slab pull/push forces while such forces can be only exerted on the lithosphere if the latter is strong enough to sustain them.

\subsubsection{Intermediate $(1.5 \div 3 \mathrm{~cm} / \mathrm{myr})$ to fast convergence rates (> $3 \mathrm{~cm} / \mathrm{myr}$ ), intermediately strong $\left(T_{e} \sim 50 \mathrm{~km}\right)$ to strong $\left(T_{e}>70 \mathrm{~km}\right)$ lithosphere. Impact of convergence rate partitioning.}

We here discuss the inferences from the experiments (Supplementary Figure 2) studying the amount of continental subduction as function of convergence rate assuming strong cold lithosphere with $T_{e}$ values on the order of $70 \mathrm{~km}$ (e.g., Indian craton, Watts, 2001). Even for such a strong lithosphere, the experiments show significant dependence of the amount of subduction on the convergence rate, for equivalent amounts of tectonic shortening. In the experiments, the amount of subduction is characterized by "subduction number" $S$ which is the ratio of the subduction length $l$ to the total amount of shortening $\Delta x(S=l / \Delta x) . l$ is measured as a plate-parallel displacement of a virtual vertical passive marker line (Supplementary Figure 2), initially placed in the lower plate at some distance from the major thrust. That is, when $S=1$, all of the tectonic shortening is accommodated by subduction (in some cases $S>1$ due to the additional stretching of the slab). If $S<1$, then some part of shortening is accommodated in pure shear or by folding of the lower plate. As demonstrated by these experiments, S number approaches 1 (100\% subduction) only for convergence rates $>3 \mathrm{~cm} . \mathrm{yr}^{-1}$ (subduction Peclet number $>10$ ). At smaller rates, an essential amount of shortening is accommodated by pure shear thickening and partly by folding. The physical reason for that is that at higher convergence rates, heat diffusion cannot affect plate viscosity (and hence plate strength and buoyancy) before the plate reaches an important depth. At smaller rates heat diffusion results in plate weakening and buoyancy rise, which hampers the possibility of subduction.

Francois et al. (2014) have also studied the conditions of the intermediate rate Zagros collision (Figures 4-6,15,16), which some workers regard as a "mini-Himalayan 
collision" (Hatzfeld and Molnar, 2010 ) due to the fact that in both cases an old strong cratonic plate slides below a younger weaker overriding plate resulting in rise of an elevated plateau. However, the similarities between these two collision zones probably do not go much further. In particular, the Iranian plateau is much shorter and lower than the Tibetan plateau, has a pronounced elevation trend, even though it is subject, as Tibetan plateau, to significant extension in the direction normal to convergence (England and Houseman, 1989); the Zagros mountain belt is also much lower than Himalaya, and it has been also suggested that relatively early slab break-off could have affected Zagros collision whereas in the Himalayan case slab break-off event did not probably take place (Toussaint et al., 2004a,b). The respective integrated strength of the Arabean plate $\left(T_{\mathrm{e}} \sim 50 \mathrm{~km}\right)$ is also much smaller than that of the Indian plate $\left(T_{\mathrm{e}} \sim 70 \div 90\right.$ $\mathrm{km})$, but both plates are much stronger than the Alpine lithosphere. Last but not least, the convergence rate in Zagros is about 2 times smaller than in Himalaya.

Figure $15 a-b$ shows zooms to the subduction interface zone for the major stages of the evolution of the "Zagros collision" experiments from Figure 4 . As in Burov et al (2001) this model shows formation of a crustal UHP "pocket" (Figure 3(e)) at 100-150 $\mathrm{km}$ depth from which the rock can be eventually exhumed to the surface at rates largely controlled by local viscosity and density contrast (eq 7). Similar crustal "pocket exhumation mechanism" has been reproduced in a number of recent studies, for example by Li et al. (2009, Figure 15c) for HP-UHP Sulu terrain in eastern China. As can be seen from Figure 15a, quite contrary to common expectations, several consequent slab-break-offs may occur before the exhumation of HP/UHP continental crust without producing major topographic response at the surface. It is also remarkable that oceanic HP/UHP material is exhumed only at the onset of the continental collision, when it is pushed/dragged up by low buoyancy continental crustal rocks. Similarly, exhumation of small amounts of HP/UHP material occurs during the initial stages of collision (at 25Myr of model time). Interestingly, the majority of exhuming HP/UHP rocks get stacked a few $\mathrm{km}$ below the surface. This explains the practical absence of UHP material in Zagros. It can be also concluded that even if the presence of UHP material at surface can serve as indicator of subduction processes, its absence, on the contrary, does not prove the absence of such. Furthermore, it follows from these and previously shown experiments that only limited parts of possible P-T paths arrive at the surface, appealing for a 
thorough study of their representativity for the bulk exhumation and collision mechanisms.

Francois et al (2014) have found that for intermediate and high convergence rates, collision style is highly dependent not only on the total value of the convergence rate but also on the partitioning of the convergence rates between the overriding and subducting plate. The explicit presence of absolute advection velocity terms (eq. 1; Appendix $A$ ) in the heat transfer equation explains the sensitivity of the behavior of the thermo-mechanical system to the partitioning of the convergence rates between the two sides of the model. For example, applying total velocity at the border of the subducting plate enhances the amount of subduction and increases plate dip, while doing so at the opposite side of the model has an opposite effect. In these particular experiments, the difference between dip angles reached almost $40^{\circ}$ at $20 \mathrm{Myr}(37 \%)$, from nearly $80^{\circ}$ in case of convergence from the side of the subducting plate to about $45^{\circ}$ in case of convergence from the opposite side, with an intermediate value for double-sided convergence. This effect is contra-intuitive, since simple mechanical noninertial inertial system should be indifferent to distribution of absolute velocities at the borders (as in case of analog models). Yet, thermo-mechanical coupling changes this rule, since absolute velocities imposed at the borders define horizontal and vertical thermal advection rates, which, in their turn, affect the mechanical properties, thermal buoyancy and phase changes. As a result, absolute velocity distribution matters, specifically because in nature many collision zones are converging only from one side, e.g. the Himalayas. In some cases the absolute velocities are not as certain and hence evaluation of absolute tectonic movements represents a great challenge for the future.

\subsubsection{Strong lithosphere, various convergence rates}

Studies of fast continental collision (> $3 \mathrm{~cm}_{\mathrm{yr}}{ }^{-1}$; Toussaint et al., 2004a,b) of strong lithosphere have shown that for rapid convergence rates and strong lower plates, continental subduction, once initialized, may continue for a very long period of time, i.e., practically for the entire life span of convergence. However, in this case the impact of convergence rate cannot be treated separately from that of surface denudation/erosion/sedimentation processes. In fast collision zones, there should be a strong feedback between surface processes and tectonic forcing. For pure-shear 
collision settings this has been demonstrated by Avouac and Burov (1996) who have shown that stable growth of orogenic topography requires a strong feedback between the erosion rate and the tectonic convergence rate. If that feedback is not present, the orogenic topography tends to collapse. An even stronger impact of surface processes is expected for continental subduction (Lavier and Steckler, 1997; Toussaint et al., 2004; Burov and Toussaint, 2007, Figure 17, Supplementary figures 3 and 4), since sedimentary loading and erosional unloading have a primary effect on the force balance and integrated strength of the lithosphere (flexural yielding/unyielding, thermal blanketing etc) in the collision zone. In particular, excessive topography, if not timely removed, exerts closing pressure on the subduction interface, increasing plate coupling and hence preventing subduction (e.g., case $S=0.8$ and $S=1.0$, Figure 17). More surprisingly, very fast erosion (e.g., cases $S=0.1,0.21,0.33,0.42,0.5$, Figure 17) also reduce the amount of subduction by producing dynamic unloading and hence elastic unbending of the subducting plate causing lock-up of the subduction interface. The experiments show that pure shear thickening or folding occur instead of simple shear subduction when erosion is either too strong (e.g., $\mathrm{k}>3000 \mathrm{~m}^{2} . \mathrm{yr}^{-1}$ for convergence rates < $\left.2 \times 2 \mathrm{~cm} \cdot \mathrm{yr}^{-1}\right)$, in that case any topographic irregularity is "too" rapidly erased by surface processes (Figure 17), or when erosion is too weak $\left(k<50 \mathrm{~m}^{2} \mathrm{yr}^{-1}\right)$. In case of slow erosion, surface elevations are unrealistically high (Figure 17, Supplementary figure 4) which leads to vertical over-loading causing flexural yielding of the lithosphere and growth of the frictional force along the major thrust fault. As a consequence, the major thrust fault is locked leading to coupling between the upper and lower plate; this results in overall buckling or folding of the region whereas the crustal root below the range starts to spread out laterally with formation of a high flat "pancake-shaped" topographies. On the contrary, in the case of a dynamic balance between surface and subsurface processes (e.g., $\mathrm{k}=2000-3000 \mathrm{~m}^{2} . \mathrm{yr}^{-1}$, for convergence rates $>2 \times 2 \mathrm{~cm}$. $\mathrm{yr}^{-1}$ or $\mathrm{k}=500-1000 \mathrm{~m}^{2} \cdot \mathrm{yr}^{-1}$ for convergence rates $<3 \mathrm{~cm} \cdot \mathrm{yr}^{-1}$ ) erosion/sedimentation results in long-term localization of the major thrust fault that keeps working during $10 \mathrm{My}$. It is noteworthy that in the experiments with $\mathrm{k}=500-1000 \mathrm{~m}^{2} \cdot \mathrm{yr}^{-1}$ (moderate feedback between surface and subsurface processes), the major thrust fault and topography were almost stationary (Supplementary Figure 4). In case of a stronger feedback ( $k=$ $2000-5000 \mathrm{~m}^{2} \cdot \mathrm{yr}^{-1}$ ) the mountain range and the thrust fault migrated horizontally in 
the direction of the subducting plate ("India"). This generally happened when both the mountain range and the foreland basin reached some critical size. In this case, the "initial" mountain range and major thrust fault were abandoned after about $500 \mathrm{~km}$ of subduction, and a new thrust fault, foreland basin and range were formed "to the south" (i.e. towards the subducting plate) of the initial location. The numerical experiments confirm the previous ideas that intercontinental orogenies could arise from coupling between surface/climatic and tectonic processes, without involvement of special mechanisms of strain localization (Burov and Avouac, 1996). Last but not least, the experiments shown in Figures 17-18 also test the influence of eclogite UHP facies and the possibility of their exhumation as a function of erosion and convergence rate (assuming $100 \%$ transformation of crustal material to eclogites at corresponding P-T conditions. The experiments suggest that this transformations occurs at much deeper depths in case of fast convergence settings so that subducting crust remains too cold (for UHP phase transition) even at important depth, thus leaving less chance for exhumation of the UHP rocks. Yet, exhumation does take place in cases when the subduction interface zone thickens and becomes large allowing for great volumes of light crustal material to delaminate from the mantle and flow back to the surface dragging up UHP material (e.g., case $S=1.1$., Figure 17). It has to be also stated that eclogitization has little effect on the development of subduction.

\subsection{Fast convergence, influence of the thermo-rheological structure}

We here summarize the results of numerous experiments (Figures 18-19) that tested the influence of rheological structure on the amount of subduction and collision style in most favoring fast convergence settings $\left(2 \times 1.5 \mathrm{~cm} \cdot \mathrm{yr}^{-1}\right)$. These experiments reveal several types of collision scenarios as a function of the thermotectonic age (geotherm, also characterized by temperature at Moho depth, $T_{m}$ ) and rheology profile:

\subsubsection{Cold geotherm $\left(T_{m}<450{ }^{\circ} \mathrm{C}\right.$, "jelly sandwich" rheology)}

An initially cold geotherm allows the collision to evolve into stable, oceanic-type subduction (Figure 18a, thermo-rheological profile " $\mathrm{C}_{1}$ ", Figure 17 case $\mathrm{S}=1.1$, Supplementary Figure 3 ). Almost all shortening is accommodated by subduction both of the continental lower crust and mantle. Because of low Moho temperatures, the lower 
crust is highly resistant to decoupling and remains "welded" to the lithospheric mantle. It can be dragged to as deep as $250 \mathrm{~km}$ depth in spite of its positive buoyancy. However, the mechanical resistance of the major part of the upper crust remains lower than the buoyancy-induced stresses. It separates from the lower crust and remains at surface or mid crustal depth at an early stage, only small amounts of the upper crust are dragged to larger depth. In these experiments, crustal material is brought down to significant depths ( > $120-150 \mathrm{~km}$ ), allowing UHP and HP metamorphism to develop in the conditions devoid of significant over-pressure (Figure 18b). These experiments closely resemble those from (Toussaint et al., 2004b) that modeled India-Asia collision. Supplementary Figure 3 shows the formation of large-scale thrust-and-fold structures that result from crust-mantle decoupling and resemble those typically observed in the field. This process explains the eventual complexity of the $P-T-t$ paths, with a limited amount of UHP material exhumed at the beginning of subduction.

\subsubsection{Intermediate geotherm $\left(T_{m}=450-600{ }^{\circ} \mathrm{C}\right.$, "jelly sandwich" rheology)}

Stable subduction of the lithospheric mantle results in decoupling of the lower crust from the mantle (Figure 18a, thermo-rheological profile " $\mathrm{C}$ "). For intermediate geotherms, shortening is still largely accommodated by subduction, but positively buoyant lower crust separates from negatively buoyant lithospheric mantle and stagnates at some intermediate level (between 100 and $200 \mathrm{~km}$ depth), sometimes forming a double crustal zone (a possible analogy are the Northern Apennines, Ponziani et al., 1995). The crustal part of the subduction interface is divided into an accretion prism and a lower crustal "pocket" (Burov et al., 2001). The geometry of the downgoing lithospheric mantle is affected by the ascent of the buoyant lower crust: the slab adopts a very low angle of subduction. As a consequence, the oceanic slab detaches early and sinks into the mantle. Small-amplitude $(1000 \mathrm{~m})$ long-wavelength $(350-400 \mathrm{~km})$ lithospheric folding also accommodates some part of the shortening, specifically in the upper plate. The crustal material is brought down to $100-120 \mathrm{~km}$ depth allowing for UHP and HP metamorphism.

\subsubsection{Hot geotherm $\left(T_{m}=600-700^{\circ} \mathrm{C}\right.$, "jelly sandwich" rheology)}


Subduction and pure-shear thickening (Figure 18a, thermo-rheological profile " $\mathrm{C}_{-1}$ ") are the results of collision under the conditions of a hot geotherm. At a Moho temperature of $650^{\circ} \mathrm{C}$, pure-shear thickening and moderate-amplitude $(1500 \mathrm{~m})$ lithospheric folding (wavelength $200-250 \mathrm{~km}$ ) accommodate a significant part of shortening. This behavior is a result of thermal weakening of the lithosphere, which makes volumetric thickening mechanically easy. The base of the overriding lithospheric plate is also weakened and can be dragged downward with the sinking lower plate. The crustal material basically does not arrive to depths larger than 60-80 km, except for very early stage of subduction (first $5 \mathrm{Myr}$ ). Hence, formation and exhumation of HP/UHP is possible only at the very beginning of subduction.

\subsubsection{Very hot geotherm ("jelly sandwich" rheology) or weak mantle ("crème brulée" rheology, $T_{m}>750{ }^{\circ} \mathrm{C}$ for weak lower crust and dry olivine mantle, or $T_{m}>600{ }^{\circ} \mathrm{C}$ for wet or dry diabase lower crust and wet olivine mantle)}

Pure-shear thickening and RT instabilities (Figure 18a, thermo-rheological profiles " $D$ " and " $B$ " dubbed "crème brulée" (Burov and Watts, 2006) result from very hot geotherms. For such a hot, weak lithosphere, stable subduction (hence HP/UHP exhumation) and lithospheric folding are impossible: convergence at the borders is entirely accommodated by pure-shear thickening and RT instabilities. Because of high temperatures, the effective viscosity at the base of the lithosphere is reduced compares to clder modelss, whereas its density is still higher than that of the asthenosphere; these two factors promote rapid (in <1 m.y.) development of RT instabilities. The slab thins in a "chewing gum" fashion, and a "cold spot" forms (possible natural examples: Vrancia body in the Romanian Carpathians, e.g., Wenzel, 2002; Cloetingh et al., 2004). The rate of "subduction" in this case is not controlled by the convergence rate but by the internal growth rate of the RT instability. We dubb this style of deformation "unstable subduction." In the conditions of these experiments, the crust is not brought down to depths below $40 \mathrm{~km}$. Hence, HP/UHP metamorphism is impossible in this case. 


\subsection{Case of strong lower crustal rheology}

The experiments of the previous section (shown in Figure 18a) were repeated assuming strong dry diabase rheology (Table 1b) for the lower crust. The resulting endmember scenarios (stable subduction vs. unstable subduction) are roughly the same as in the previous experiments. Yet, there are some noticeable differences in the intermediate cases.

\subsubsection{Cold lithosphere}

For experiments with very cold lithospheres $\left(T_{\mathrm{m}}<450{ }^{\circ} \mathrm{C}\right)$, the convergence produces stable subduction. However, the results of these experiments differ in many ways from homologue experiments with "weak" (undried granulite) lower crust. In particular, subduction involves the entire continental crust, including the upper crust and its sedimentary rocks. The lithosphere also has a much higher tendency for folding while the predicted topography is $20-30 \%$ higher than in the experiments with weak lower crust.

\subsubsection{Intermediate thermal gradients in the lithosphere}

For higher Moho temperatures $\left(T_{\mathrm{m}}=450-750^{\circ} \mathrm{C}\right)$, stable subduction is progressively replaced by pure-shear thickening and by large-scale lithospheric folding. Folding is favored by a stronger rheology of the lower crust, which ensures its mechanical coupling with the lithospheric mantle and has a positive effect on the growthrate of folding istability. Note that for the same temperature range, but for a weak lower crust, subduction was a dominant mechanism of deformation.

\subsubsection{Very hot lithosphere}

The results of very "warm" experiments $\left(T_{m}>750{ }^{\circ} \mathrm{C}\right.$, case D, Figure 18a) are similar to the corresponding experiments with weak lower crust (case B, Figure 18a) from the previous section (no subduction), despite the fact that the integrated strength of the lithosphere in this case is the same in case $C_{-1}$ from Figure 18a. Therefore, it can be concluded that strong mantle lithosphere is a paramount condition for continental subduction and, consequently, for formation and exhumation of HP/UHP rocks. These results showing that strong crust cannot "replace" strong mantle in subduction 
mechanics can be easily interpreted: different than the mantle lithosphere, the lower crust is positively buoyant. It cannot subduct by its own, without being dragged by a negatively buoyant strong mantle. If such strong mantle layer is absent, the crust will not subduct.

\subsection{Summary of the results concerning the role of LP/MP/HP metamorphic phase changes and fluids in subduction processes}

Metamorphic phase transformation have potentially weakening impact on crustal rheology (e.g., Wassmann and Stoeckhert, 2013) and, hence, on subduction evolution reducing mechanical coupling between the subducting and the overriding plate (Gerya et al., 2008; Angiboust et al., 2012). The role of low or medium grade metamorphism is essential for weakening of the subduction interface by creating or propagating weak shear zones at lithospheric scale. The low-grade facies have very low rheological strength, which lubricates the subduction interface controlled by the formation of the localized shear zones. In oceans, serpentinite layers forming at crustmantle interface and fluid release due to its dehydration at depth play a major role in weakening of the subduction channel allowing for stable subduction (Faccenda et al., 2009a).

The major effect of UHP metamorphic changes (eclogitisation) is that it better decouples the subducting and the overriding plate and results in a steeper subduction angle of the continental slab. The experiments suggest that eclogite phase changes do not significantly improve the chances for "normal" subduction: when the Moho temperature exceeds $550-600{ }^{\circ} \mathrm{C}$ (temperature of onset of UHP metamorphism), subduction is not a dominant mechanism, whatever the degree of eclogite metamorphism is. This statement is valid for the commonly used assumption that eclogite has a weak rheology (about the same as quartz rheology), which was used in most experiments. Any assumptions on the badly constrained eclogite rheology may be questioned while the degree of eclogitization may also vary in a wide range. Additional experiments hint that the assumption of strong eclogite rheology (such as that of dry granulites) would be equivalent, in terms of the mechanical behavior, to additional slab 
pull, improving the chances for continental subduction with an effect that is equivalent to the assumption of a colder denser plate with Moho temperature of about $150-200^{\circ} \mathrm{C}$ lower than in the reference case.

\subsection{Exhumation of metamorphic terranes and their impact on subduction cycle}

In the previous sections, we have considered a general scenario in which continental crust subducts as a part of large-scale continental collision. However, a number of situations exist in which continental crust can be buried with the oceanic lithosphere. This refers to subduction of relatively small continental terrains embedded within oceanic plate, which further exhumation gives birth to formation of the impressive high-pressure (HP) metamorphic belts that comprise rocks regurgitated to the Earth's surface from depths of up to $150 \mathrm{~km}$ (Tirel et al., 2013 and references therein). In the intensively studied Aegean back-arc domain in the Mediterranean (Figure 20), the origin of diverse HP belts appear to be related to the continuous subduction of the same African lithospheric plate, which indicates that their exhumation is a transient and recurrent process (Tirel et al., 2013 and references therein). Here we discus thermo-mechanical numerical experiments that test this idea and show that successive subduction of multiple continental blocks - and the associated variations in slab buoyancy and rollback rate may be responsible for the episodic rollbackexhumation cycles. In these experiments, a single self-consistent model reproduces the major structural patterns and pressure-temperature-time (P-T-t) paths of the HP rocks in different parts of the Aegean and elucidates a new fundamental mechanism of HP exhumation.

Structural complexity of subducting oceanic plates, in particular the presence of small continental blocks within them, influenced the Tertiary evolution and rate of retreat of the subduction zones in the Mediterranean; it must also have had an effect on the HP rock burial and exhumation cycles (Figure 20). The Aegean's three main continental blocks-Adria, Pelagonia and Rhodopia-were once separated by the Pindus and Vardar Oceans, their closure recorded in the Pindus and Vardar Suture Zones (Figures 20a and 20b). Following the Vardar Ocean closure, Pelagonia subducted below Rhodopia, with the thrusting ending at 60-55 Ma. In the middle Eocene, after the Vardar suturing was complete, Pelagonia and the oceanic blueschists of the Cyclades 
began to exhume. With the Pindus Ocean now subducting, Pelagonia and Rhodopia underwent extension since $45 \mathrm{Ma}$, and high-temperature (HT) core complexes developed in northern Greece and southern Bulgaria.

The eclogites and blueschists in the northernmost Cyclades Islands derived from Pindus oceanic material and were exhumed in two stages, first from the mantle to lower crustal depths (at 45-37 Ma) and then up to the upper crustal depths (30-14 Ma) (Fig. 20c). The blueschists atop Adria's granitic basement were subducted below Pelagonia up to the middle Eocene in the Cyclades and up to the Oligocene in Peloponnese and Crete, where they recorded pressures of up to $17 \mathrm{~kb}$ around $26 \mathrm{Ma}$ and reached upper crustal depths around 12-10 Ma (Fig. 20d).

Upon the second, late-Oligocene stage of their exhumation-during the subduction of the Mediterranean oceanic lithosphere-the HP rocks of the Cyclades, Peloponnese and Crete formed a flat-lying domain of HP metamorphic rocks, over 250 $\mathrm{km}$ in width (Fig. 20b). Since $15 \mathrm{Ma}$, the entire Aegean domain was affected by distributed extension, with deposition of sedimentary basins.

P-wave tomography shows that the docking and subduction of continental blocks in the Aegean are related to the subduction of a single lithospheric slab. We thus assume an initial geometry with an already initiated oceanic subduction and with two blocks of continental crust located on the subducting plate, each destined to be accreted to the overriding plate in the course of the experiment (Figure 21). In this model, subduction is unforced, i.e. driven by the slab pull force while the opposite sides of the plates are attached to the model walls. This assumption is realistic because both European and African lithosphere represent very large continental blocks, which far field dynamics would not be affected by a small subduction zone.

Figure 22a shows the step-by-step evolution of the model at the upper-mantle scale. Two continental blocks are subducted and then exhumed one after the other during the continuous retreat of the subduction zone. It is noteworthy that the subduction of a continental block induces an increase in the slab dip angle and a decrease in the subduction velocity, due to the change in slab buoyancy. The slab, heated by the hotter ambient mantle, breaks at its weakest points, the former location of the continental blocks (such slab break-off is not seen in the tomography at this location3, but it has little effect on HP exhumation). 
Structural development associated with the two subduction-exhumation cycles is summarized in the key snapshots in Figure 22b. Pressure-temperature (PT) paths through time $(\mathrm{t})$ of material points within the block 2 are illustrated using coloured markers (Figures 22b, 22c). At the onset (6.1 Ma), the subducting slab drags down the tip of the overriding plate, inducing asthenospheric ascent below the extending overriding continental lithosphere. Extension is driven by slab rollback, caused by the negative buoyancy of the slab. The subducting continental block reaches HP-UHP metamorphic conditions and is progressively delaminated from the mantle lithosphere, as it is thrust beneath the accretionary wedge. Despite the deep burial, continentalcrust rocks remain cold, partially insulated from the warm asthenosphere by the lithospheric-mantle material of the upper plate that is being dragged down. The delaminated rear part of the subducting block then moves back to the surface along an extensional detachment that reactivates the suture zone, while the front part continues to move downward (12.3 Myr), to be exhumed later. When back to the surface, the crustal block is delaminated completely from the underlying lithospheric mantle, and the asthenosphere flows into the wedge that opens (36.6 Myr). During the exhumation process (6.1-36.6 Myr), the block-scale deformation mimics one step of a caterpillar walk, with the block's tail slipping along a basal décollement, approaching the head and making a large buckle, which then unrolls as soon as the entire block is delaminated. This caterpillar walk process is accommodated structurally, first, by stacking of thrust slices at the rear of the block and, then, by extensional detachment at the rear when the thrusting reaches the front of the block. When exhumed completely, the block undergoes extension almost along its entire length. It is noteworthy that small slices of oceanic lithosphere that are thrust on top of the continental-block rear are then exhumed together with the continental block. These oceanic slices correspond to ophiolites that undergo HP-UHP metamorphism prior to their thrust emplacement atop continental crust at the surface.

When block 2 enters the subduction zone, it undergoes subduction and exhumation as block 1 before it (36.6-70.4 Myr). The ascent of the asthenosphere due to the slab-dip increase causes strong heating and thermal weakening of the first, exhumed continental block. Consequently, the exhumed block 1 undergoes extension during the exhumation of block 2, with extensional reactivation of thrust faults and 
development of high-temperature (HT) metamorphic core complexes (MCC). The yellow marker (Figure 22) shows that this isobaric heating can reach $700^{\circ} \mathrm{C}$ beginning at about 10 kbars. Pervasive flow in the middle and lower crust accommodates considerable stretching, with the Moho remaining flat.

The modelled deformation sequence during the subduction-exhumation cycle of a continental block (Figures 22 and 23) shows remarkable similarity to the evolution of the blueschists and eclogites of the Adria block (Figure 20): i) thrust emplacement of HP ophiolites on top of continental crust at the block rear is observed in the northwest Cyclades; ii) the stacking of thrust slices starting at the block rear and propagating frontward directly corresponds to the thrusting in the middle Eocene in the Cyclades, ending in the Oligocene in the external Hellenides; iii) block exhumation accommodated by the extensional reactivation of the suture zone-coeval with the last stages of the thrusting at the block front 4 -is illustrated by the reactivation of the Vardar suture zone at the front (relative to its entrance in subduction) of the Adria block (Figure 20); iv) partial melting and HT core-complex development in the exhumed block is observed, for example, in Naxos, central Cyclades, pervasive flow in the lower crust associated with the MCC development in the Cyclades is evidenced by seismic anisotropy; vi) distributed extension of the exhumed block is seen in the widespread development of sedimentary basins across the Aegean since the late Miocene; vii) the modelled PTt paths closely match those observed in the northern Cyclades (including the isobaric increase of temperature at the Adria block front; Figure 20c) and in Peloponnese (Adria block rear; Figure 20d).

These numerical experiments show that the subduction of small continental blocks, as documented in the Mediterranean, is followed by rapid exhumation of HP metamorphic belts, driven, fundamentally, by slab rollback. Because it is the space created by the trench retreat that allows the block to reach the surface, the rate of the exhumation of the block depends on the velocity of the trench retreat. During the entire process, the block delamination (by thrusting) and exhumation are driven by the buoyancy of the crust. Tectonically, exhumation promoted by slab rollback invokes extensional reactivation of a suture zone and accounts for the emplacement at the surface of HP rock units with a horizontal envelope at regional scale that keep their lithological-stratigraphical continuity over long distances (several hundred kilometres) 
along the direction of trench retreat. Our results also cast doubt on the view that HP rock exhumation must occur during continental collision. Subduction of a small continental block that rapidly returns to the surface as subduction continues does not indicate, strictly speaking, a collisional setting. This may have been difficult to establish, until now, due to the fact that HP units exhumed in this way are often squeezed, subsequently, in a continental collision zone.

\subsection{D configuration of plate boudnaries and UHP exhumation}

Deviations from 2D cylindrical geometry may result in sometimes strong spatial variations of the subduction and UHP exhumation conditions. One of the evident examples refers to the Himalayan syntaxes (Chemenda et al., 1995) where deep structures and geodynamic conditions are very different from those in the Central Himalayas. Few models have investigated so far the effect of 3D geometry on continental subduction (e.g., Li et al. 2013, Figure 24) to show, in particular, the possibility of lateral propagation of the tearing of the slab leading to spatially progressive along-strike exhumation of the subducted continental crust. The 3D effects can also include along-strike corrugations of the subduction interface and hence to spatially periodic or punctual UHP exhumation.

\section{Discussion and Conclusions}

(1). The numerical experiments discussed here show that subduction processes can result in the formation and exhumation of HP/UHP terranes for physically reasonable parameter ranges. When subduction takes place, the UHP P-T-t data can be decoded in terms of the exhumation depths within 10-20\% accuracy from lithostatic pressure gradients. Yet, the presence of UHP rocks can be regarded as solid evidence for subduction only in association with subduction-compatible PT/PTt data and structural evolution, and under condition that the UHP assemblages are statistically representative for the targeted area. In this study we have discussed application of subduction models to the Alps, Zagros and Himalaya. A lot of observational work on the UHP rocks has been done in a number of other orogens such as in Dabie (e.g., Hacker et al., 2004), Norway (e.g., Kylander-Clark et al., 2009), Kokchetav (Hacker et al., 2003), 
where the presence of UHP terranes and mechanisms of their exhumation may eventually receive a different interpretation, even though, at a first glance, all these areas can be treated in the framework of the subduction hypothesis. It cannot be excluded that at some stages of collision evolution, various (tectonic or local) overpressure mechanisms can affect formation of the UHP rocks. However, the all overpressure hypotheses need to be tested through complete regional modelling approach, so that the adequate models should reproduce all stages of burial and exhumation of the UHP material while generating realistic PT/PTt paths, surface and geotectonic evolution.

(2). The possibility and duration of the subduction phase is mainly conditioned by the convergence rate and thermo-rheological structure of the crust and lithosphere (e.g., Figures 12-13 and 18-19) that have major control both on the possibility of subduction and exhumation. The experiments suggest a wide variety of collision scenarios. Sustainable continental subduction and HP-UHP exhumation is possible only in the case of a relatively strong mantle lithosphere (Moho temperatures below $T_{\mathrm{m}}<$ $\left.550-600^{\circ} \mathrm{C}\right)$ and relatively fast initial convergence rates $\left(>1-3 \mathrm{~cm} \cdot \mathrm{yr}^{-1}<10 \mathrm{~cm} \cdot \mathrm{yr}^{-1}\right)$. Yet, only a small portion of UHP material probably exhumes to the surface, while large UHP volumes can be formed at depth. For hot $\left(T_{\mathrm{m}}>650^{\circ} \mathrm{C}\right)$ or slow convergence settings $(<$ $1 \mathrm{~cm} . \mathrm{yr}^{-1}$ ) continental subduction is possible as follow-up of the oceanic subduction stage and represents a transient process that lasts less than 5-10 Myr. It probably ends after the slab break-off (Yamato et al., 2008).

(3). It can be overall concluded that the convergence rates and the integrated strength of the lithosphere are interlinked (Figure 19), since higher convergence rates require higher slab pull/push forces while such forces can only be exerted if the lithosphere is sufficiently strong to sustain them.

(4). A rather counter-intuitive finding refers to the dependence of the convergence style (slab dip, time of slab break-off, eventually amount of subduction) on the partitioning of the absolute convergence velocities at the borders of the convergent zone (Figure 16). These results emphasize the importance of elucidation of absolute plate tectonic movements and sub-lithospheric mantle flow directions.

(5). The exhumation of HP/UHP material might be most favoured during the initial stages of continental subduction and is eased by slow convergence settings $\quad<2$ 
$\mathrm{cm} . \mathrm{yr}^{-1}$ ), which is rather in the lower limit of the convergence rate range favoring subduction. There is, hence, a trade-off between the range of convergence rates favoring subduction and the range of the convergence rates favoring maximal amounts of exhumation. It can be therefore also proposed that exhumation of the oceanic UHP rocks occurs during the transition from the oceanic to continental subduction phase, when the subduction slows down (eq. 9) and the UHP rocks can be effectively dragged to the surface by positively buoyant delaminated continental crustal units.

(6). The exhumation of UHP units is a poly-phase process driven by different physical mechanisms occurring at the subduction interface zone: (1) the LP and MP rocks are exhumed by a classical accretion prism mechanism and erosion; the final stages (above $40 \mathrm{~km}$ depth) of HP/UHP exhumation also take the same path; (2) within the HP/UHP depth interval, small-to-middle sized HP and UHP terranes can be largely exhumed by buoyancy, within partly metamorphosed low-density crustal units, slices or melanges, as a result of RT instabilities and small-scale convection and viscous drag in the deep "crustal pockets" created due to separation of the subducting crust from the mantle below $80-120 \mathrm{~km}$ depth. Large UHP terranes can be exhumed by buoyancy, within large multi-decakilometer blocks of intermediate or lower crust that delaminate from the mantle lithosphere and are additionally pushed to the surface by tectonic forces (e.g., Figure 10, Yamato et al., 2008). One can suggest that deep exhumation is mainly conditioned by viscosity and buoyancy within and around the metamorphic bodies. Since metamorphic reactions are activated by fluids, which presence is not always granted during the burial path, some UHP material may form only during exhumation.

(7). UHP exhumation may occur in slab-roll back context when oceanic lithosphere embeds one or more continental terrains (Tirel et al., 2013). Successive subduction of continental terrains results in pulsating regime, with periodical rollbacks and episodes of exhumation. Sliding of the blocks one below the other may results in versatile metamorphic evolution, for example, simultaneous exhumation of cold and hot rocks.

(8). 3D geometries of plate boundaries may have strong impact on timing and localization of exhumation of UHP terranes. 


\section{Acknowledgements}

We are very much thankful to the both reviewers, Boris Kaus and Brad Hacker for their very helpful comments and suggestions. Boris Kaus is also thanked for many useful corrections concerning manuscript wording and style. Different parts of the MS have benefited from discussions with T. Gerya, S. Wolf and B. Huet. This publication was supported by the Advanced ERC Grant Rheolith. 


\section{References}

Andersen, T.B., Austrheim, H., 2008. The Caledonian infrastructure in the Fjord-region of Western Norway; with special emphasis on formation and exhumation of highand ultrahigh-pressure rocks, late- to post-orogenic tectonic processes and basin formation. Field Trip Guidebook 33 IGC excursion No 29, 88 (August 15-22nd).

Angiboust, S., Wolf, S., Burov, E., Ph. Agard, and P. Yamato, 2012. Effect of Fluid Circulation on Subduction Interface Tectonic Processes: Insights from Thermomechanical Numerical Modelling, Earth and Planetary Sci. Lett., 357-358, 238-248. Agard, P., L. Jolivet, Goffé, B., 2001. Tectonometamorphic evolution of the Schistes Lustrés complex: implications for the exhumation of HP and UHP rocks in the Western Alps, Bulletin de la Societe Geologique de France, 172 (5), 617-636.

Agard, P., P. Yamato, L. Jolivet, Burov, E. , 2009. Exhumation of oceanic blueschists and eclogites in subduction zones: timing and mechanisms, Earth Sciences Reviews, 92, 53-79.

Afonso J. C. , Zlotnik, S., 2011. The Subductability of Continental Lithosphere: The Before and After Story, Arc-Continent Collision, Frontiers in Earth Sciences, Part 1, 53-86, DOI: 10.1007/978-3-540-88558-0_3.

Austrheim, H., 1991. Eclogite formation and the dynamics of crustal roots under continental collision zones: Terra Nova, 3, 492-499.

Avouac, J.P., Burov, E.B., 1996. Erosion as a driving mechanism of intracontinental mountain growth, Journal of Geophysical Research-Solid Earth, 101 (B8), 1774717769.

Avouac, J. P. , 2003. Mountain building, erosion and the seismic cycle in the Nepal Himalaya, Advances in Geophysics, 46, 1-80.

Beaumont, C., Kamp, P.J.J., Hamilton, J., Fullsack, P., 1996. The continental collision zone, South Island, New Zealand: Comparison of geodynamical models and observations, Journal of Geophysical Research, 101, 3333-3359.

Beaumont, C., J. A. Muñoz, J. Hamilton, Fullsack, P. , 2000. Factors controlling the Alpine evolution of the central Pyrenees inferred from a comparison of observations and geodynamical models, Journal of Geophysical Research, 105(B4), 8121-8146. 
Beaumont, C., Jamieson, R.A., Butler J.P., Warren, C.J., 2009. Crustal structure: a key constraint on the mechanisms of ultra-high-pressure rock exhumation. Earth and Planetary Science Letters 287, 116-129.

Bürgmann, R., Dresen, G., 2008. Rheology of the lower crust and upper mantle: evidence from rock mechanics, geodesy, and field observations, Annual Review of Earth and Planetary Sciences, Vol. 36: 531-567, DOI: 10.1146/annurev.earth.36.031207.124326.

Brun, J.-P., Faccenna, C., 2008. Exhumation of high-pressure rocks driven by slab rollback. Earth and Planetary Science Letters 272, 1-7.

Burov, E., 2010a. The equivalent elastic thickness (Te), seismicity and the long-term rheology of continental lithosphere: Time to burn-out "crème brûlée"?: Insights from large-scale geodynamic modeling, Tectonophysics, 484 , 4-26, doi:10.1016/j.tecto.2009.06.013.

Burov, E., 2010b. Thermo-Mechanical Models for Coupled Lithosphere-Surface Processes: Applications to Continental Convergence and Mountain Building Processes, In: S. Cloetingh and J. Negendank (Edt), New Frontiers in Integrated Solid Earth Sciences, International Year of Planet Earth, Springer Science+ Business Media, 103-143, doi: 10.1007/978-90-481-2737-5_4.

Burov, E., Rheology and strength of the lithosphere, Marine and Petroleum Geology, 28,8,1402-1443, DOI: 10.1016/j.marpetgeo.2011.05.008, 2011.

Burov, E.B., Kogan, M.G., Lyon-Caen, H., P. Molnar, 1990. Gravity anomalies, the deep structure, and dynamic processes beneath the Tien Shan, Earth and Planetary Science Letters, 96, 367-383.

Burov E. B., Diament, M., 1995. Effective Elastic Thickness of the Continental Lithosphere - what does it really mean?, Journal of Geophysical Research, 100, 3905-3927.

Burov, E.B., Podladchikov, Y., Grandjean, G., J.-P. Burg, 1999. Validation of multidisciplinary data using thermo-mechanical modelling: application to the Western and Nothern Alps, Terra Nova, 11:124-131.

Burov, E.B., Jolivet, L., Le Pourhiet, L., Poliakov, A., 2001. A thermemechanical model of exhumation of HP and UHP methamorphic rocks in Alpine mountain belts, Tectonophysics, 342, 113-136. 
Burov E., Jaupart, C., Guillou-Frottier, L., 2003. Emplacement of magma reservoirs in the upper crust, Journal of Geophysical Research, 108 (B4), 2177-2189, 2003.

Burov, E., Watts, A.B., 2006. The long-term strength of continental lithosphere: "jellysandwich" or "crème-brûlé"?, GSA Today, 16, 4-10.

Burov E. , Toussaint, G., 2007. Surface processes and tectonics: forcing of continental subduction and deep processes, Global and Planetary Change, Special volume on Topography of Europe , 58, 141-164.

Burov, E. , Yamato, Ph., 2008. Continental plate collision, P-T-t-z conditions and unstable vs. stable plate dynamics : Insights from thermo-mechanical modelling, Lithos, 103, 178-204.

Burtman, V.S., Molnar, P., 1993. Geological and geophysical evidence for deep subduction of continental crust beneath the Pamir. Geological Society of America Special Paper 281, 1-76.

Burg, J.-P., Gerya, T.V., 2005. Viscous heating and thermal doming in orogenic metamorphism: numerical modeling and geological implications. Journal of Metamorphic Geology, 23, 75-95.

Burg, J.-P., Podladchikov, Y., 2000. From buckling to asymmetric folding of the continental lithosphere: Numerical modelling and application to the Himalayan syntaxes, in Khan, M.A., et al., eds., Tectonics of the Nanga Parbat syntaxis and the western Himalaya: Geological Society of London Special Publication 170, $219-236$.

Byerlee, J.D., 1978. Friction of rocks, Pure and Applied Geophysics, 116, 615-629.

Chemenda, A.I., Mattauer, M., Malavieille, J., Bokun, A.N., 1995. A mechanism for syncollisional rock exhumation and associated normal faulting: results from physical modelling. Earth and Planetary Science Letters 132, 225-232.

Chemenda, A.I., Mattauer, M., Bokun, A.N., 1996. Continental subduction and a mechanism for exhumation of high-pressure metamorphic rocks: new modeling and field data from Oman. Earth and Planetary Science Letters 143, 173-182.

Chopin, C., 1984. Coesite and pure pyrope in high-grade blueschists of the western Alps: A first record and some consequences. Contributions to Mineralogy and Petrology, 96, 253-274. 
Chopra, P.N., Paterson, M.S., 1981. The Experimental Deformation of Dunite, Tectonophysics, 78, 453-473.

Chen, Y., Cogne, J.-P., Courtillot, V., Tapponnier, P. \&, Zhou, X.Y., 1993. Cretaceous paleomagnetic results from western Tibet and tectonic implications, Journal of Geophysical Research, 98, 17981-18000.

Cloetingh, S.A.P.L., Wortel, M.J.R., Vlaar, N.J., 1982. Evolution of passive continental margins and initiation of subduction zones, Nature, 297, 139-142.

Cloetingh, S., Burov, E., 1996. Thermomechanical structure of European continental lithosphere: constraints from rheological profiles and EET estimates. Geophysical Journal International, 124, 695-723.

Cloetingh, S., Burov, E., Poliakov, A., 1999. Lithosphere folding: Primary response to compression? (from central Asia to Paris Basin). Tectonics, 18, 1064-1083.

Cloetingh, S.A.P.L., Burov, E., Matenco, L., Toussaint, G., Bertotti, G., Andriessen, P.A.M., Wortel, W.J.R. , Spakman, W., 2004. Thermomechanical controls on the model of continental collision in the SE Carpathians (Romania), Earth and Planetary Sciences Letters, 218, 57-76.

Cloos, M., 1993. Lithospheric buoyancy and collisional orogenesis: Subduction of oceanic plateaus, continental margins, island arcs, spreading ridges and seamounts. Geological Society of America Bulletin, 105, 715-737.

Coleman, R.G ., 1971. Plate tectonic emplacement of upper mantle peridotites along continental edges. Journal of Geophysical Research, 76, 1212-1222.

Connolly, J.A.D., 2005. Computation of phase equilibria by linear programming: $A$ tool for geodynamic modeling and its application to subduction zone decarbonation. Earth and Planetary Sciences Letters, 236, 524-541.

Culling, W.E.H., 1960. Analytical theory of erosion, Journal of Geology, 68 (333-336).

Cundall, P.A., 1989. Numerical experiments on localization in frictional material. Ingenieur-Archiv, 59, 148-159.

Dahlen, F.A., 1990. Critical taper model of fold-and-thrust belts and accretionary wedges, Annual Review of Earth and Planetary Science, 18, 55-99.

Dahlen, F.A., Suppe, J., 1988. Mechanics, growth and erosion of mountain belts, Spec. Pap. Geol. Soc. Am., 218, 161-178.

Davies, J.H., 1999. Simple analytic model for subduction zone thermal structure. 
Geophysical Journal International, 139, 823-828.

Davis, D.M., J. Suppe, Dahlen, F.A., 1983. Mechanics of fold-and-thrust belts and accretionary wedges. Journal of Geophysical Research, 88 (B2), 1153-1172.

De Capitani, C., 1994. Gleichgewichts-Phasendiagramme: Theorie und Software, in:

Beihefte zum European Journal of Mineralogy-Jahrestagung der Deutschen Mineralogischen Gesellschaft, pp. 48.

DeCelles, P. G.,Robinson, D. M., Zandt, G., 2002. Implications of shortening in the Himalayan fold-thrust belt for uplift of the Tibetan Plateau, Tectonics, 21(6), 1062, doi:10.1029/2001TC001322

Diez Fernández, R., Martínez Catalán J.R., Arenas R., Abati, J., 2012. The onset of the assembly of Pangaea in NW Iberia: Constraints on the kinematics of continental subduction, Gondwana Research, 22, 20-25.

Doin, M.-P., Henry, P., 2001. Subduction initiation and continental crust recycling: The roles of rheology and eclogitization. Tectonophysics, 342, 163-191.

Duretz, T., Gerya, T.V., May, D.A., 2011. Numerical modelling of spontaneous slab breakoff and subsequent topographic response. Tectonophysics, 502, 244-256.

Duretz, T., Gerya, T.V., Kaus, B.J.P., Andersen, T.B., 2012. Thermomechanical modelling of slab eduction. Journal of Geophysical Research 117. http://dx.doi.org/10.1029/2012JB009137.

Hacker, B.R., Ratschbacher, L., Webb, L.E., McWilliams, M., Calvert, A., Dong, S., Wenk, H.-R., and Chateigner, D., 2000. Exhumation of ultrahigh-pressure rocks in eastcentral China: Late Triassic-Early Jurassic tectonic unroofing. Journal of Geophysical Research, 105, 13339-13364.

Hacker, B.R., Ratschbacher, L., Liou, J.G., 2004. Subduction, collision and exhumation in the ultrahigh-pressure Qinling-Dabie orogen, In: Malpas,J., Fletcher, C.J.N., Ali, J.R., and Aitchison, J.C.(eds), Aspects of the Tectonic Evolution of Chiua. Geol. Soc. London, Spec. Pub., 226, 157-175.

Hacker, B.R, McClelland, W.C., Liou, J. G. , 2006. Ultrahigh-pressure Metamorphism: Deep Continental Subduction, Geological Society of America, 206 pp.

Hacker, B.R., Andersen, T.B., Johnston, S., Kylander-Clark, A.R.C., Peterman, E.M., Walsh, E.O., Young, D., 2010. High-temperature deformation during continentalmargin subduction \& exhumation: the ultrahigh-pressure Western Gneiss Region 
of Norway. Tectonophysics 480 (1-4), 149-171.

Hacker, B.R., Kelemen, P.B., and Behn, M.D., 2011. Differentiation of the Continental Crust by Relamination. Earth and Planetary Science Letters, v. 307, p. 501-516.

Hacker, B.R., and T.V. Gerya, 2013. Paradigms, new and old, for ultrahigh-pressure tectonism. Tectonophysics 603, 79-88.

Handy, M. R., S. M. Schmid, R. Bousquet, E. Kissling, Bernoulli, D. , 2010. Reconciling plate-tectonic reconstructions of Alpine Tethys with the geological-geophysical record of spreading and subduction in the Alps. Earth-Science Reviews, 102, 121158.

Hassani, R., D. Jongmans, Chery, J., 1997. Study of plate deformation and stress in subduction processes using two-dimensional numerical models. Journal of Geophysical Research, 102 (B8), 17951-17965.

Hatzfeld, D., Molnar, P. , 2010. Comparisons of the kinematics and deep structures of the Zagros and Himalaya and of the Iranian and Tibetan plateaus and geodynamic implications, Reviews of Geophysics, 48, RG2005, doi:10.1029/2009RG000304, 48pp.

Hirth, G., Kohlstedt, D.L., 1996. Water in the oceanic upper mantle: Implications for rheology, melt extraction and the evolution of the lithosphere. Earth and Planetary Sciences Letters, 144, 93-108.

Houseman, C.A., Molnar, P., 1997. Gravitational (Rayleigh-Taylor) instability of a layer with nonlinear viscosity and convergence thinning of continental lithosphere. Geophysical Journal International, 128, 125-150.

Emerman, S. H., Turcotte, D. L., 1983. A fluid model for the shape of accretionary wedges. Earth and Planetary Science Letters, 63, 379-384.

England, P.C., Houseman, G.A., 1989. Extension during continental convergence, with application to the Tibetan Plateau. Journal of Geophysical Research, 94, 1756117579.

Ernst, W.G., 1973. Blueschist metamorphism and P-T regimes in active subduction zones. Tectonophysics, 17, 255-272.

Ernst W.G. , 2010. Subduction-zone metamorphism, calc-alkaline magmatism, convergent-margin crustal evolution. Gondwana Research, 18, 8-16. 
Faccenda, M., Gerya, T.V., Chakraborty, S., 2008. Styles of post-subduction collisional orogeny: Influence of convergence velocity, crustal rheology and radiogenic heat production. Lithos, 103, 257-287.

Faccenda, M., Gerya, T.V., Burlini, L. , 2009a. Deep slab hydration induced by bending related variations in tectonic pressure. Nature Geoscience, 2, 790-793,

Faccenda, M., Minelli, G. ., Gerya, T.V., 2009b. Coupled and decoupled regimes of continental collision: Numerical modeling. Earth and Planetary Science Letters, 278, 337-349.

Ford, M., S. Duchêne, D. Gasquet, Vanderhaeghe , O. , 2006. Two-phase orogenic convergence in the external and internal SW Alps, Journal of Geological Society of London, 163, 1-12.

Francois, T., Burov, E., Agard, P., Meyer, B., 2012. Evaluating the effect of rheology on the evolution of continental collision: Application to the Zagros orogen, Geophysical Research Abstracts, 14, EGU2012-10283, 2012, EGU General Assembly.

Francois, T., Burov, E., Agard, P., Meyer, B., 2014. Build-up of a dynamically supported orogenic plateau: numerical modelling of the Zagros/Central Iran case study, submitted to $\mathrm{G} 3$.

Jolivet, L., Daniel, J. M., Truffert, C., Goffé, B., 1994. Exhumation of deep crustal metamorphic rocks and crustal extension in back-arc regions. Lithos, 33, 3-30.

Jolivet, L., H. Raimbourg, L. Labrousse, D. Avigad, Y. Leroy, H. Austrheim, Andersen, T. B., 2005. Softening trigerred by eclogitization, the first step toward exhumation during continental subduction. Earth Planetary Sciences Letters, 237, 532-547.

Gerya, T.V., B. Stöckhert, Perchuk, A.L., 2002. Exhumation of high-pressure metamorphic rocks in a subduction channel: A numerical simulation. Tectonics, 26 (6), 1-15.

Gerya, T.V., Yuen, D.A., 2003. Rayleigh-Taylor instabilities from hydration and melting propel "cold plumes" at subduction zones. Earth and Planet Sciences Letters, 212, 47-62.

Gerya, T.V., Stöckhert, B., 2006. Two-dimensional numerical modeling of tectonic and metamorphic histories at active continental margins. International Journal of Earth Sciences 95, 250-274.. 
Gerya T.V., Perchuk, L.L., Burg J.-P., 2008. Transient hot channels: perpetrating and regurgitating ultrahigh-pressure, high temperature crust-mantle associations in collision belts. Lithos, 103, 236-256.

Gray, R., Pysklywec, R. N., 2010. Geodynamic models of Archean continental collision and the formation of mantle lithosphere keels. Geophysical Research Letters, 37, L19301, doi:10.1029/2010GL043965.

Gray, R., Pysklywec, R. N. , 2012. Geodynamic models of mature continental collision: Evolution of an orogen from lithospheric subduction to continental retreat/delamination. Journal of Geophysical Research, doi:10.1029/2011JB008692.

Gleason, G.C., Tullis, J., 1995. A flow law for dislocation creep of quartz aggregates determined with the molten salt cell. Tectonophysics, 247, 1-23.

Goetze, C., Evans, B. , 1979. Stress and temperature in the bending lithosphere as constrained by experimental rock mechanics. Geophysical Journal of Royal Astronomy Society, 59 , 463-478.

Gorczyk, W., Gerya, T.V., Connolly, J.A.D., Yuen, D.A., Rudolph, M., 2006. Large-scale rigid-body rotation in the mantle wedge and its implications for seismic tomography. Geochemistry Geophysics Geosystems, 7, doi:10.1029/2005GC001075.

Guillot, S., K. Hattori, de Sigoyer, J. , 2000. Mantle wedge serpentinization and exhumation of eclogites: insights from eastern Ladakh, northwest Himalaya. Geology, 28, 199-202.

Guillot, S., K. Hattori, J. Sigoyer de, T. Nägler, Auzende, A. L., 2001. Evidence of hydration of the mantle wedge and its role in the exhumation of eclogites. Earth Planetary Sciences Letters, 193, 115-127.

Guillot, S., K. Hattori, P. Agard, S. Schwartz, Vidal, O., 2009. Exhumation processes in oceanic and continental subduction contexts: a review, In S. Lallemand and F. Funiciello (eds.) "Subduction Zone Dynamics", Springer-Verlag Berlin Heidelberg, doi 10.1007/978-3-540-87974-9, 175-204.

Labrousse, L., Jolivet, L., Agard, P., Hebert, R., Andersen, T. , 2002. Crustal-scale boudinage and migmatization of gneiss during their exhumation in the UHP Province of Western Norway. Terra Nova 14(4), 263-270. 
Lanari, P., S. Guillot, S. Schwartz, O. Vidal, P. Tricart, N. Riel, Beyssac, O., 2012. Diachronous evolution of the alpine continental subduction wedge: Evidence from P-T estimates in the Briançonnais Zone houillère (France - Western Alps). Journal of Geodymics, doi:10.1016/j.jog.2011.09.006.

Lavier, L., Steckler, M., 1997. The effect of sedimentary cover on the flexural strength of continental lithosphere, Nature, 389, 476-479.

Le Pichon, X., Fournier, M., Jolivet, L., 1992. Kinematics, topography, shortening and extrusion in the India-Eurasia collision. Tectonics, 11, 1085-1098.

Le Pourhiet L, Burov E, Moretti, I., 2004. Rifting through a stack of inhomogeneous thrusts (the dipping pie concept), Tectonics, 23 (4), TC4005, doi:10.1029/2003TC001584.

Little, T.A., Hacker, B.R., Gordon, S.M., Baldwin, S.L. Fitzgerald, P.G., Ellis, S., and Korchinski, M., 2011. Diapiric Exhumation of Earth's youngest (UHP) eclogites in the gneiss domes of the D'Entrecasteaux Islands, Papua New Guinea. Tectonophysics, 510, 39-68.

Li, Z., Gerya, T.V., 2009. Polyphase formation and exhumation of HP-UHP rocks in continental subduction zone: Numerical modeling and application to the Sulu UHP terrane in eastern China. Journal of Geophysical Research, 114, Article Number: B09406.

Li, Z. H., Gerya T. V., Burg, J.-P., 2010. Influence of tectonic overpressure on P-T paths of HP-UHP rocks in continental collision zones: thermomechanical modeling. Journal of Metamorphic Geology , 28(3), 227-247.

Li, Z.H., Xu, Z.Q., Gerya, T.V., 2011. Flat versus steep subduction: contrasting modes for the formation and exhumation of high- to ultrahigh-pressure rocks in continental collision zones. Earth and Planet. Sci. Lett., 301, 65-77.

Li, Z. H., Xu, Z. Q., Gerya, T.V., et al. 2013. Collision of continental corner from 3-D numerical modeling. Earth Planet. Sci. Lett., 380, 98-111.

Li Sanzhong, Kusk Timothy M., Liu Xiaochun, et al. , 2009. Two-stage collision-related extrusion of the western Dabie HP-UHP metamorphic terranes, central China: Evidence from quartz c-axis fabrics and structures. Gondwana Research, 16, 294309. 
Liou, J.G., Ernst, W.G., Zhang, R.Y., Tsujimori, T., Jahn, J.G., 2009. Ultrahigh-pressure minerals and metamorphic terranes-the view from China. Journal of Asian Earth Sciences 35, 199-231.

Kylander-Clark A.R.C., Hacker, B.R., Johnson, C.M., Beard, B.L., and Mahlen, N.J., 2009, Slow subduction and rapid exhumation of a thick ultrahigh-pressure terrane, Tectonics v. 28, TC2003, doi:10.1029/2007TC002251

Kylander-Clark, A.R.C., Hacker, B.R., and Mattinson, C.G., 2011. Size and exhumation rate of ultrahigh-pressure terranes linked to orogenic stage. Earth and Planetary Science Letters, 321-322, 115-120.

Mackwell, S.J., Zimmerman, M.E., Kohlstedt, D.L., 1998. High-temperature deformation of dry diabase with applications to tectonics on Venus, Journal of Geophysical Research, $103,975-984$.

Mancktelow, N., 1995. Nonlithostatic pressure during sediment subduction and the development and exhumation of high pressure metamorphic rocks. Journal of Geophysical Research, 100, 571-583.

Mancktelow, N. S., 2008. Tectonic pressure: Theoretical concepts and modelled examples, Lithos, 103, (1-2), 149-177.

Maruyama Shigenori, Masago H. Katayama I., et al., 2010. A new perspective on metamorphism and metamorphic belts. Gondwana Research, 18, 106-137.

McAdoo, D.C., Martin, C.F., and Poulouse, S., 1985. Seasat observations of flexure: Evidence for strong lithosphere. Tectonophysics, 116, 209-222.

Mouthereau, F., Watts, A.B., and E. Burov, 2013. Collisional orogens, structural inheritance and the long-term strength of continental lithosphere, Nature Geoscience, 6, 9, 785-789.

Parsons, B.E., Sclater, J.G., 1977. An analysis of the variation of ocean floor bathymetry and heat flow with age. Journal of Geophysical Research, 82, 803-827.

Patriat, P., Achache, J., 1984. India-Eurasia collision chronology has implications for crustal shortening and driving mechanism of plates. Nature, 311, 615-621.

Pérez-Gussinyé, M., Watts, A.B., 2005. The long-term strength of Europe and its implications for plate-forming processes, Nature, 436, doi:10.1038.

Petrini K., Podladchikov, Yu., 2000. Lithospheric pressure-depth relationship in compressive regions of thickened crust. Journal of Metamorphic Geology, 18, 67- 
78.

Patzelt, A., H. Li, Wang, J., Appel, E., 1996. Palaeomagnetism of Cretaceous to Tertiary sediments from southern Tibet: evidence for the extent of the northern margin of India prior to the collision with Eurasia. Tectonophysics, 259, 259-284.

Peterman, E.M., Hacker, B.R., Baxter, E.F., 2009. Phase transformations of continental crust during subduction and exhumation: Western Gneiss Region, Norway, Eur. J. Mineral., 21, 1097-1118.

Platt, J. P., 1986. Dynamics of orogenic wedges and the uplift of high-pressure metamorphic rocks. Geological Society of America Bulletin, 97, 1037-1053.

Platt, J. P., 1993. Exhumation of high-pressure rocks: a review of concept and processes, Terra Nova, 5, 119-133.

Poliakov, A.N.B., Podladchikov, Yu. and Talbot C., 1993. Initiation of salt diapirs with frictional overburden: numerical experiments, Tectonophysics, 228, 199-210.

Ponziani, F., De Franco, R., Minelli, G., Biella, G., Federico, C., Pialli, G., 1995. Crustal shortening and duplication of the Moho in the Northern Apennines: A view from seismic refraction data. Tectonophysics, 252, 391-418.

Pysklywec, R., Beaumont, C., Fullsack, P., 2000. Modeling the behavior of the continental mantle lithosphere during plate convergence. Geology, 28, 655658.

Pysklywec R. N., C. Beaumont, Fullsack, P., 2002. Lithospheric deformation during the early stages of continental collision: Numerical experiments and comparison with South Island, New Zealand. Journal of Geophysical Research, 107 (B7), doi:10.1029/2001JB000252.

Pysklywec. R.N., 2006. Surface erosion control on the evolution of the deep lithosphere. Geology, 269, 34(4), 225-228.

Raimbourg, H., Jolivet, L., Leroy, Y., 2007. Consequences of progressive eclogitization on crustal exhumation, a mechanical study. Geophysical Journal International, 168, 379-401.

Ranalli, G., 1995. Rheology of the Earth, $2^{\text {nd }}$ ed., Chapman and Hall, London, 413 pp.

Ranero, C.R., Phipps Morgan, J., McIntosh, K., Reichert, C., 2003. Bending-related faulting and mantle serpentinization at the Middle America trench, Nature, 425, 367-373.

Ring, U., Will, T., Glodny, J., Kumerics, C., Gessner, K., Thomson, S., Gungor, T., Monie, P., 
Okrusch, M., Druppel, K., 2007. Early exhumation of high-pressure rocks in extrusion wedges: Cycladic blueschist unit in the eastern Aegean, Greece, and Turkey. Tectonics 26 (2), TC2001. doi:10.1029/2005tc001872.

Royden, L.H., 1993. The steady State Thermal Structure of Eroding Orogenic Belts and Accretionary Prisms. Journal of Geophysical Research, 98 (B3), 4487-4507.

Sizova, E., Gerya, T.V., Brown, M., 2012. Exhumation mechanisms of melt-bearing ultrahigh pressure crustal rocks during collision of spontaneously moving plates. Journal of Metamorphic Geology 30, 927-955.

Schmalholz , S.M., Podladchikov, Y.Y., 2013. Tectonic overpressure in weak crustal-scale shear zones and implications for the exhumation of high-pressure rocks, Geophys. Res. Lett., 40, 1984-1988.

Schmalholz , S.M., Podladchikov, Y.Y., Duretz, T., 2014, 2-D numerical modelling of nappe formation and pressure-temperature evolution in a shortening heterogeneous crust: Implications for high and ultrahigh pressure tectonism, Tectonophysics, this volume.

Smith, D., 1984. Coesite and pyroxene in Caledonides and its implications for geodynamics, Nature, 310, 641-644

Sobouti, F., Arkani-Hamed, J., 2002. Thermo-mechanical modeling of subduction of continental lithosphere: Physics of the Earth and Planetary Interiors, 131, 185203.

Spear, F.S., 1993. Metamorphic Phase Equilibria and Pressure-Temperature-Time Paths, Mineralogical Society of America, 800 pp.

Stöckhert, B., Gerya, T.V., 2005. Pre-collisional high pressure metamorphism and nappe tectonics at active continental margins: a numerical simulation. Terra Nova, 17 (2), 102-110.

Thielmann M., Kaus B.J.P., 2012. Shear heating induced lithospheric localization: does it result in subduction? Earth and Planetary Science Letters, 359-360, 1-13, doi:10.1016/j.epsl.2012.10.002.

Thompson, A. B, Jezek, J., Schulmann, K., 1997. Extrusion tectonics and rapid elevation of lower crustal metamorphic rocks in convergent orogens. Geology, 25, 491494.

Tirel, C., Brun, J-P, Burov, E., Wortel, MJR, S. Lebedev, 2013. A plate tectonics oddity: 
Caterpillar-walk exhumation of subducted continental crust Geology, 41,5, 555558.

Tetsuzo, S., Rehman H.U. , 2011. When and why the continental crust is subducted: Examples of Hindu Kush and Burma. Gondwana Research, 19, 327-333.

Toussaint, G., E. Burov, Jolivet, L., 2004a. Continental plate collision: unstable versus stable slab dynamics. Geology, 32 (1), 33-36.

Toussaint, G., E. Burov, Avouac, J.-P., 2004b. Tectonic evolution of a continental collision zone: a thermo mechanical numerical model. Tectonics, 23.

Turcotte, D.L., Schubert, G., 2002. Geodynamics, Second Edition, Cambridge University Press, Cambridge, 456 pp.

Warren, C. J.; Beaumont, C. , Jamieson, R.A., 2008a. Formation and exhumation of ultra-high-pressure rocks during continental collision: Role of detachment in the subduction channel. Geochemistry Geophysics Geosystems, 9(4), doi:10.1029/2007GC001839.

Warren, C. J.; Beaumont, C. and Jamieson, R. A., 2008b. Modelling tectonic styles and ultra-high pressure (UHP) rock exhumation during the transition from oceanic subduction to continental collision. Earth and Planetary Science Letters, 267(1-2), pp. $129-145$.

Wassmann, S., and Stockhert, S., 2013. Rheology of the plate interface - Dissolution precipitation creep in high pressure metamorphic rocks, Tectonophysics, 608, 129.

Watts, A.B., 2001. Isostasy and Flexure of the Lithosphere, Cambridge University Press, 458pp.

Weinberg, R.F., Podladchikov, Y., 1994. Diapiric ascent of magmas through power law crust and mantle. Journal of Geophysical Research, 99, 9543-9559.Yamato, P., Agard P., Burov E., Le Pourhiet L., Jolivet L., Tiberi C., 2007. Burial and exhumation in a subduction wedge: Mutual constraints from thermo-mechanical modelling and natural p-t-t data (sch. Lustres, w. Alps). Journal of Geophysical Research, 112, B07410, doi:10.1029/2006JB004441.

Yamato P., Burov E., Agard P., Le Pourhiet L., Jolivet L., 2008. HP-UHP exhumation processes during continental subduction (W. Alps): when thermomechanical models reproduce P-T-t data, Earth and Planetary Sciences Letters, 271, 63-75. 
Yamato, P., Mouthereau, F., Burov, E., 2009. Taiwan mountain building: insights from 2D thermo-mechanical modelling of a rheologically-stratified lithosphere, Geophysical Journal Int., 176, p. 307-326, doi:10.1111/j.1365-246X.2008.03977.x. von Huene, R., Ranero, C.R., Vannucchi, P., 2004. Generic model of subduction erosion. Geology 32, 913-916.

Zhang R. Y., Liou J. G., Ernst W. G. , 2009. The Dabie-Sulu continental collision zone: A comprehensive review. Gondwana Research, 16, 1-26.

Zheng ,Y.-F., Metamorphic chemical geodynamics in continental subduction zones, 2012. Chemical Geology, 328, 5-48. 


\section{FIGURE CAPTIONS}

Figure 1. Possible collision scenarios: (A) unstable (Rayleigh-Taylor) pure or simple shear instability; (B) pure shear in stable mode and (C) unstable mode (folding); (D) simple shear in stable mode (subduction). Related large-scale parameters characterising collision style, lithospheric strength and rheology: $T_{e,} F, \sigma, u, D e, \tau_{m}, h, L, \lambda, \phi . T_{e}$ is equivalent elastic thickness. $F, \sigma, u$ are respectively the horizontal force, stress and convergence/extension velocity, that are linked to the lithospheric strength and possible deformation styles. De and $\tau_{\mathrm{m}}$ are respectively Deborah number and relaxation time related to viscosity contrasts in the lithosphere. $\lambda$ is the characteristic wavelength of unstable deformation related to the thickness of the competent layers in the lithosphere. $h, L$ are respectively the vertical and horizontal scale for process-induced topography supported by lithospheric strength, Argand number $\operatorname{Ar}=\rho g h L / F . \varphi$ is subduction or major thrust fault angle that is indicative of the brittle properties and of the overall plate strength.

Figure 2. Oceanic subduction versus continental subduction. Oceanic subduction is favoured by several factors such as fast convergence rate, negative buoyancy, high bulk plate strength, flexural plastic hinging (yielding), serpentinisation of the crust-mantle interface, hydration of the mantle wedge and shear heating. Many of these factors are absent in case of continental subduction which is disfavoured by overall positive buoyancy of the lithosphere, slow convergence (leading to additional thermal buoyancy, mechanical weakening and rapid slab break-off) and the lack of lubrication of the subduction interface. One of the frequently evoked (possibly important) factors favouring continental subduction refers to metamorphic (LP/MP/HP) reactions leading to weakening of the subduction interface and the UHP eclogitisation of the crust (leading to negative buoyancy) and low ductile strength of the intermediate and lower crust.

Figure 3a. Global distribution of UHP terranes recognized in continental subduction zones (coesite or diamond bearing). Modified from Zheng (2012) and Liou et al. (2009). 
Figure 3b. Pressure-temperature paths of UHP terranes (after Kyalander et al., 2012). Large (Big), slowly formed terranes in red/orange define a region (pink) with higher overall temperatures than the small (Small), slowly formed terranes (blue and green). The Kokchetav terranes is not associated with a group and shown in grey. The numbers in legend correspond to the references in Kyalander et al. (2012).

Figure 3c. Various exhumation/collision concepts linked to different ideas on collision mechanics: (A) classical accretion prism mechanisms for LP-LT to MP-MT conditions (Davis et al., 1983; Dahlen, 1990; Dahlen and Suppe, 1988); (B) Thrusting model, superimposed here onto accretion prism mechanism (LP-LT to MP-MT conditions, e.g., Jolivet et al., 1994); (C) Mancktelow's (1995) "rocket nozzle" dynamic overpressure model (LP to UHP conditions, Mancktelow, 1995); (D) rigid block UHP exhumation model (Chemenda et al., 1995); (E) multi-stage soft crust exhumation model (LP to UHP conditions, high or low degree of metamorphism, or high or low density of the metamorphic grades, Burov et al., 2001) that may be combined with the hot channel mechanism suggested by Gerya et al. (2008); (G) "eduction" model, in which the subductiong plate rebounds after slab break-off bringing crustal volumes back to the surface (Duretz et al., 2012).

Figure 4. Representative model setup (e.g., Francois et al., 2012; 2013). The experiment starts from the oceanic subduction that transforms into continental collision / subduction. The upper boundary condition is a free surface combined with surface erosion and sedimentation in case of continental lithosphere. The bottom boundary condition is pliable Winkler basement. The lateral boundary conditions are velocities. The brittle-elastic-ductile rheology is different for the upper crust, lower crust, mantle lithosphere, slab, sediments, asthenosphere and deep mantle (Table 1, Figure 5). The model eclogites have the same (weak) rheology as the upper crust, but higher density (up to $3400 \mathrm{~kg} / \mathrm{m}^{3}$ ). The crustal lithological and rheology profile that assumes mafic lower crust is consistent with seismic and gravity data. This assumption may not be generally valid, however (Hacker et al. 2011). 
Figure 5. Representative thermal and rheology profiles for continental lithosphere as function of thermo-tectonic age. EET $=T_{e}$ is Equivalent Elastic Thickness, directly measurable proxy (from isostatic observations) to the integrated strength of the lithosphere. Initial geotherms (left) and associated rheological strength profiles (middle and right) are computed for lithosphere with a 40-km-thick crust, deforming at a strain rate of $10^{-15} \mathrm{~s}^{-1}$. Middle (1): Weak lower crust. Right (2): Strong lower crust. Black line: cold lithosphere (thermotectonic age $=450 \mathrm{~m} . \mathrm{y} ., \mathrm{T}_{\text {Moho }}=400-450{ }^{\circ} \mathrm{C}$ ); black dashed lines: intermediate lithosphere $\left(150\right.$ m.y., $\left.550^{\circ} \mathrm{C}\right)$; gray line: hot lithosphere (75 m.y., $\left.650-700^{\circ} \mathrm{C}\right)$; gray dashed line: very hot lithosphere $\left(25 \mathrm{~m} . \mathrm{y} ., 1000^{\circ} \mathrm{C}\right)$. Note also that the maximal strength of the mantle lithosphere is limited by Peierls flow law when the predicted dislocation or brittle strength is higher than Peierls strength.

Figure 6a. Example of implementation of a numerical collision model (see Figure 4) that starts from the oceanic subduction phase with progressive transition to continental subduction (Zagros collision settings) after slab-break off (Francois et al., 2012). The figure shows finite strain distributions during the oceanic subduction phase demonstrating extreme strain localization around the slab and at the LAB. The model lithosphere is shortening with a rate of $4 \mathrm{~cm} / \mathrm{y}$ on both sides.

Figure 6b. Progressive transition from oceanic to continental subduction in the experiment similar to the one shown in Figure 6 a, with same total convergence rate of $4 \mathrm{~cm} / \mathrm{yr}$. Note earlier slab break-off at 6.5 Myr. Shown are the logarithm of the effective viscosity (ratio of shear stress to strain rate) and surface topography. The star symbol corresponds to the slab break-off zone, and the number near the star - to the number of break-off event (there are three consecutive slab break-offs in this experiment).

Figure 7. Oceanic phase of Alpine convergence: example of self-consistent subduction experiments (Yamato et al., 2006), for the case of an oceanic plate subducting below a 160 Myr old continental lithosphere. This experiment implements thermo-dynamically consistent phase changes. Densities for all material phases are computed using the algorithm THERIAK (de Capitani, 1994; Table 1, Appendix). Squared zones show the position of zoom area shown in Figure 8. Shown at the bottom are the assumed 
rheological profiles, for the continental (left) and oceanic plate (right). The profiles were derived for the mentioned thermotectonic age under assumption of quartz-rich upper continental crust, diabase lower crust, and olivine mantle (Table 1). Olivine is used for the entire oceanic lithosphere.

Figure 8. Zoom to the oceanic subduction interface, for the experiments shown in Figure 7. Marker field at $5 \mathrm{Myr}$ traces the movements of the particles, which allows us to trace $P$-T-t paths at each moment of time (bottom). In this model, exhumation of HP rocks was achieved at 10-13 Myr under assumption of low viscosity of the serpentinite layer. All markers used for the construction of the $P$ - $T$ - $t$ paths were initially located in the normal (un-subducted) oceanic sediments (the uppermost $2 \mathrm{~km}$ layer of the crust). The lower panel shows pressure distribution in the subduction channel compared to theoretically admissible upper and lower bounds (double lithostatic and half-lithostatic). Note less than $20 \%$ deviations from the lithostatic gradient.

Figure 9. Example of two-phase flow version of the Alpine subduction (oceanic phase) experiments shown in figures 7-8 (Angiboust et al., 2012), in which thermo-mechanical and themodynamic model is coupled with porous flow model (top) where permebiality and viscosity are functions of strain rate, pressure and temperature. As can be seen, hydration/dehydration reactions result in strong changes of fluid content in the oceanic subduction interface zone. A $1-2 \%$ fluid content variation is sufficient to drop viscous strength by a factor of 10 . As result, the interface zone and the mantle wedge are essentially weakened allowing for stable subduction. This weak interface zone is re-used by the arriving continental lithosphere at the initial stages of the continental subduction.

Figure 10. Thermo-dynamically coupled high-resolution model of continental phase of Alpine collision (Yamato et al. 2008) revealing fine details of subduction and exhumation mechanics in slow convergent context. Marker regions of blue and grey colour correspond to initial sediments (grey markers are those totally eroded after the $20 \mathrm{Myr}$ of experiment). Red and orange markers correspond, respectively, to the upper crust and the lower crust. Green markers represent lithospheric mantle and black ones the 
oceanic crust. Abbreviations: CC, continental crust; SL, accretionary wedge sediments of the "Schistes Lustrés". The position of the "F point" in the sedimentary accretionary wedge is virtually stable as well as that of two other characteristic points (UCDP and LCDP, Upper and Lower Crustal Decoupling Points, respectively). Note that within the pre-existing subjacent sedimentary accretionary wedge, sediments form a "rigid block", which stays non-deformed and moves, by rotation, around the stable point F. This mechanism can explain why "Schistes Lustrés" found at this place in the Western Alps are dated from the oceanic subduction. The markers shown with stars (CC1,CC2,CC3) correspond, respectively, to the units of Dora Maira, Gran Paradiso, and to formerly surface unit currently buried at great depth. CC1 and CC2 are exhumed at surface at the end of the experiment ( $25 \mathrm{Ma}$ ) after traveling to a more than a $100 \mathrm{~km}$ depth (CC1).

Figure 11. P-T-t paths of particles (passive markers) coming from the upper continental crust and comparison with the observed P-T paths of the Western Alps (experiment of Figure 10). Color and symbols as for GP: Gran Paradiso; DM: Dora Maira. See caption to Figure 10 for other notations. The experiments predict P-T trends that are very similar to nature, assuring that the models realistically reproduce subduction/collision dynamics. Temperature shift of $100-150^{\circ} \mathrm{C}$ can be explained by underestimated contribution of shear heating.

Figure 12. Influence of crustal rheology on the collision style in case of slow $\left(6 \mathrm{~mm} . \mathrm{yr}^{-1}\right)$ Alpine-type collision (weak lithosphere). The general setup of experiments corresponds to that of Figure 10. Shown are morphologies for the models at 20 Myr for different crustal strength profiles. QD: quartz-diabase double-layer crustal structure (upper and lower crust, respectively). QQ: quartz-quartz double-layer crustal structure; DD: strong single-layer structure simulated by diabase. Color code: blue - mantle, orange - lower crust, yellow - upper crust, grey - asthenosphere and sub-lithosphere mantle.

Figure 13. Morphologies of the Alpine (weak lithosphere with $T_{e} \sim 30 \mathrm{~km}$ ) collision models for different convergence rates. The general setup of the experiments corresponds to that of Figure 10 (shortening with a constant rate at both sides, the rheology profile corresponds to the top experiment "QD" - "QD" of Figure 12 ); colors 
correspond to definitions of Figure 12 . Left: configuration after $5 \%$ of shortening (compared to the initial width of the box). Right: configuration at $20 \mathrm{Ma}$ since onset of convergence. As can be seen, high convergence rate promotes sustainable subduction while at slow rate slab break-off and RT instabilities shorten the duration of the subduction stage. Color code: see caption to Figure 12.

Figure 14. UHP exhumation rates for the experiments shown in Figure 13. Note that high convergence rates reduce exhumation rates until fully prohibiting UHP exhumation.

Figure 15a. Continental subduction experiments testing the case of intermediate convergence rate of $2 \mathrm{~cm} . \mathrm{yr}^{-1}$ (Zagros collision model, Francois et al., 2012). Shown are zooms to the subduction interface zone for the major stages of the evolution of the experiments from Figures 4-6. Note formation of a "crustal pocket" at depth of 100150 that may eventually serve as a source for HP or UHP exhumation. Color code: same is in Figure 4. See also (Figures 4-6). SBO means "Slab break-off". (There consequent slab-break-offs occur before the first exhumation of HP/UHP continental crust). Red arrows show the area of initial exhumation of metamorphosed HP/UHP oceanic material. Purple (violet) arrow shows the area of the first exhumation of HP/UHP continental crustal material. Note that oceanic HP/UHP materials exhumes at the onset of the continental collision, when it is pushed/dragged up by low buoyancy continental crustal rocks. It is noteworthy that most exhuming HP/UHP rocks get blocked just few km below the surface. Shown is material field ( 1 pixel - one grid element).

Figure 15b. Exhumation of the oceanic crust as a result of the onset of continental subduction (top panels). The bottom panel shows corresponding PT-paths. See caption to Figure 15 a for further details.

Figure 15c. Similar exhumation mechanism reproduced in the study by Li et al (2009) applied to Sulu terranes in eastern China. The authors used the term "sublithosphere plume" for what Burov et al. (2001) have called "crustal pocket" - a deep 
area of crustal underplating that serves as a source for eventually fast periodic HP/UHP exhumation (see also Figure 3(e)). Bottom panel - predicted PT paths. Shown is passive marker field (1 pixel - 1 marker, there are tens of markers per grid element. The real grid resolution is coarser). Color squares in the bottom panel correspond to the representative marker domains shown by the same symbols in the upper and middle panel.

Figure 16. Importance of the boundary velocity partitioning (Zagros collision model, Francois et al., 2012). The models inspired by Zagros collision settings (Figures 4-6,15) test the model sensitivity to the choice of partitioning of convergence velocities between the borders of the model. It is commonly assumed that distribution of velocities between the borders is of no importance in case of non-inertial systems. However, thermal coupling results in appearance of explicit advective terms in the energy equations describing the thermo-mechanical problem (Appendix). In additions, slab interaction with mantle wind may be also dependent on absolute slab velocity. Hence, the way how the velocities are distributed between the opposite borders of the model becomes highly important, specifically because the ductile properties are exponential function of temperature. As can be seen, applying shortening velocity at one side of the model or at both sides changes the final amount of subduction and slab dip (hence also affecting the amount of slab roll-back and back-arc extension and the timing of slab-break off). These experiments illustrate the importance of exact knowledge of the absolute plate tectonic velocities in nature (absolute plate tectonics versus relative plate tectonics). Color code: blue - mantle, orange - lower crust, yellow - upper crust, red - oceanic crust, grey - initial material of oceanic subduction interface, purple-sediments.

Figure 17. Interaction between surface erosion rate and tectonic convergence rate in fast collision settings (Burov and Toussaint, 2008), strong lithosphere ("Indian craton" type, the initial rheology profile is equivalent to that used for the experiments of Supplementary Figure 2). Green color indicates the eclogitized crust produced at the beginning of the experiment but later metamorphic changes are not shown with specific colors. Other colors are explained in caption to Figure 12. Surface erosion/deposition 
rate has a major impact on the collision style and amount of subduction, specifically for high convergence rates $u$ (up to $100 \%$ variation of the total amount of subduction). Summary of the results of the numerical experiments show the dependence of the "subduction number" $S(S=$ amount of subduction to the total amount of shortening) on the erosion coefficient, $k$, for different values of the convergence rate (values are given for each side of the model, $k=50,100,500,1000,3000,6000$ and $11000 \mathrm{~m}^{2} \cdot \mathrm{yr}^{-1}$ ). Note local maximum on the $S-k-u$ for $u>1.75 \mathrm{~cm} \cdot \mathrm{yr}^{-1}$ and $k>1000 \mathrm{~m}^{2} \cdot \mathrm{yr}^{-1}$. Numbers below the subducting plate correspond to the maximal number of subduction achieved in the corresponding experiment. As can be seen, the amount of subduction strongly depends on the degree of feedback between the tectonic forcing and surface processes, with more than factor of 2 difference between the cases of strong balance between the tectonic input and surface reaction and those characterized by strong misbalance. It can be seen that exhumation of initially buried UHP material is quite rare, as well as the later buried material also returns to the surface only in a few cases.

Figure 18a. Summary of continental collision/subduction styles predicted by numerical experiments, as function of rheology profile (Toussaint et al., 2004a,b; Burov and Yamato, 2008). The tested rheology profiles incorporate either weak lower crust (experiments " $C$ "), or strong lower crust ("D" and "B"). Snapshots at $5.5 \mathrm{My}$, convergence rate $2 \times 3 \mathrm{~cm} . \mathrm{yr}^{-1}$. Moho temperatures are, respectively, $450{ }^{\circ} \mathrm{C}, 600{ }^{\circ} \mathrm{C}$, $650{ }^{\circ} \mathrm{C}$ (profiles $\mathrm{C}_{1}, \mathrm{C}, \mathrm{C}_{-1}$ ), and $600{ }^{\circ} \mathrm{C}$ (profiles $\mathrm{D}$ and $\mathrm{B}$ ). Profiles $\mathrm{C}$ correspond to dry olivine mantle, wet quartz-rich upper crust and wet diabase lower crust. Profile D corresponds to the thermo-rheological hypothesis of Mackwell et al. (1998) that combines common wet quartz rheology for the upper crust with strong dry diabase rheology for the lower crust and a weak wet olivine rheology for the mantle. The profile $\mathrm{C}_{1}$ was used in Toussaint et al. (2004b) to model the initial stages of India-Asia collision (see also Figure 17). The length of arrows is proportional to material velocity. The insert shows the effective strain distribution for the central part of the "Indian" experiment $C_{1}$ superimposed with a 'marker grid' - a grid connecting markers initially placed at the nodes of the starting regular Lagrangian grid. Distortion of the "marker grid" illustrates relative displacement of different units and deformation in the subduction channel. 
Figure 18b. Non-lithostatic pressure distributions for experiment $C_{1}$ of Toussaint et al (2004a) shown in Figure 18a (left upper panel) at various amounts of subduction, dx (from $85 \mathrm{~km}$ to $460 \mathrm{~km}$ ). Shown are horizontal total pressure profiles at depth of $50 \mathrm{~km}$, which corresponds to the strong core of the lithosphere mantle everywhere outside the subduction channel. This depth is chosen as it represents targeted depth of overpressure models for UHP rocks (e.g. Petrini and Podladchikov, 2001). Overpressure (up to $+50 \%$ ) occurs in the upper crustal and mantle layer outside the subduction channel, which undergoes only small underpressures and overpressures at $50 \mathrm{~km}$ depth $(<20 \%$ or $0.3 \mathrm{GPa})$. It is noteworthy that this experiment presents an extreme case (very fast convergence), so the predicted deviations from the lithostatic pressure correspond to upper-bound values. The values of overpressure may be overestimated because of the use of the Byerlee's law and kinematic boundary conditions and due to the neglect by shear heating (in these experiments). The subduction channel remains +$20 \%$ lithostatic during almost $500 \mathrm{~km}$ of subduction, while its walls are exposed to moderate overpressures and under-pressures produced by flexural stresses in the upper and lower plate.

Figure 19. Graph showing dependence of the amount of subduction (before the slab break-off) on the convergence rate and the integrated strength $\left(T_{\mathrm{e}}\right)$ of the lithosphere according to the results of the experiments shown in Figures 13-18, and those from (Yamato et al., 2008; Burov and Yamato, 2008; Yamato et al., 2009; Sizova et al., 2012).

Figure 20. Tectonic set-up of the Aegean and P-T-t paths of HP rocks (after Tirel et al., 2013). The three main continental blocks and other major features of the Aegean are shown in map view (a) and in cross-section (b), KD, VSZ, PSZ, NCD, NAF, TB are Kerdylion Detachment, Vardar Suture Zone, Pindos Suture Zone, North Cycladic Detachment, North Anatolian Fault and Thrace Basin, respectively. P-T-t paths are from northwest Cyclades, Tinos (point T) (c) and from Peloponnese (point P) (d). 
Figure 21. Setup for the model studying the impact of subduction of continental terrains embedded in the oceanic lithosphere. In this experiment, two continental terrains are considered (Tirel et al., 2013). Pliable Winkler hydrostatic basement allows to accommodate vertical flow associated with subduction.

Figure 22. Step-by-step development of the subduction-exhumation cycles (after Tirel et al., 2013). (a), The evolution at the lithosphere-upper mantle scale (grey colour: subducting lithosphere mantle). Dashed line shows the retreat of the trench. (b), Zooms to block deformation during the subduction-exhumation cycle (here lithosphere mantle is marked with grey colour). Interpreted shear zones are plotted with white lines. (c), PT-t paths of the colour-coded markers shown in (b).

Figure 23. Summary of the revealed relationship between the continental-block subduction and caterpillar walk exhumation, slab dip changes and crustal deformation (after Tirel et al., 2013). Numbers "1,2,3" indicate turning buckles in the caterpillar walk of the exhuming crustal blocks

Figure 24. 3-D numerical model for the collision of continental corner with progressively decreasing convergence velocity (modified from Li et al., 2013). The slowdown of the convergence results in slab-retreat followed by slab break-off and exhumation of continental crustal material. $(a, b)$ View from the oceanic subduction side. (c,d) View from the continental collision side. 


\section{APPENDIX. Numerical algorithm}

\section{Thermo-mechanical module}

The mixed finite-element volume/finite difference code FLAMAR (outgrowth of Paravoz by Poliakov et al., 1993) is based on the FLAC algorithm (Cundall, 1989). It solves simultaneously Newtonian dynamic equations of motion (A1), in a Lagrangian formulation, coupled with visco-elasto-plastic constitutive equations (A2), heat transport equations (A3) and state equation (A4) (see Appendix A, (Burov et al., 2001;

2003; Burov and Yamato, 2008; Le Pourhiet et al., 2004) for details concerning numerical implementation).

$$
\begin{gathered}
\rho \frac{D u_{i}}{D t}-\frac{\partial \sigma_{i j}}{\partial x_{j}}=\rho g_{i} \\
\frac{D \sigma}{D t}=F(\sigma, \mathbf{u}, \mathbf{v}, \nabla \mathbf{v}, \ldots T \ldots) \\
\rho C_{p}(\partial T / \partial t+\mathbf{u} \nabla T)-\nabla(k \nabla T)-H_{r}-H_{\mathrm{a}-} f r a c \times \sigma_{\|} \partial \varepsilon_{\|} / \partial t=0 \\
\rho=f(P, T)
\end{gathered}
$$

Here $u, \sigma, g, k$ are the respective terms for velocity, stress, acceleration due to body forces and thermal conductivity. The terms $t, \rho, C_{p}, T, H_{r}, H_{\mathrm{a}}, \alpha, f r a c \times \sigma_{\|} \partial \varepsilon_{\|} / \partial t$ designate respectively time, density, specific heat, temperature, internal heat production, adiabatic heating/cooling term, thermal expansion coefficient and shear heating term moderated by experimentally defined frac multiplier (frac is set to conservative value of 0.1 in most experiments. It is noteworthy that some studies advocate for stronger efficiency of shear heating, advancing frac values on the order of 0.9 (Thielman and Kaus, 2012). However, in the absence of direct observational data we decided to keep frac at relatively low level). The terms $\partial / \partial t, D \sigma / D t, F$ are a time derivative, an objective (Jaumann) stress time derivative and a functional, respectively. In the Lagrangian framework, the incremental displacements are added to the grid coordinates allowing the mesh to move and deform with the material. This enables solution of large-strain problems locally using small-strain formulation: on each time step the solution is obtained in local coordinates, which are then updated in the large strain mode. Volume / density changes due to phase transitions are accounted via application of equivalent stresses to affected material elements. It is noteworthy that 
the inertial term (first parameter in the equation $\mathrm{A} 1$ ) is negligible for geodynamic applications. It is retained here because the FLAC method is written in fully dynamic formulation. While modelling geodynamic processes this term is still present, yet for numerical reasons since FLAC then employs an artificial inertial dampening density allowing to slow-down the elastic waves and hence advance with much larger time steps (Cundall, 1989) than would be required in a fully inertial mode.

Solution of (A1) provides velocities at mesh points used for computation of element strains and of heat advection $\mathbf{u} V T$. These strains are used in (A2) to calculate element stresses, and the equivalent forces are used to compute velocities for the next time step.

All rheological terms are implemented explicitly. The rheology model is serial viscous-elastic-plastic (Table 1). The plastic term is given by explicit Mohr-Coulomb plasticity (non-associative with zero dilatency) assuming linear Navier-Coulomb criterion. We imply internal friction angle $\phi$ of $30^{\circ}$, maximal cohesion $S$ of $20 \mathrm{Mpa}$, and dilatation angle $\varphi$ of $0^{\circ}$, which fit best the experimental Byerlee's law of rock failure (Byerlee, 1978):

$$
\tau=S+\sigma_{\mathrm{n}} \operatorname{tg} \phi
$$

where $\tau$ is the shear stress and $\sigma_{\mathrm{n}}$ is the normal stress that accounts both for rock and fluid pressure. Linear cohesion softening is used for better localization of plastic deformation $\varepsilon_{\mathrm{p}}\left(S\left(\varepsilon_{\mathrm{p}}\right)=S_{0} \min \left(0,1-\varepsilon_{\mathrm{p}} / \varepsilon_{\mathrm{p} 0}\right)\right.$ where $\varepsilon_{\mathrm{p} 0}$ is 0.01$)$. Specific properties are applied to soft serpentinised rock (Hassani et al., 1997).

The ductile-viscous term is represented by non-linear power law with three sets of material parameters (Table 1 ) that correspond to the properties of four lithological layers: upper crust (quartz), middle-lower crust (quartz-diorite), mantle and asthenosphere (olivine):

$$
\eta_{\mathrm{eff}}=\left(\frac{\partial \varepsilon}{\partial t}\right)_{\mathrm{II}}^{d(1-\mathrm{n}) / \mathrm{n}}\left(\mathrm{A}^{*}\right)^{-1 / \mathrm{n}} \exp (H / n R T)
$$

where $\left(\frac{\partial \varepsilon}{\partial t}\right)_{\mathrm{II}}^{d}=\left(\operatorname{In} v_{I I}\left(\left(\frac{\partial \varepsilon}{\partial t}\right)_{\mathrm{II}}^{d}\right)\right)^{1 / 2}$ is the effective strain rate and $\mathrm{A}^{*}=1 / 2 \mathrm{~A} \cdot 3^{(\mathrm{n}+1) / 2}$ is the material constant, $H$ is the activation enthalpy, $H=Q+P V$ where $Q$ is activation energy and $V$ is molar volume, $R$ is the gas constant, $n$ is the power law exponent (Table 2). The 
elastic parameters (Table 1) correspond to commonly inferred values from Turcotte and Schubert (2002).

The surface processes are taken into account by diffusing (A7) the topographic elevation $h$ of the free surface along $x$ using conventional Culling erosion model (Culling, $1960)$ with a diffusion coefficient $k_{\text {ero. }}$

$$
\frac{\partial^{2} h}{\partial t^{2}}=k_{\text {ero }} \frac{\partial^{2} h}{\partial x^{2}}
$$

This simple model is well suited to simulate fan deltas, which can be taken as a reasonably good analogue of typical foreland basin deposits. This model is not well adapted to model slope dependent long-range sedimentation, yet, it accounts for some most important properties of surface processes such as dependency of the erosion/sedimentation rate on the roughness of the relief (surface curvature).

The fluid transport algorithm is based on an enhanced variant of Darcy's flow approximation with strain-rate dependent permeability (Angiboust et al., 2012). In this algorithm it is assumed that the fluid flux $q_{f}$ is driven by fluid pressure gradient through a medium with dynamic permeability $K$, as follows:

$$
q_{f}=-K \nabla P_{f l}^{*}
$$

where fluid pressure $P_{f l}^{*}$ is related to the non-lithostatic pressure $\delta P$ through a fluid "saturation factor" $\left[\mathrm{H}_{2} \mathrm{O}\right] /\left[\mathrm{H}_{2} \mathrm{O}\right]_{\text {sat }}$ as follows:

$$
P_{f l}^{*}=\delta P \frac{\left[\mathrm{H}_{2} \mathrm{O}\right]}{\left[\mathrm{H}_{2} \mathrm{O}\right]_{s a t}},
$$

where $\left[\mathrm{H}_{2} \mathrm{O}\right]$ is the current water content (in wt.\%) in the material for each element of the numerical grid and $\left[\mathrm{H}_{2} \mathrm{O}\right]_{\text {sat }}$ is the maximum water content thermodynamically calculated for the same material as a function of P-T conditions. The dynamic permeability $K$ is defined as a function of the intrinsic permeability $k$, normalized strain rate and inversed viscosity of the fluid (Angiboust et al., 2012):

$$
K=\frac{k}{\mu_{f}} \times \frac{\dot{\varepsilon}}{\varepsilon_{0}}
$$

where $\quad \mu_{f}=2.414 \times 10^{-5} \times 10^{\frac{247.8}{T-140}} \quad$ and $\quad \varepsilon_{0}=10^{-14} \mathrm{~s}^{-1}$ are respectively temperature dependent experimentally defined fluid viscosity and reference strain rate.

FLAMAR allows for large displacements and strains in particular owing to an 
automatic remeshing procedure, which is implemented each time the mesh becomes too destorted to produce accurate results. The remeshing criterion is imposed by a critical angle of grid elements. This angle is set to $10^{\circ}$ to reduce frequency of remeshing and thus limit the associated numerical diffusion. The numerical diffusion was effectively constrained by implementation of the passive marker algorithm. This algorithm traces passively moving particles that are evenly distributed in the initial grid. This allows for accurate recovering of stress, phase and other parameter fields after each remeshing. FLAMAR has been already tested on a number of geodynamical problems for subduction/collision context (Burov et al., 2001; Toussaint et al., 2004a, 2004b).

\section{Thermodynamic coupling}

Buoyancy (and, eventually, rheology changes) is an important component of the force balance at subduction zone (Bousquet et al., 1997; Burov et al., 2001; Doin and Henry, 2001). For this reason, the thermodynamic THERIAK (de Capitani, 1994) and PERPLE_X (Conolly, 2005) algorithms have been incorporated to introduce progressive density changes during evolution. Both algorithms (THERIAK is used for sedimentary rocks, PERPLE_X - for the rest) minimize free Gibbs energy for a given chemical composition to calculate an equilibrium mineralogical assemblage for given P-T conditions (de Capitani, 1994).

$$
G=\sum_{i=1}^{n} \mu_{i} N_{i}
$$

where $\mu_{\mathrm{i}}$ is the chemical potential and $N_{i}$ the moles number for each component $i$ constitutive of the assemblage. Given the mineralogical composition, the computation of the density is then straightforward.

Mineralogical composition and hence density, is re-evaluated every $10^{4}$ time steps ( 200 kyr) according to the current P-T conditions. Equivalent stresses are applied to the elements to account for volume-density changes associated with the metamorphic transitions. Unfortunately, changes in rheological properties of the metamorphic facies cannot be implemented in the same way as the density changes, due to the lack of the appropriate experimental data. We took into account rheology changes only for key facies such as serpentinite and eclogite. 


\section{Initial thermal structure.}

To compute the initial continental geotherm $T_{\text {cont, }}$, one can use the equation (A12) taking into account, in $T_{\text {std }}$, the stationary part of the geotherm and contribution due to the radiogenic heat production $H_{s}$ in the crust, and correction $T$ (age) due to transient cooling of the lithpshere that depends on its age.

$$
T_{\text {cont }}\left(z, a g e, H_{s}\right)=T_{s t d}\left(z, H_{s}\right)+T(\text { age })
$$

Radiogenic contribution $T_{r}$ in the crust depends of the thickness of the crust $h_{c}$, density $\rho_{c}$, radiogenic production $H_{s}$, radiogenic production decay depth $h_{r}$, and thermal conductivity coefficient $k_{c}(\mathrm{~A} 10)$ :

$$
T_{r}=\frac{\rho_{c} \cdot H_{s} \cdot h_{r}^{2}}{k_{c}} \cdot\left(1-e^{-\frac{h_{c}}{h_{r}}}\right)
$$

Temperature $T_{m}$ at Moho depth, $h_{c}$, is used for the calculation of the temperature for depths below the Moho and is given by :

$$
T_{m}=T_{0}+\frac{q_{m}}{k_{c}} \cdot h_{c}+T_{r}
$$

where $T_{0}$ and $q_{m}$ correspond, respectively, to the temperature at the surface and the heat flux calculated at the Moho. This heat flux is given by:

$$
q_{m}=\frac{T_{h l}-T_{0}-T_{r}}{\frac{h_{c}}{k_{c}}+\frac{h_{l}-h_{c}}{k_{m}}}
$$

where $T_{h l}$ is temperature at the thermal base of lithosphere (of a thickness $h_{l}$ ) and $k_{m}$ is coefficient of thermal conductivity for the mantle.

Temperature at a depth $z$ can thus be calculated as:

$$
\begin{array}{ll}
\text { - If } z \leq h_{c}: & T_{s t d}(z)=T_{0}+\frac{q_{m}}{k_{c}} \cdot z+T_{r} \\
\text { - If } z \succ h_{c}: & T_{s t d}(z)=T_{m}+q_{m} \cdot \frac{\left(z-h_{c}\right)}{k_{m}}
\end{array}
$$

This obtained temperature is then corrected for transient cooling that depends on thermotectonic age (age) of the lithosphere using formulation from Parsons and Sclater (1974) adapted for the continental lithosphere.

$$
T(\text { age })=\frac{2}{\pi} \cdot\left(T_{h_{l}}-T_{0}\right) \cdot T T(\text { age })
$$


where $\quad T T($ age $)=\sum_{n=1}^{\infty} \frac{(-1)^{n+1}}{n} \cdot \exp \left(\frac{-k_{m} \cdot \pi^{2} \cdot a g e \cdot n^{2}}{\rho_{m} \cdot C_{m} \cdot h_{l}^{2}}\right) \cdot \sin \left(\frac{n \cdot \pi \cdot z}{h_{l}}\right)$

with $C_{m}$ and $\rho_{m}$ are respectively the specific heat capacity and the density for the mantle. Values for the parameters used for the initial geotherm are given in Table 1. 
Table 1a. Summary of thermal and mechanical parameters used in model calculations (Turcotte and Schubert, 2002; Ranalli, 1995; Burov, 2010;2011)

\begin{tabular}{|c|c|c|}
\hline Type & Definition & Units \\
\hline \multirow[t]{10}{*}{ Thermal } & Surface temperature (0 km depth) & $0^{\circ} \mathrm{C}$ \\
\hline & Temperature at the base of thermal lithosphere & $1330^{\circ} \mathrm{C}$ \\
\hline & Temperature at the base of upper mantle (650 & $1700^{\circ} \pm 100^{\circ} \mathrm{C}$ \\
\hline & $\mathrm{km})$ & \\
\hline & Thermal conductivity of crust & $2.5 \mathrm{Wm}^{-1}{ }^{\circ} \mathrm{C}^{-1}$ \\
\hline & Thermal conductivity of mantle & $3.5 \mathrm{Wm}^{-1}{ }^{\circ} \mathrm{C}^{-1}$ \\
\hline & Thermal diffusivity of mantle & $10^{-6} \mathrm{~m}^{2} \cdot \mathrm{s}^{-1}$ \\
\hline & Radiogenic heat production at surface & $9.5 \times 10^{-10} \mathrm{~W} \mathrm{~kg}^{-1}$ \\
\hline & Radiogenic heat production decay length & $10 \mathrm{~km}$ \\
\hline & Thermo-tectonic age of the lithosphere & 50 to $600 \mathrm{Myr}$ \\
\hline \multirow[t]{9}{*}{ Mechanical } & Density of the upper crust ${ }^{*}$ & $2700 \mathrm{~kg} \mathrm{~m}^{-3}$ \\
\hline & Density of lower crust ${ }^{*}$ & $2900 \mathrm{~kg} \mathrm{~m}^{-3}$ \\
\hline & Density of oceanic crust ${ }^{*}$ & $2900 \mathrm{~kg} \mathrm{~m}^{-3}$ \\
\hline & Density of sediment ${ }^{*}$ & $2600 \mathrm{~kg} \mathrm{~m}^{-3}$ \\
\hline & Density of undepleted mantle ${ }^{*}$ & $3330 \mathrm{~kg} \mathrm{~m}^{-3}$ \\
\hline & Density of asthenosphere ${ }^{*}$ & $3310 \mathrm{~kg} \mathrm{~m}^{-3}$ \\
\hline & Lamé elastic constants $\lambda, G$ (Here, $\lambda=G)$ & $30 \mathrm{GPa}$ \\
\hline & Byerlee's law - Friction angle & $30^{\circ}$ \\
\hline & Byerlee's law - Cohesion & $20 \mathrm{MPa}$ \\
\hline
\end{tabular}

* We here provide average densities, in thermo-dynamically coupled models densities are derived directly from the assumed mineralogical composition as function of pressure and temperature conditions 
Table 1b. Example of ductile flow parameters assumed in model calculations. Compilation of Mackwell et al. (1998), who used data from Gleason and Tullis (1995), Wilks and Carter(1990), Hirth and Kohlstedt (1996), Chopra and Patterson (1981). More recent data (see compilation in Bürgmann and Dresen, 2008) predict slightly different values for ductile flow parameters. However, in practice these differences are negated by adjusting geotherms or thicknesses of the rheological layers in way that the integral strength of the lithosphere matches the observed $\mathrm{T}_{\mathrm{e}}$ values.

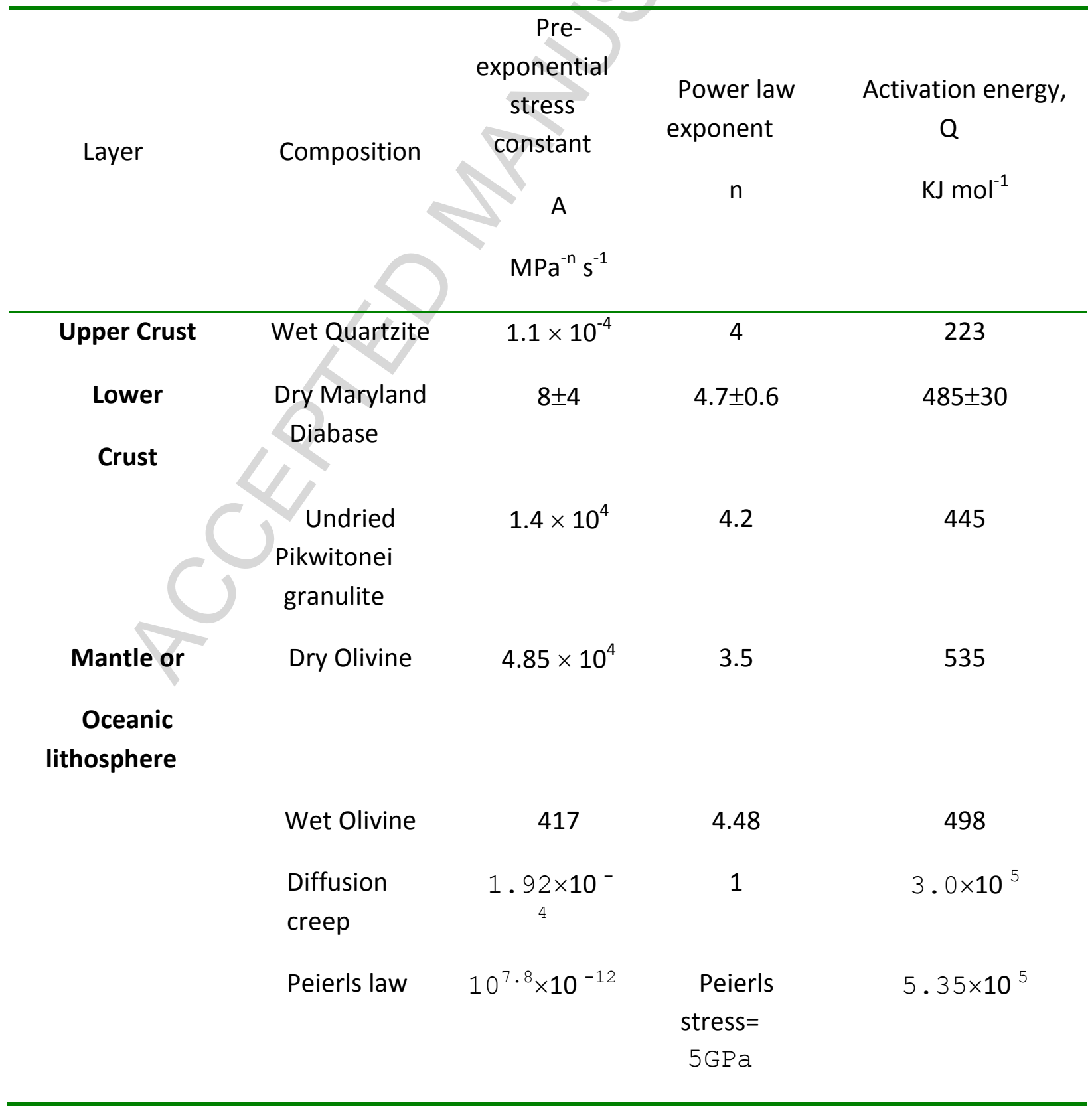




\section{collision modes}
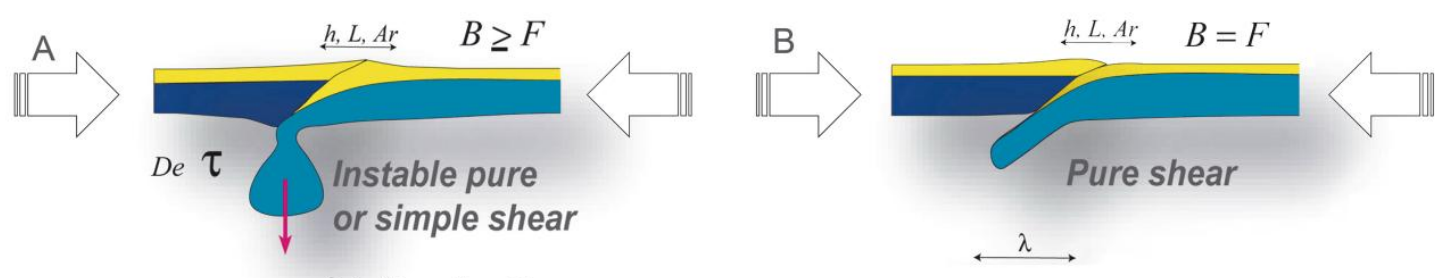

$\stackrel{h, L, A r}{\longrightarrow} \quad B=F$
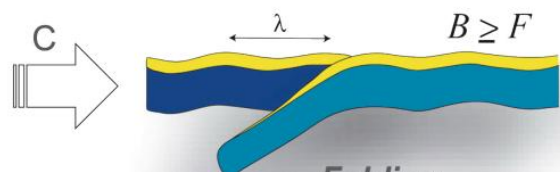

Folding

h, $L, A r$
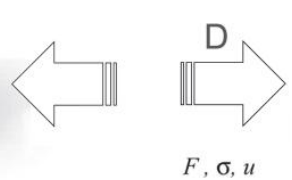

$B \geq F$

$B>F$

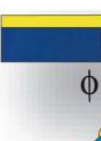

$\phi$

Stable

subduction

Figure 1 

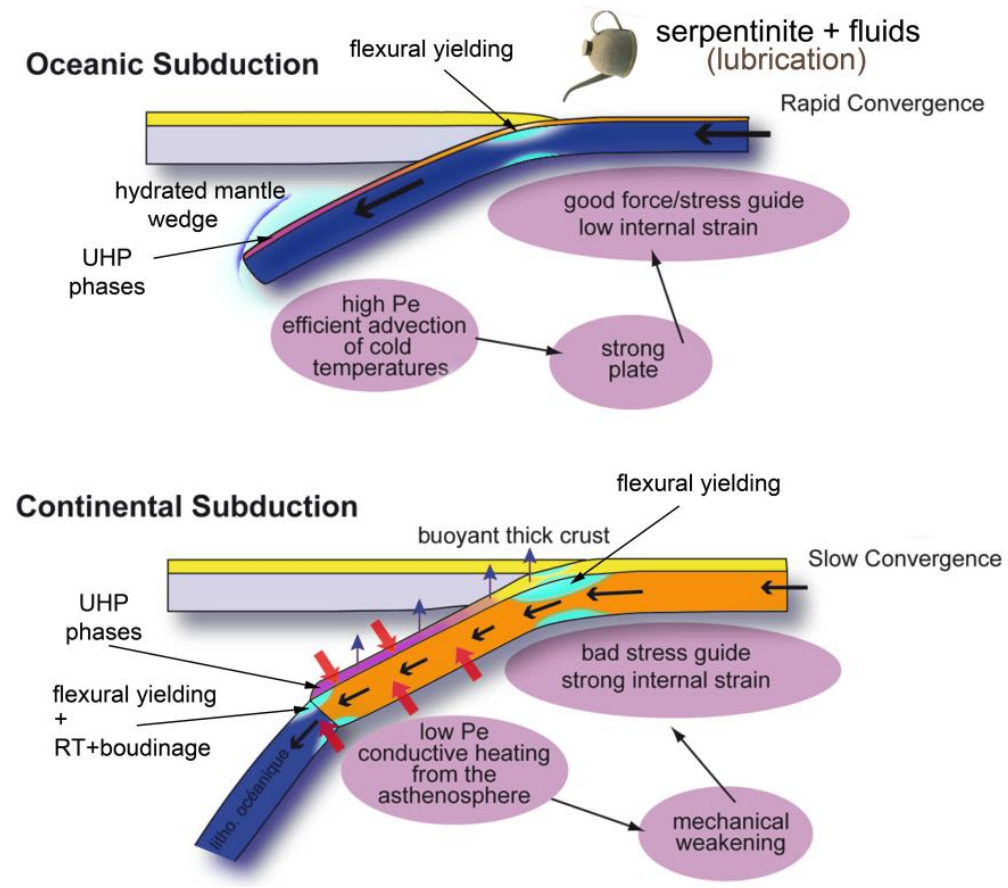

Figure 2 


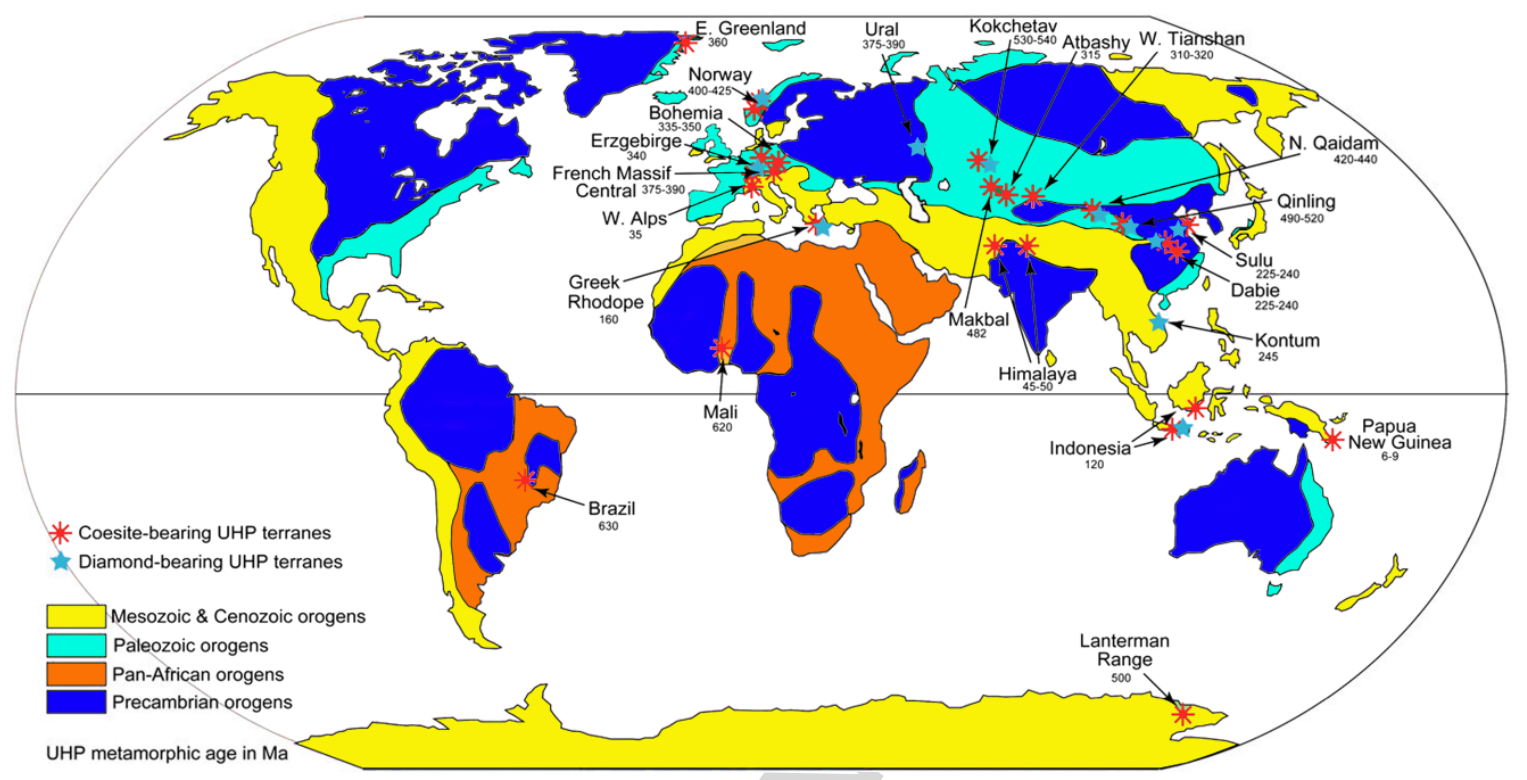

Figure 3a 


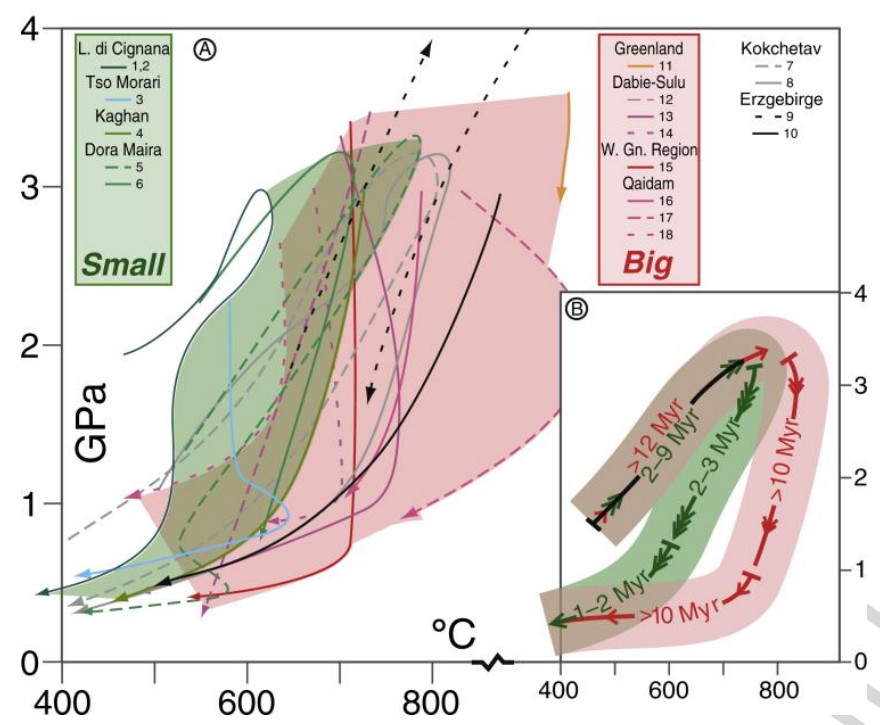

Figure $3 b$ 


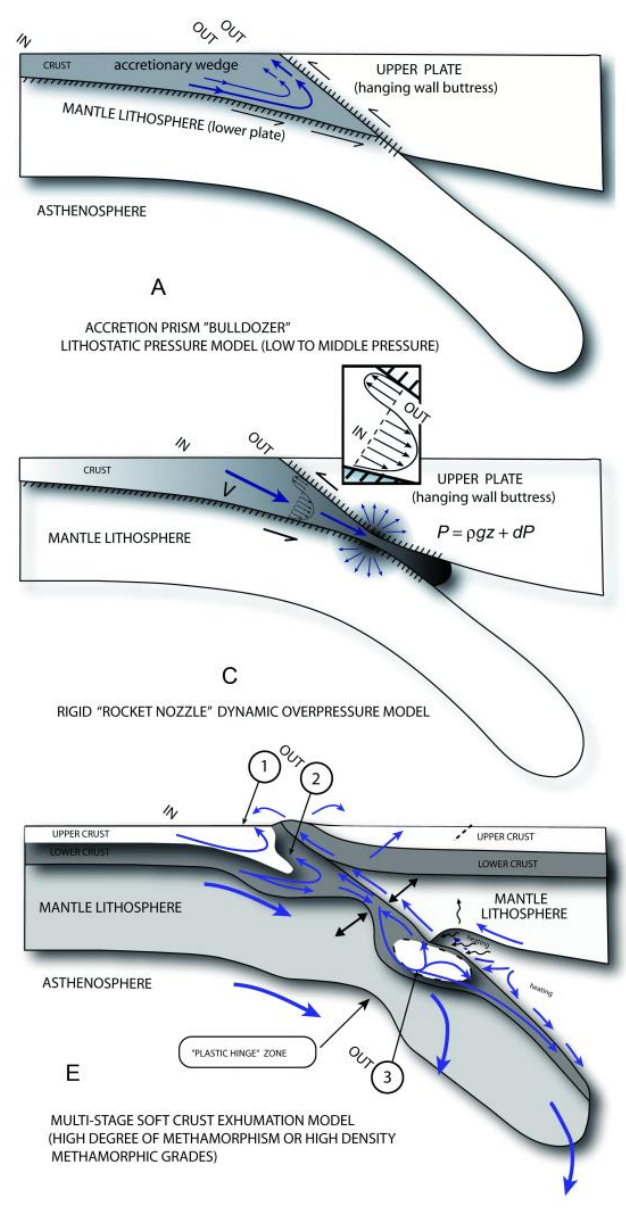

Figure $3 c$
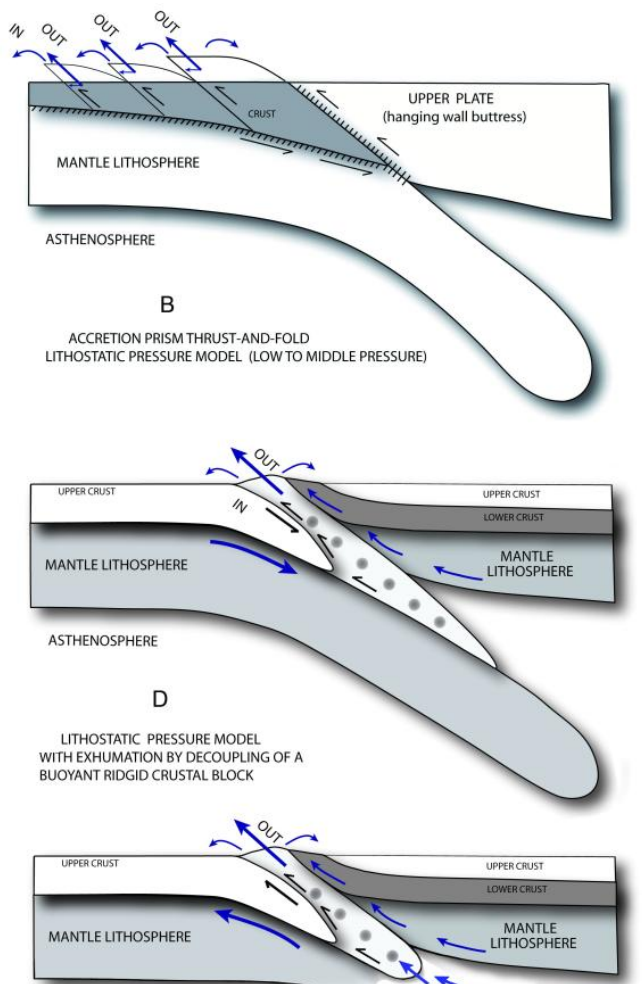

ASTHENOSPHERE

G

EDUCTION MODEL

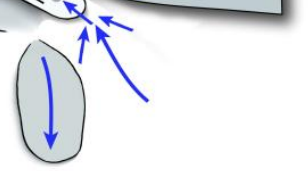




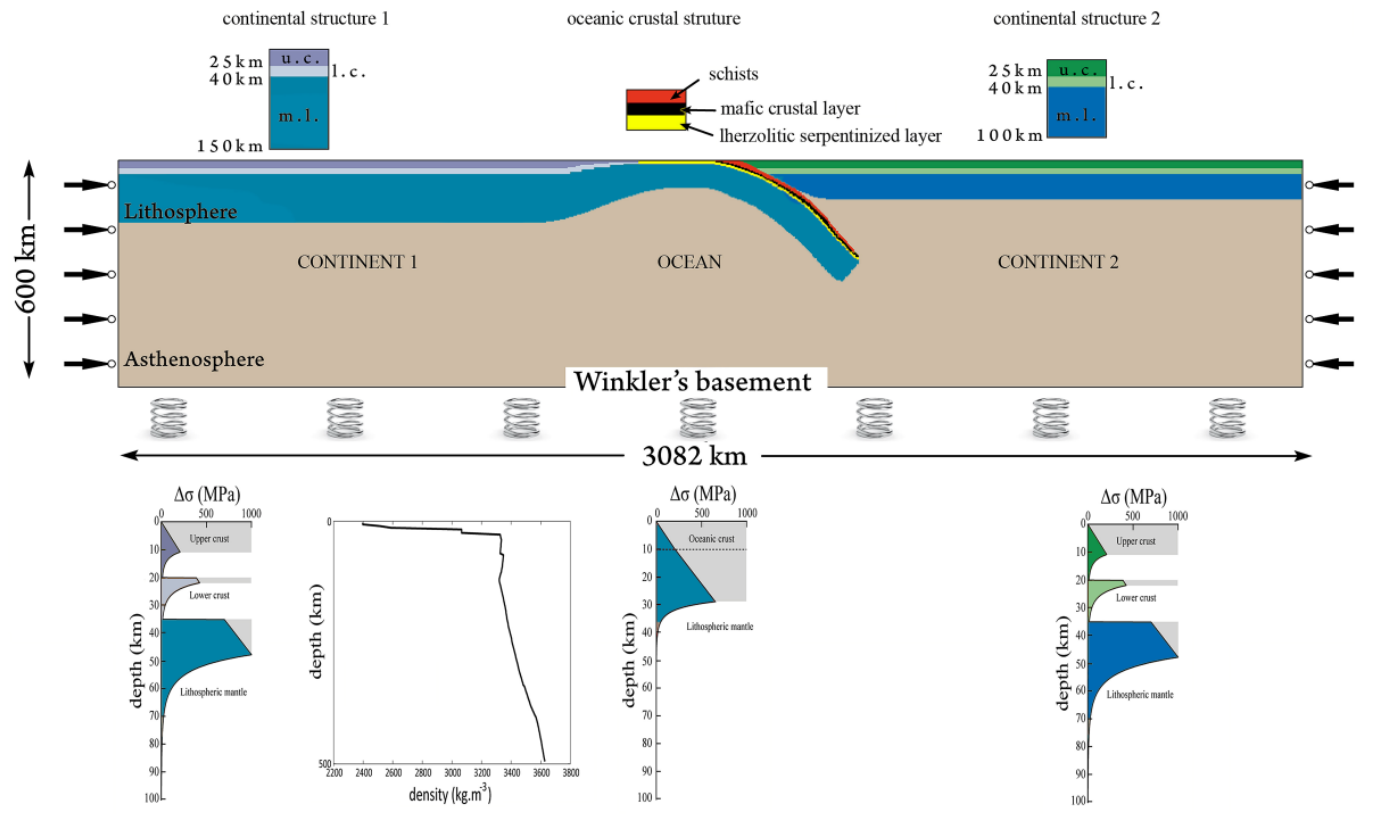

Figure 4 


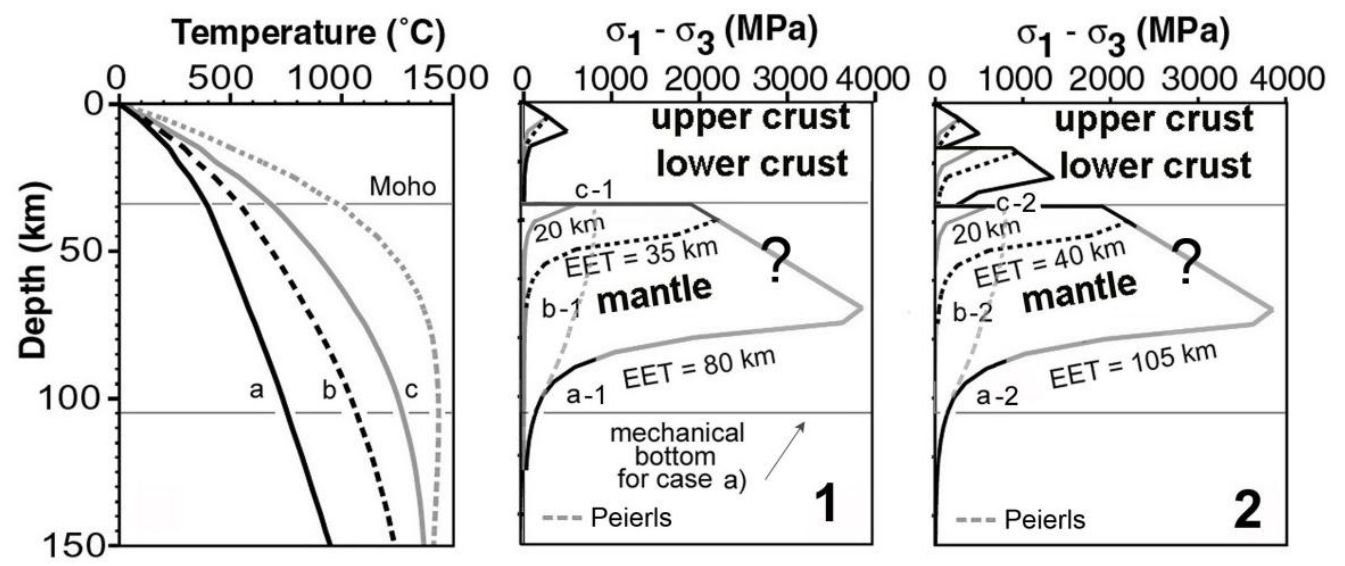

Figure 5 

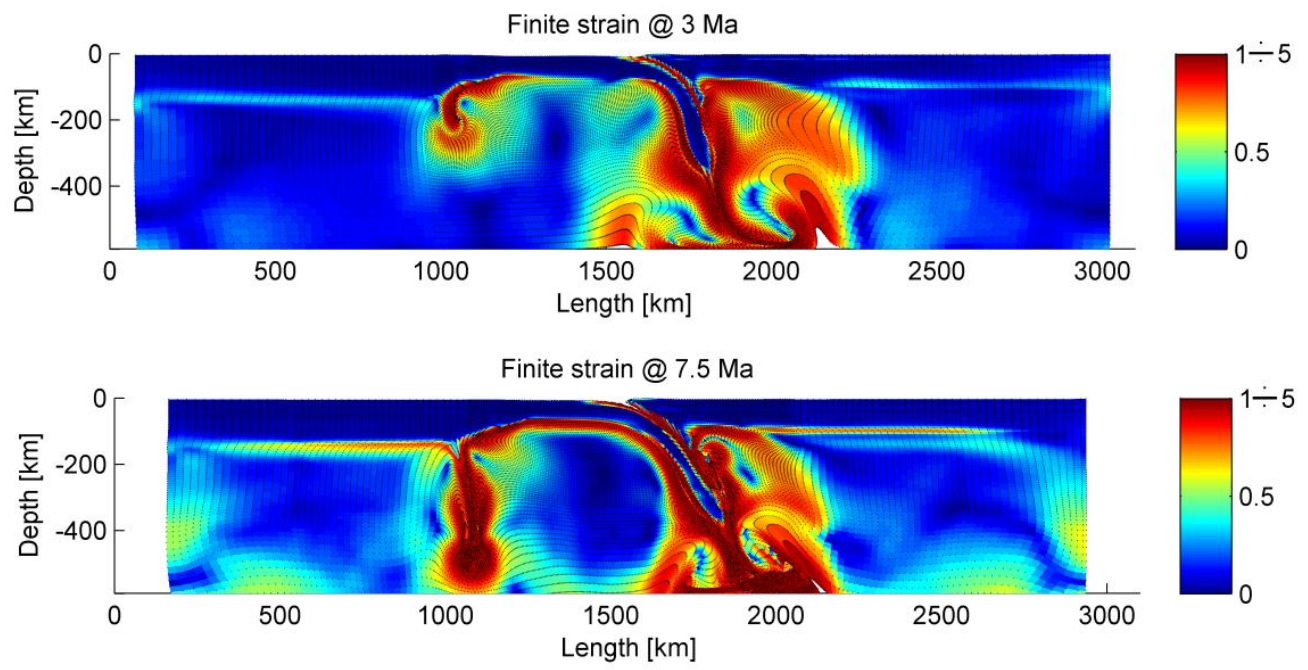

Figure 6a 

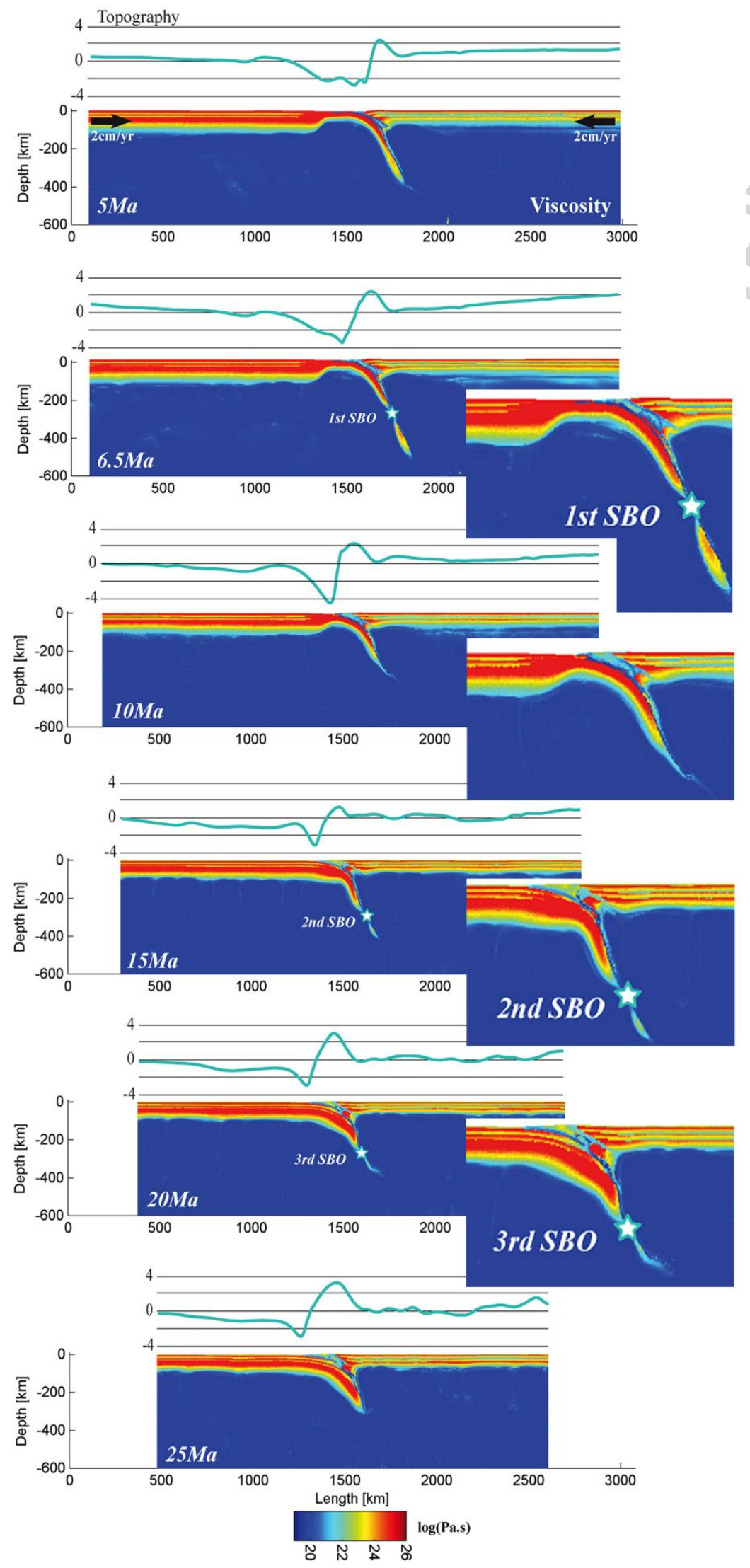

Figure $6 b$ 
Temperatures
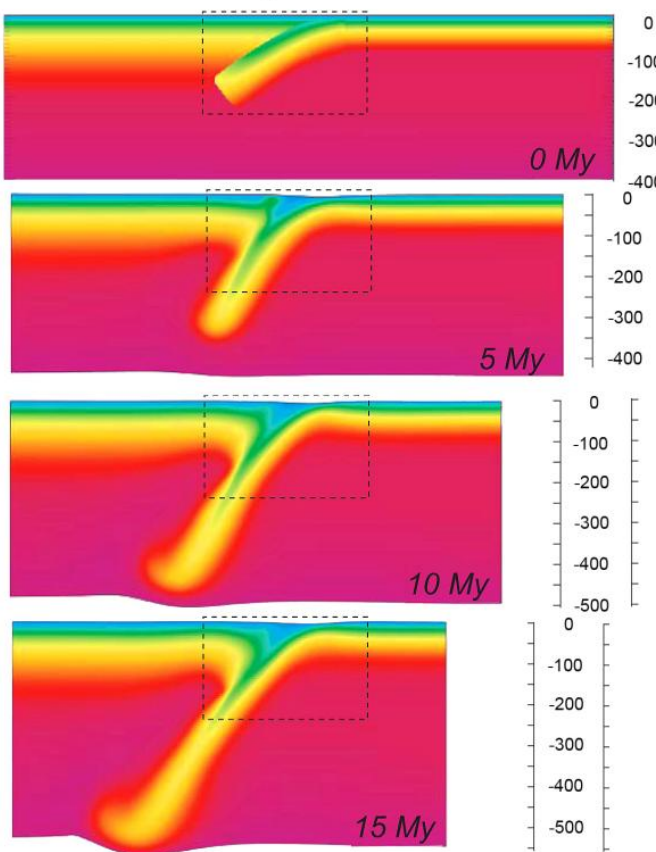

$T\left({ }^{\circ} \mathrm{C}\right)$

0

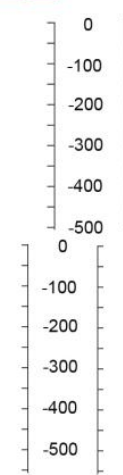

0
-100
-200
-300
-300
-400
-500
0
-100
-200
-300
-400
-500

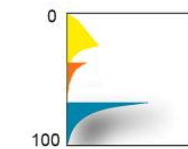

Morphologies
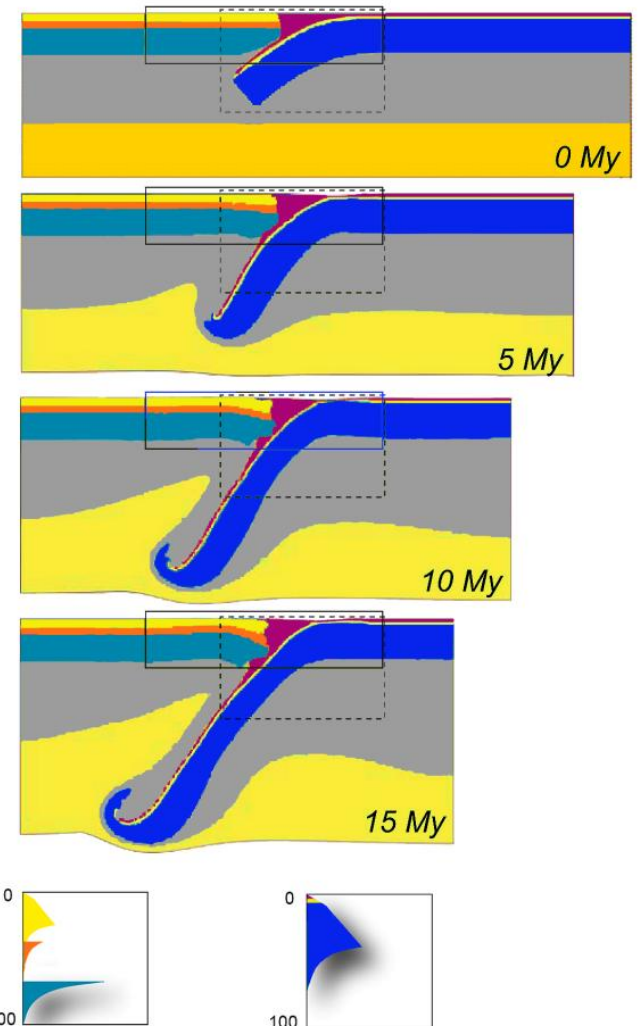

Figure 7 

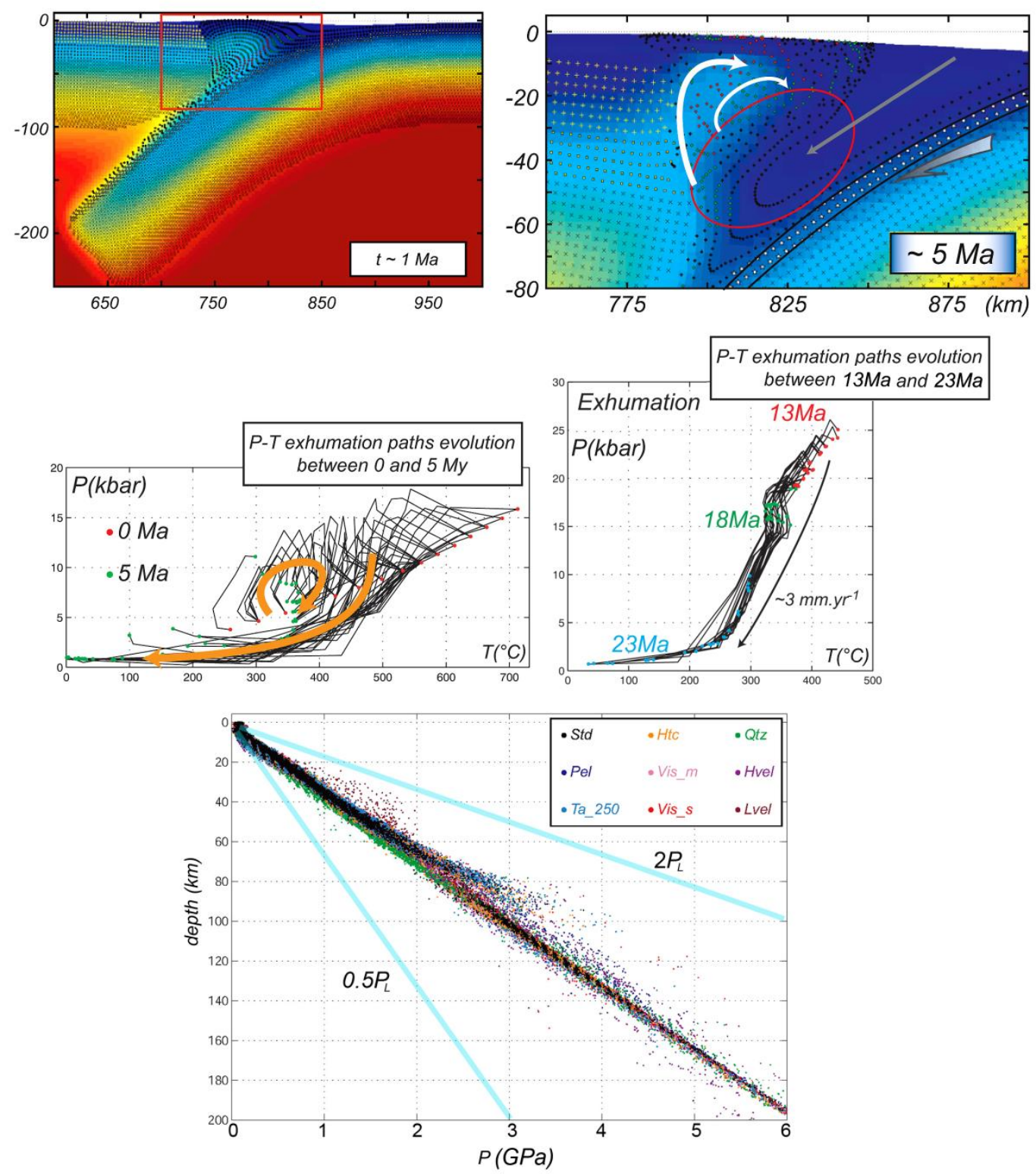

Figure 8 

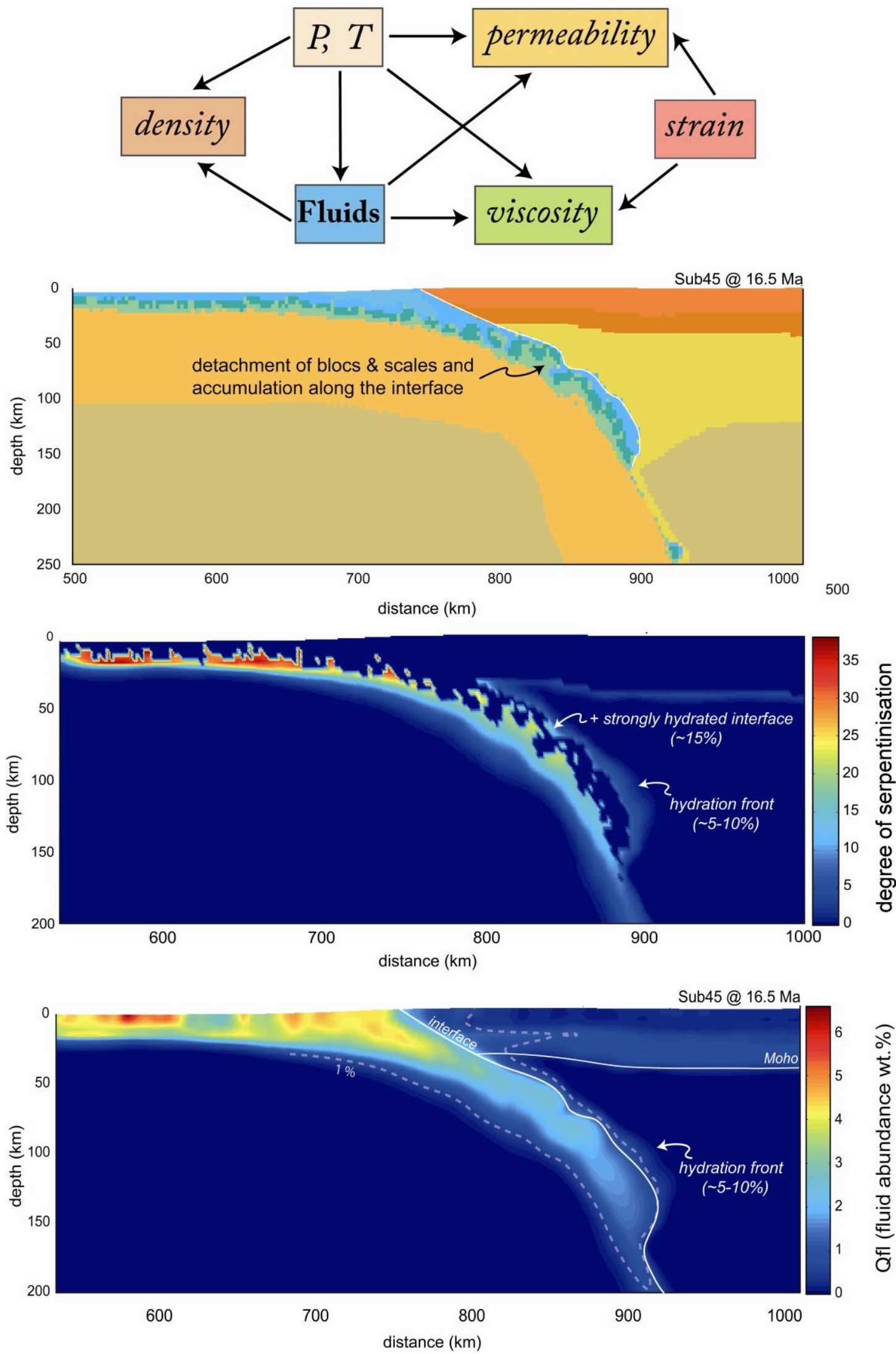

Figure 9 

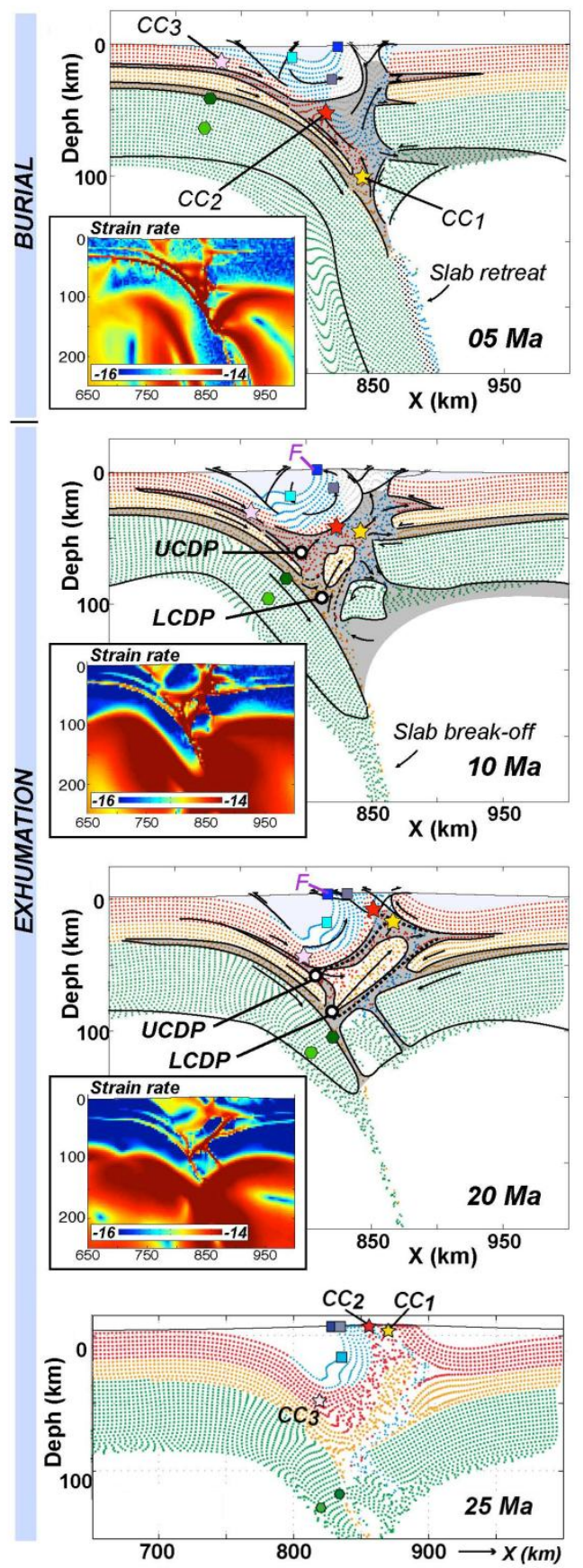

Figure 10 

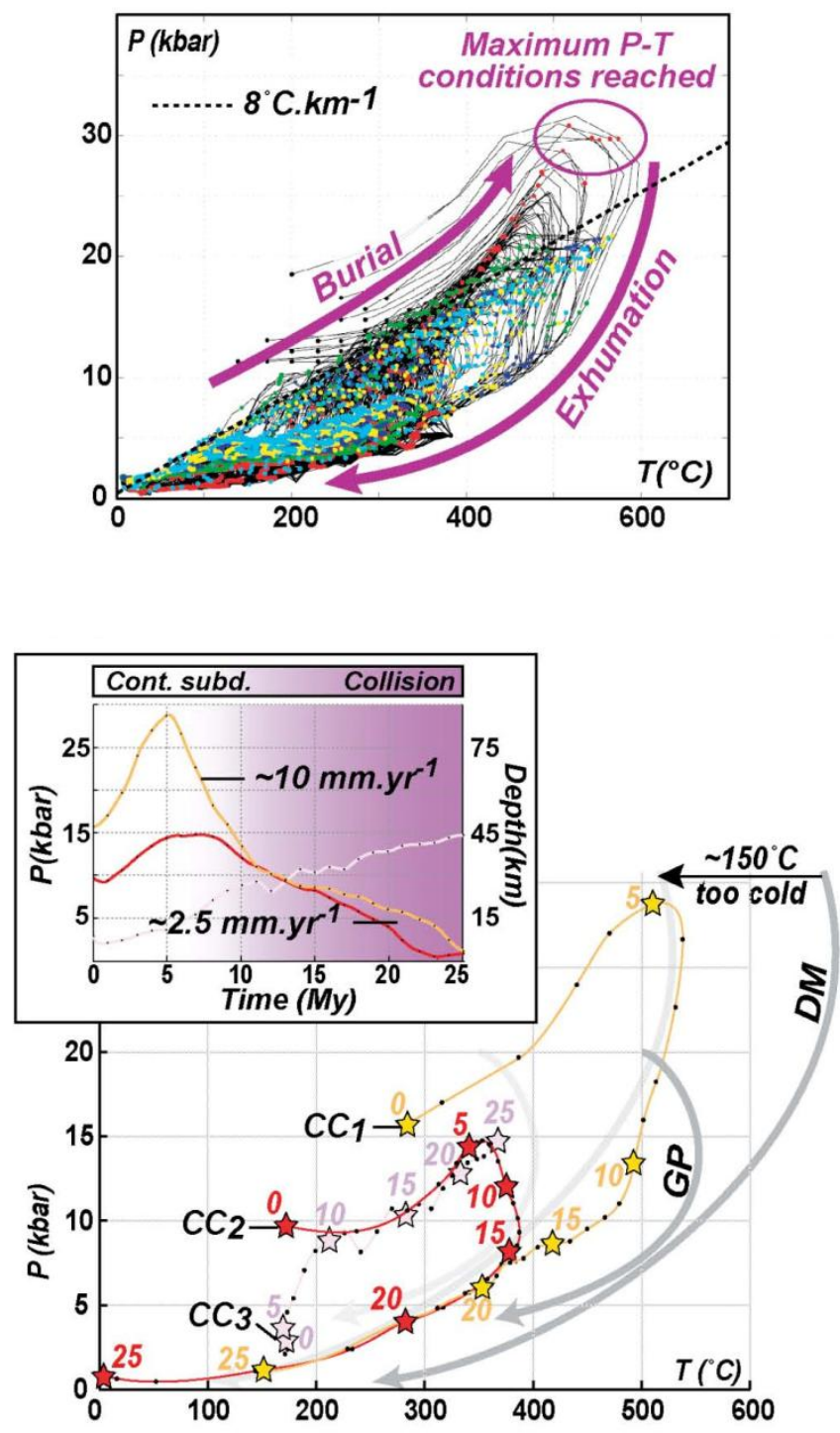

Figure 11 

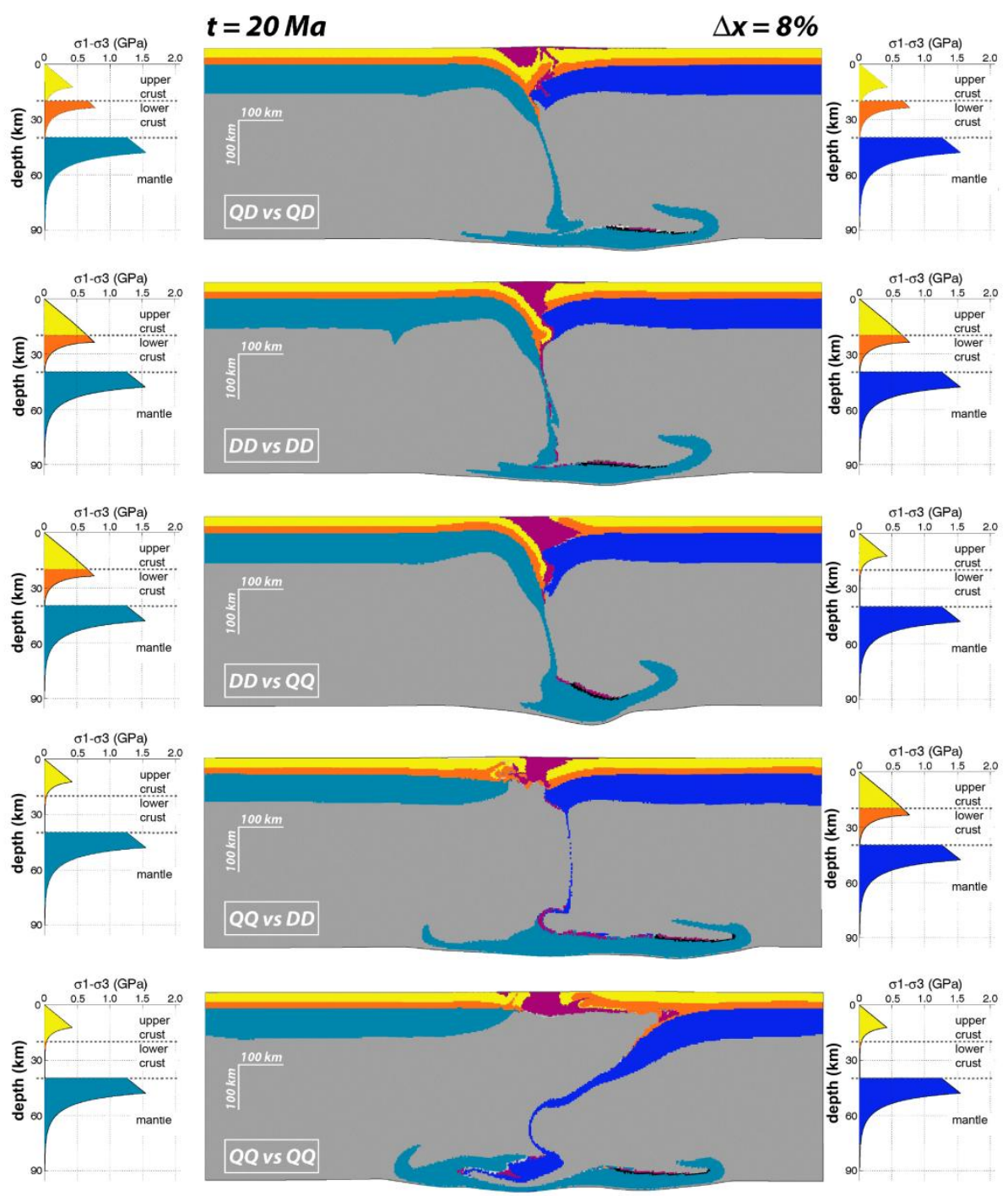

Figure 12 

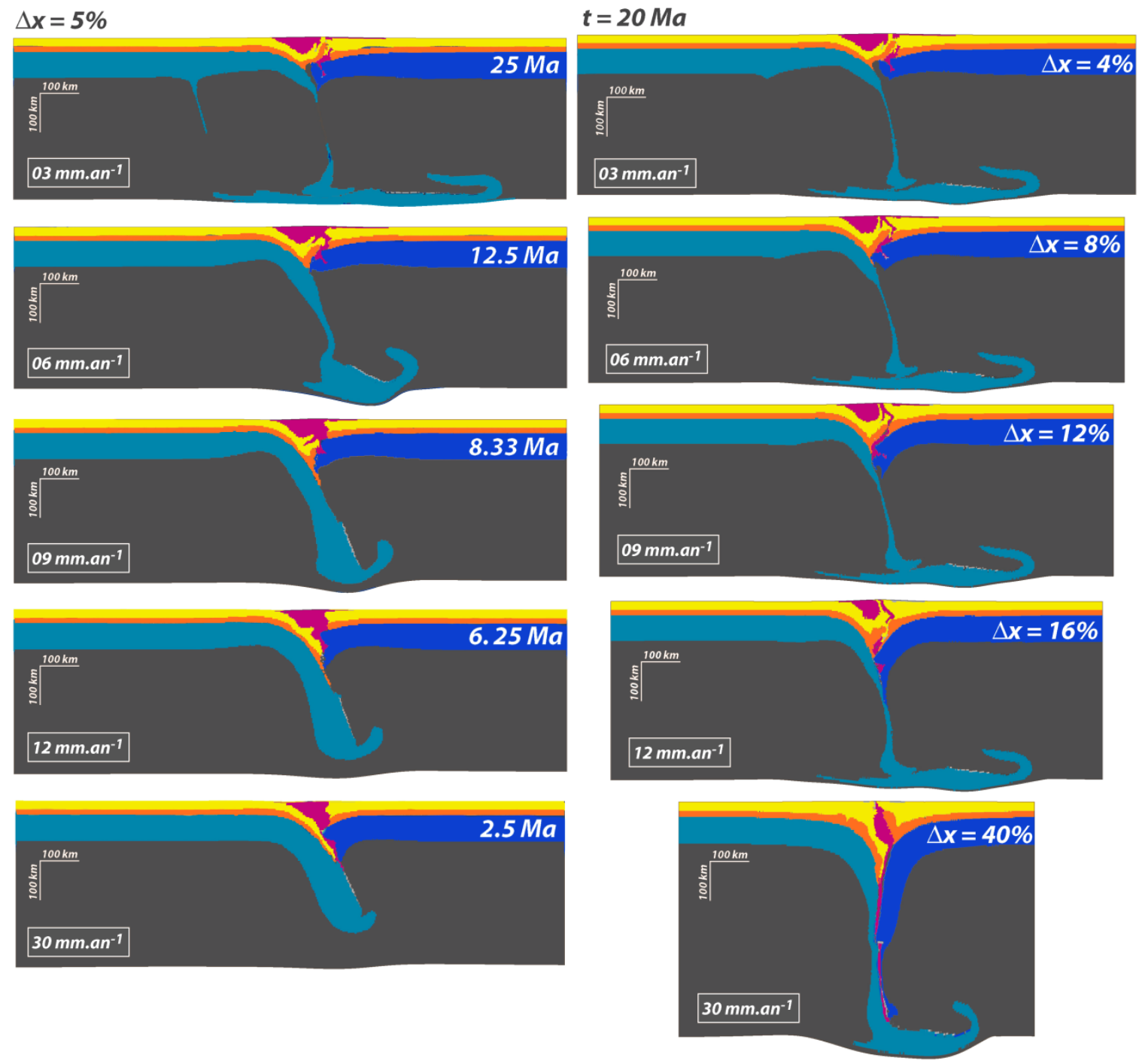

Figure 13 


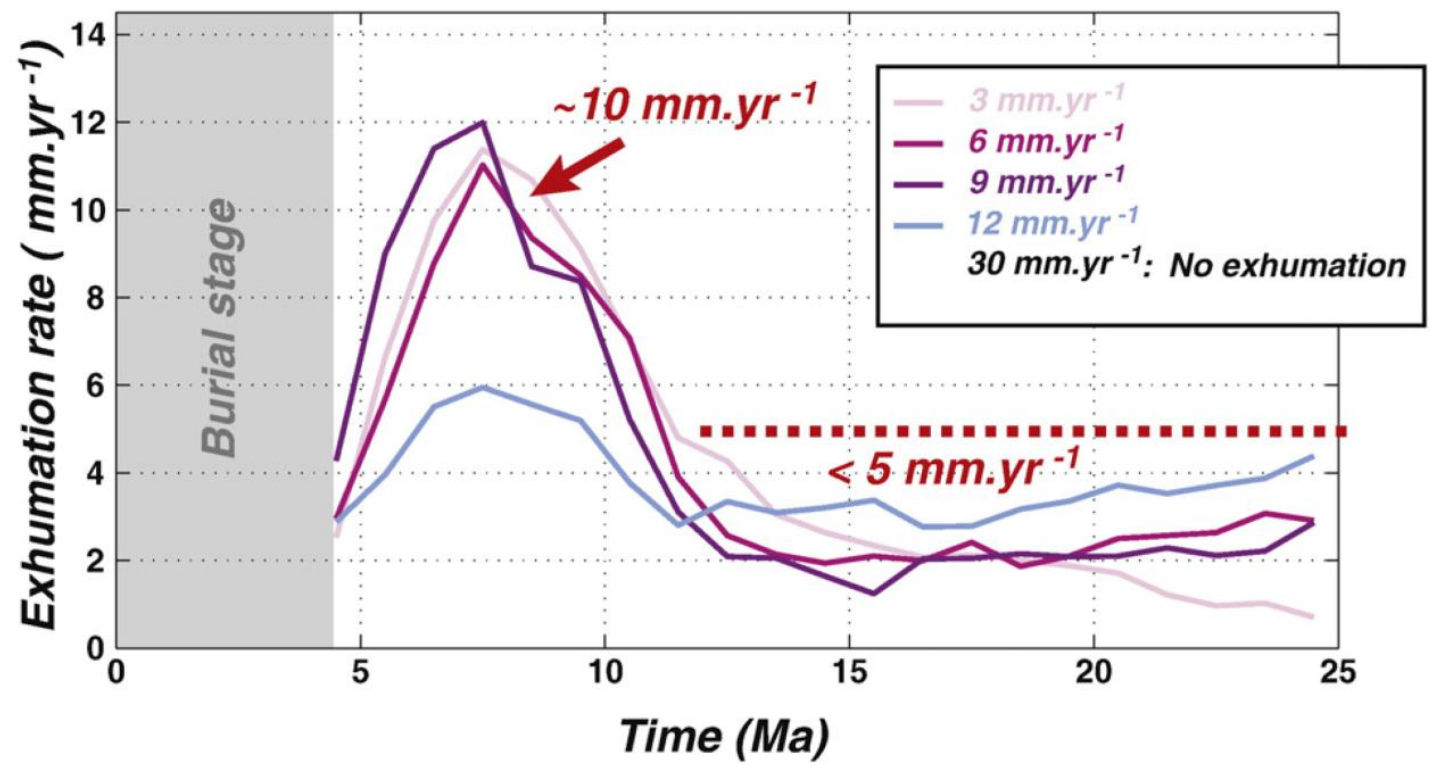

Figure 14 

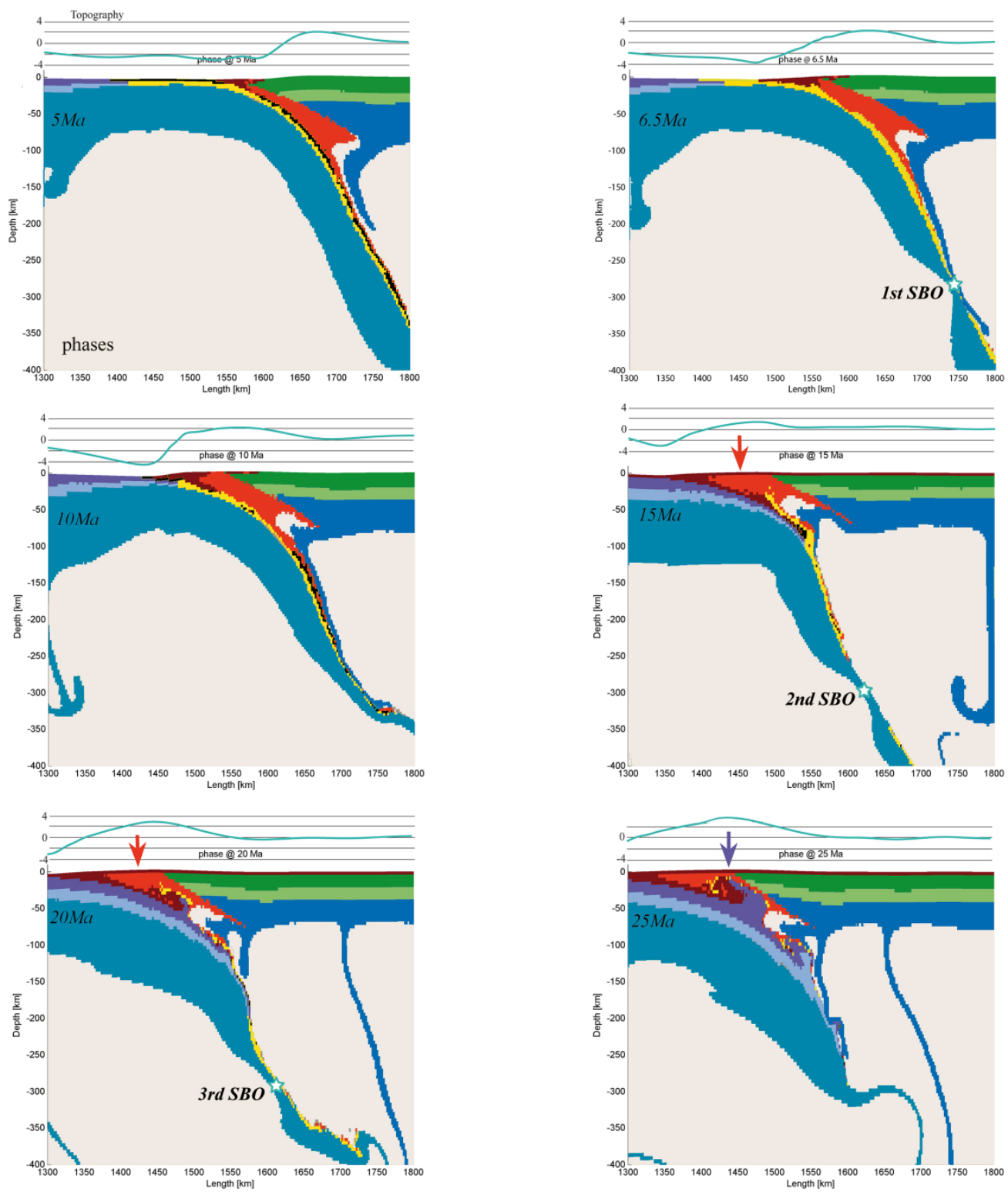

Figure 15a 

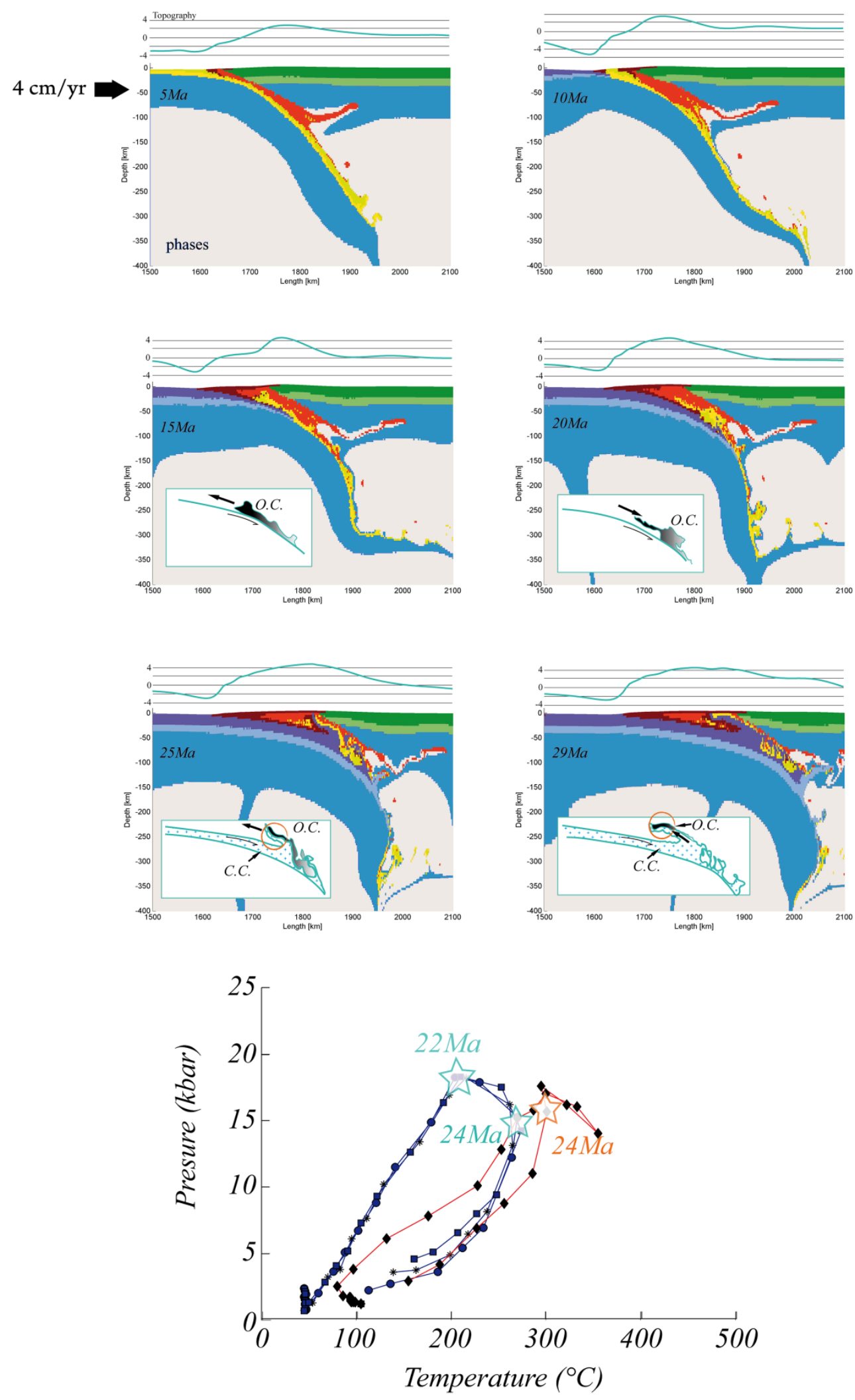

Figure 15b 

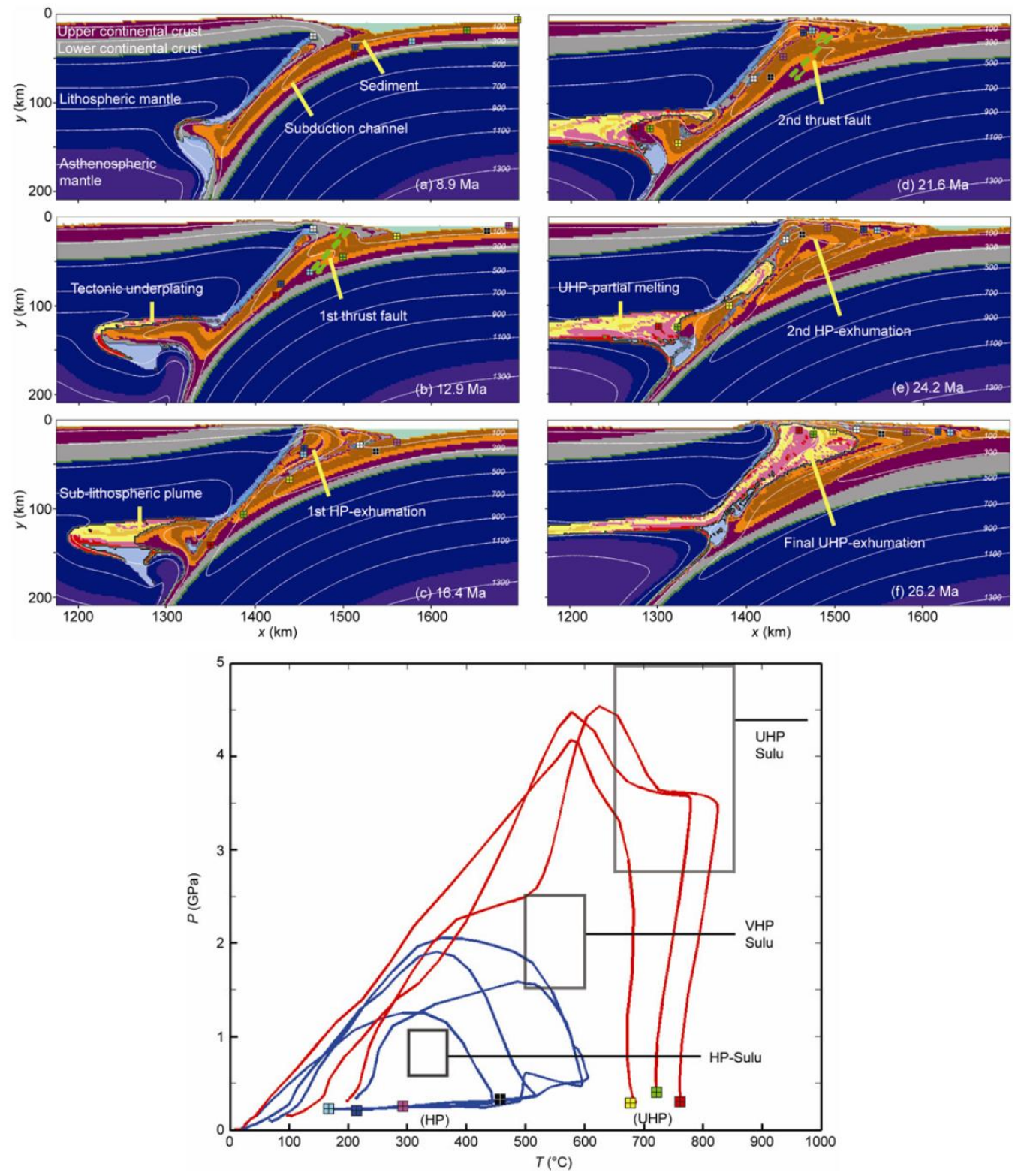

Figure 15c 
influence of convergence polarity (pushing at one side)
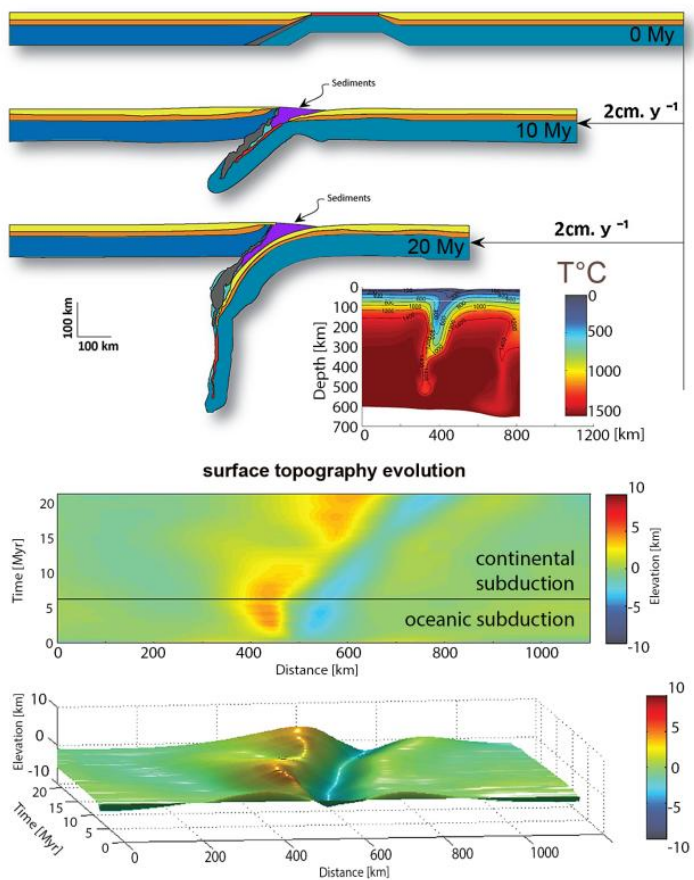

Figure 16 influence of convergence polarity (pushing at two sides)
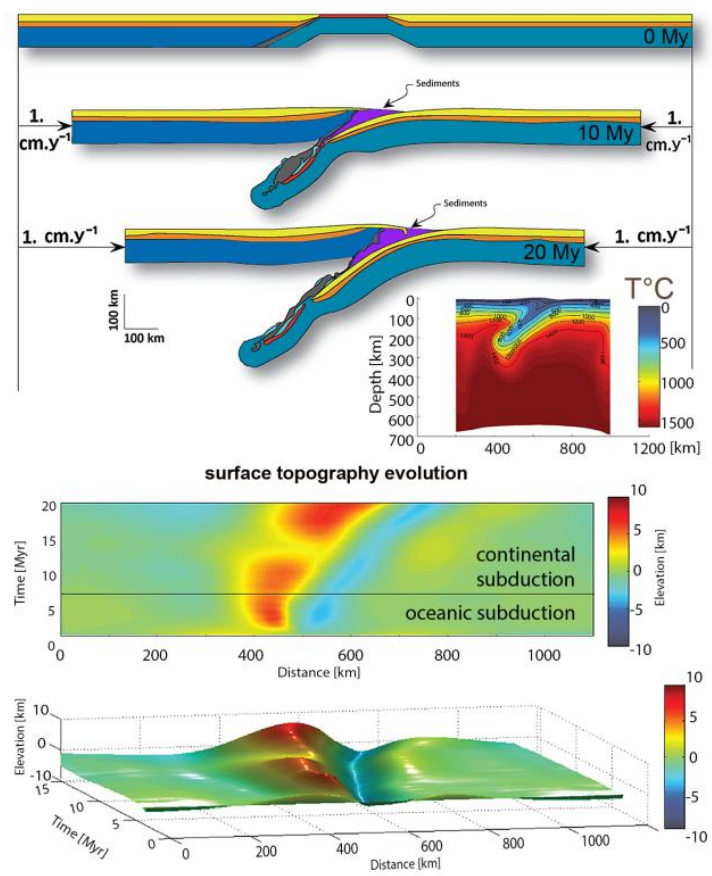
Final stages of subduction-collision, as function of convergence and erosion rate

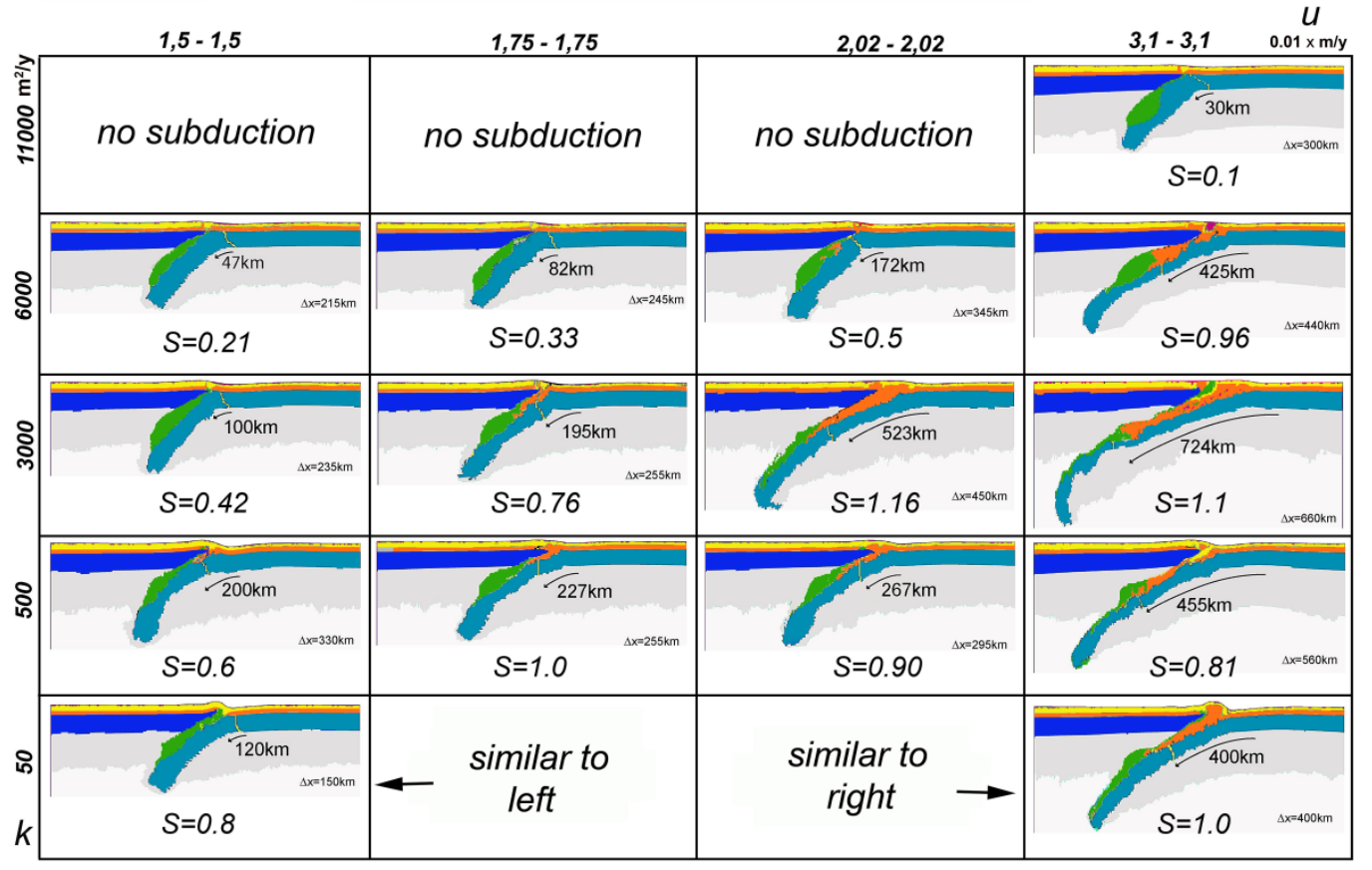

Figure 17 

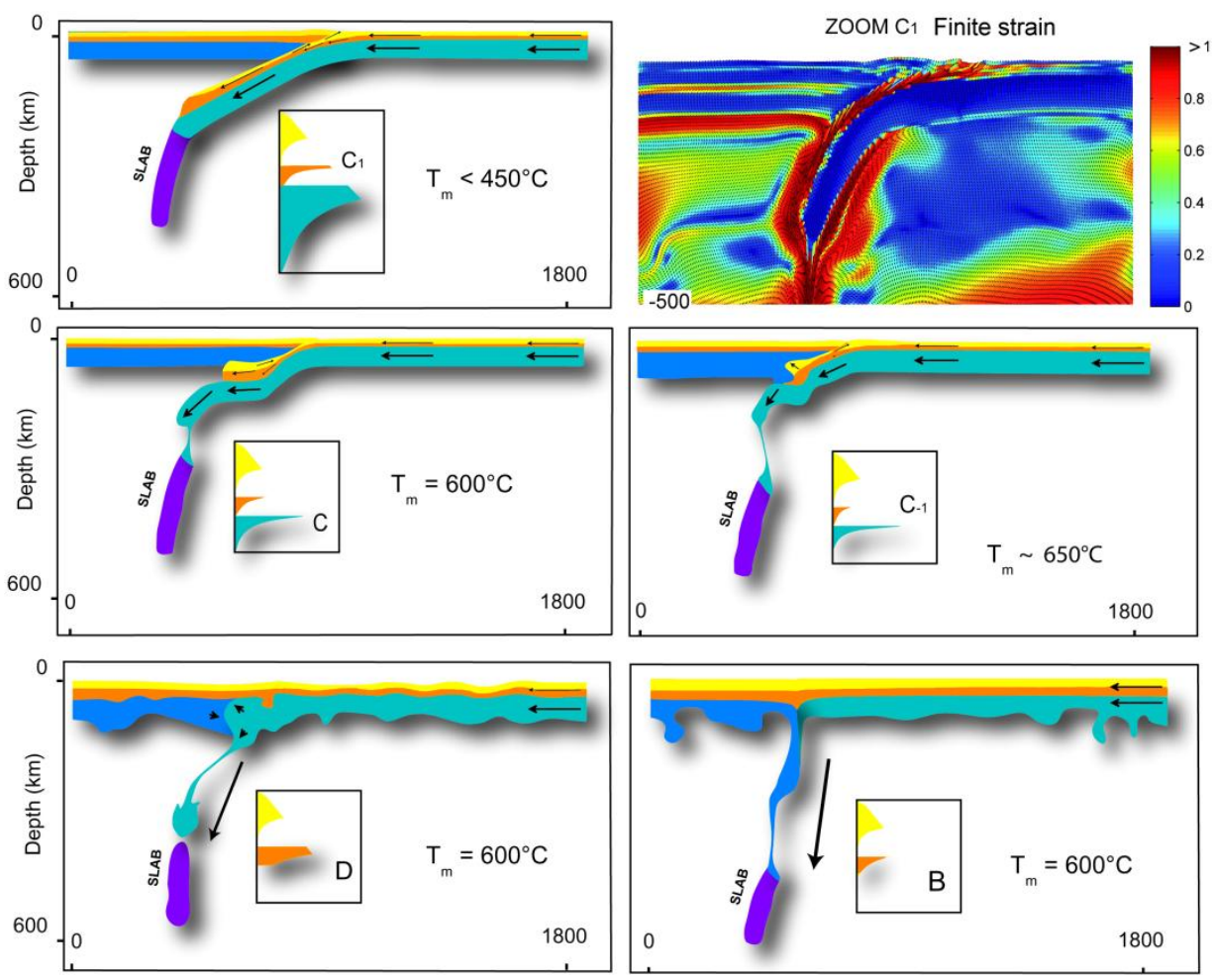

Figure 18a 


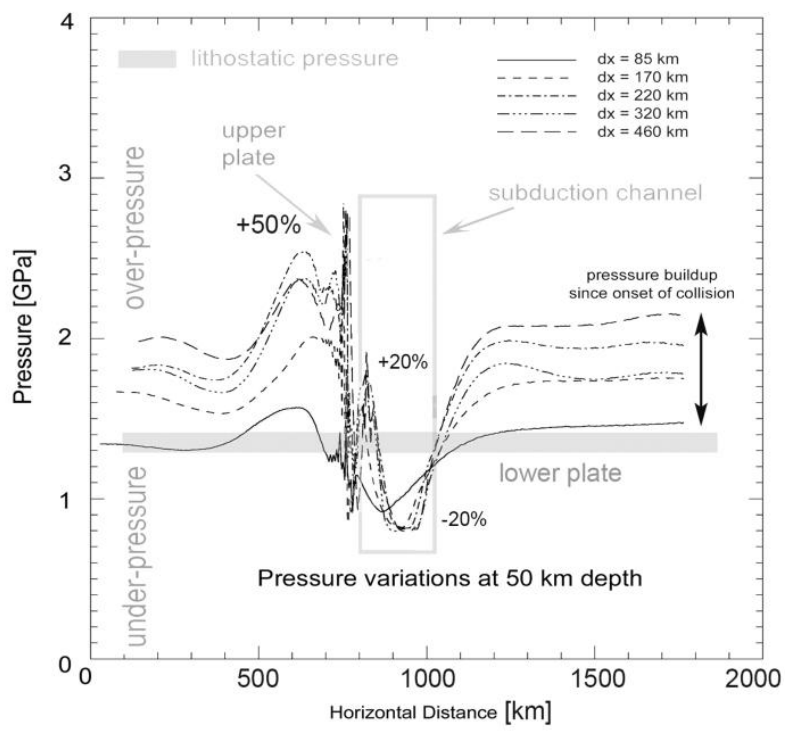

Figure 18b 


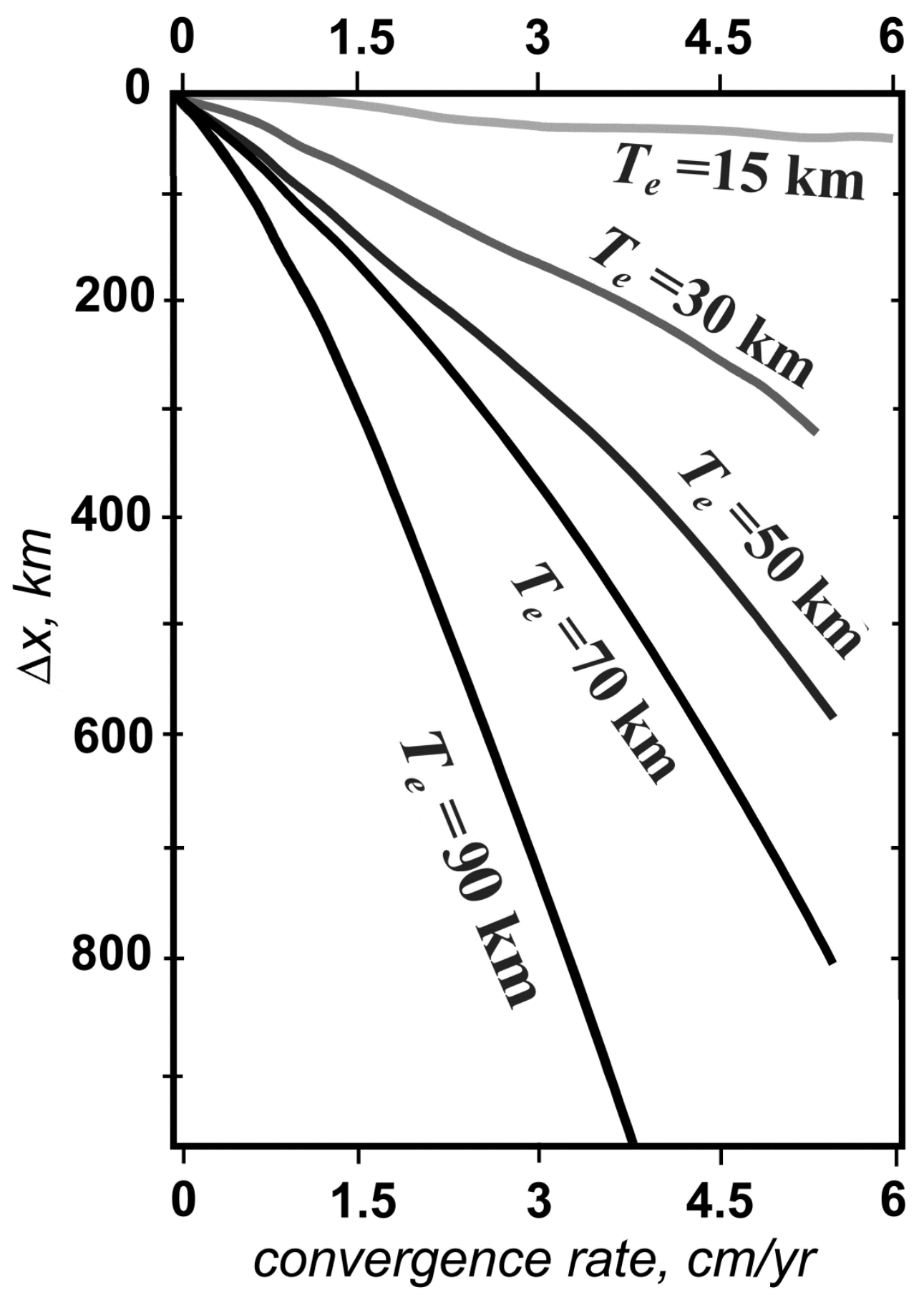

Figure 19 
a)

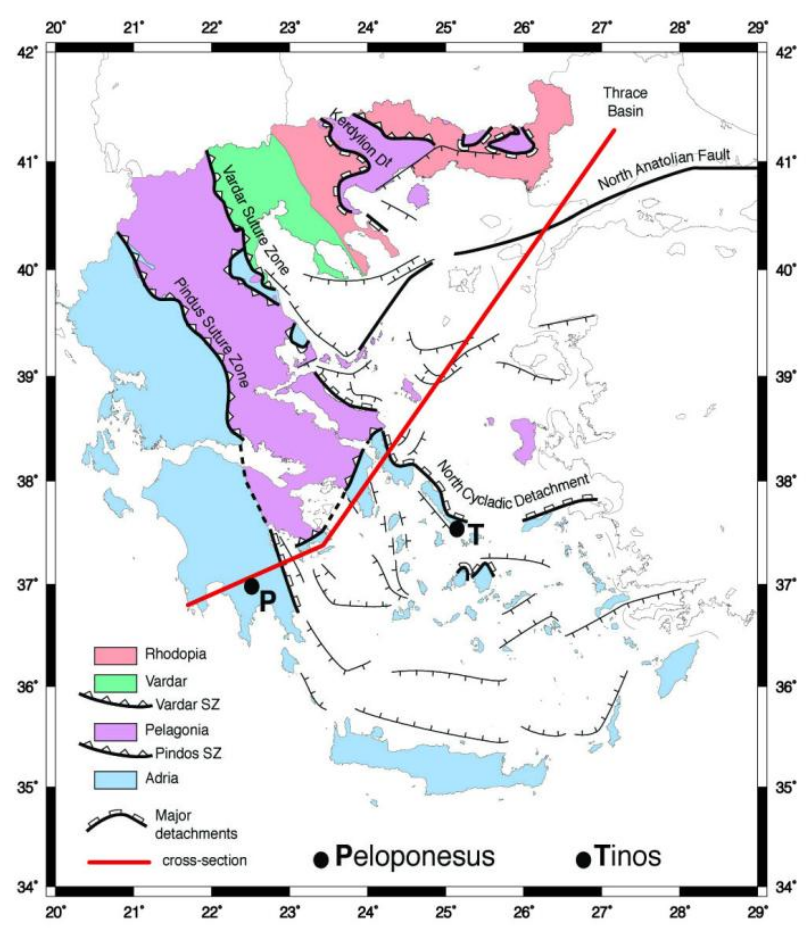

c)

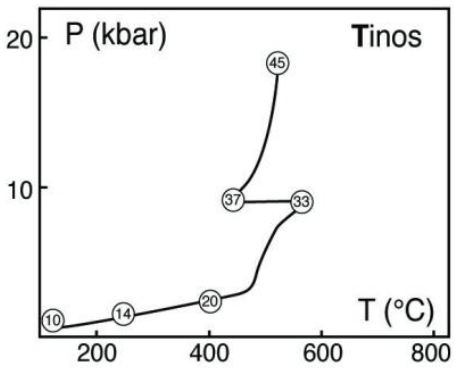

d)

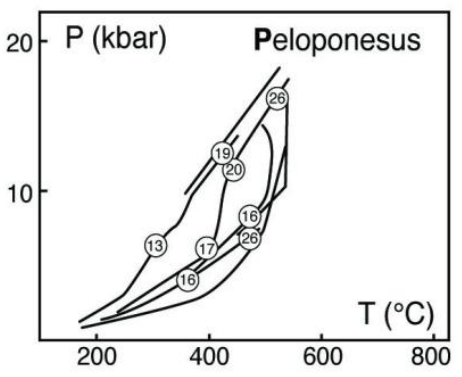

b)

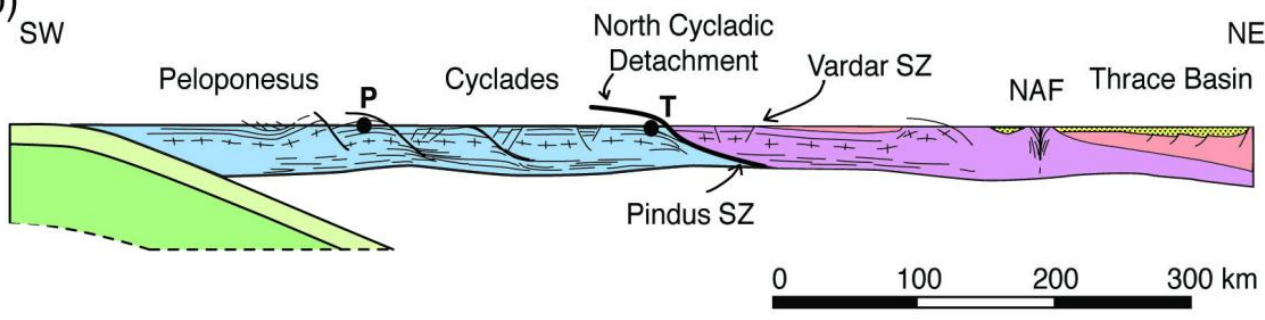

Figure 20 
a)

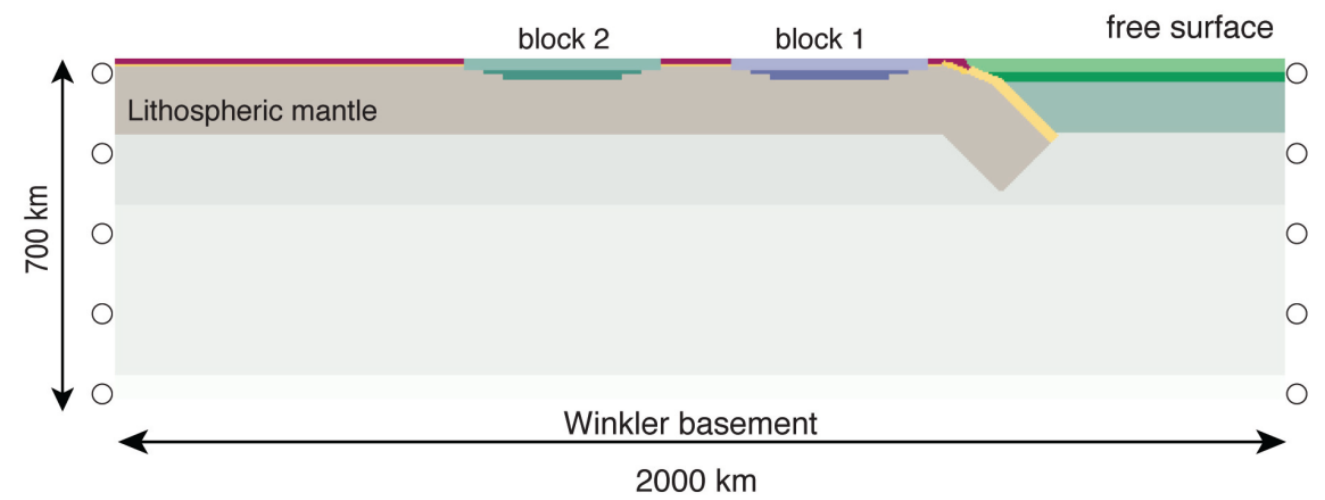

b)
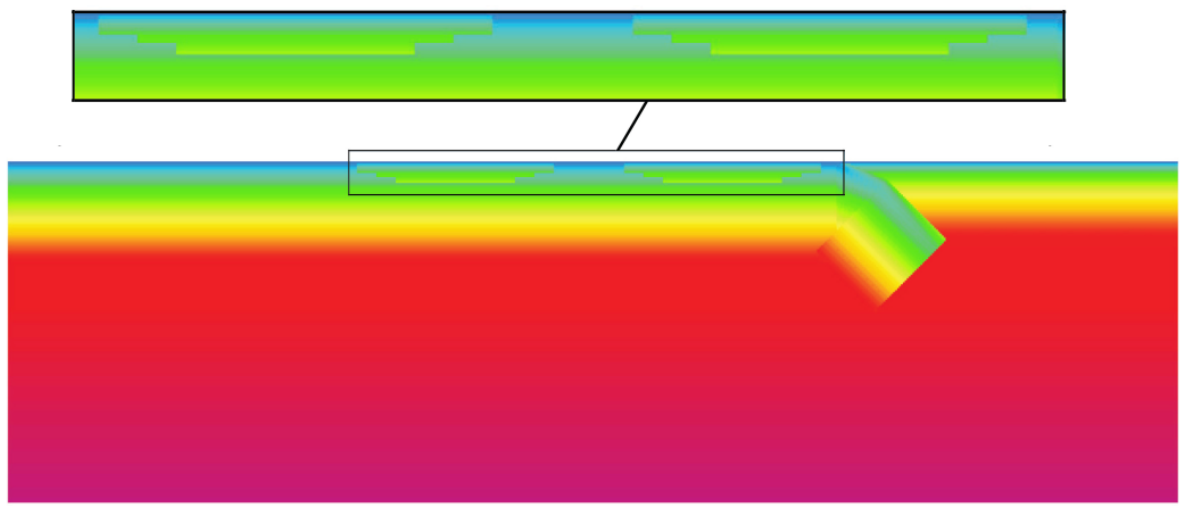

$0^{\circ} \mathrm{C}$

$1500^{\circ} \mathrm{C}$

Figure 21 
a)

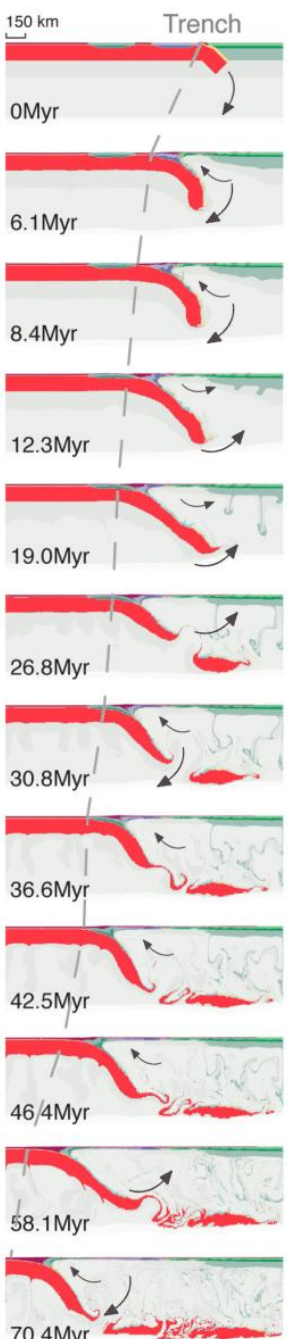

b)
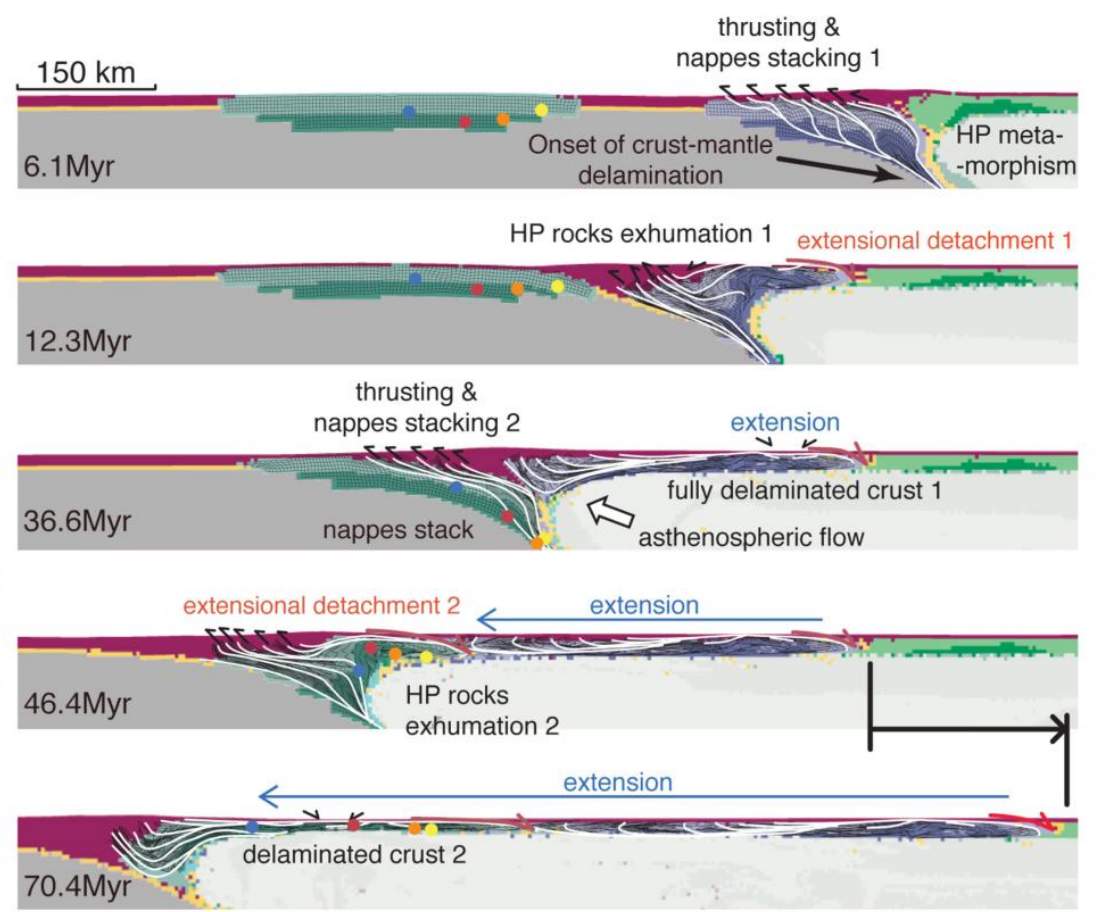

c)

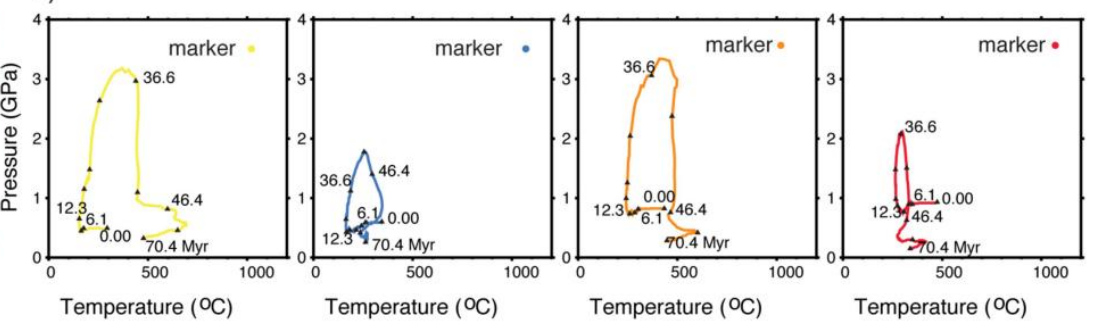

Figure 22 


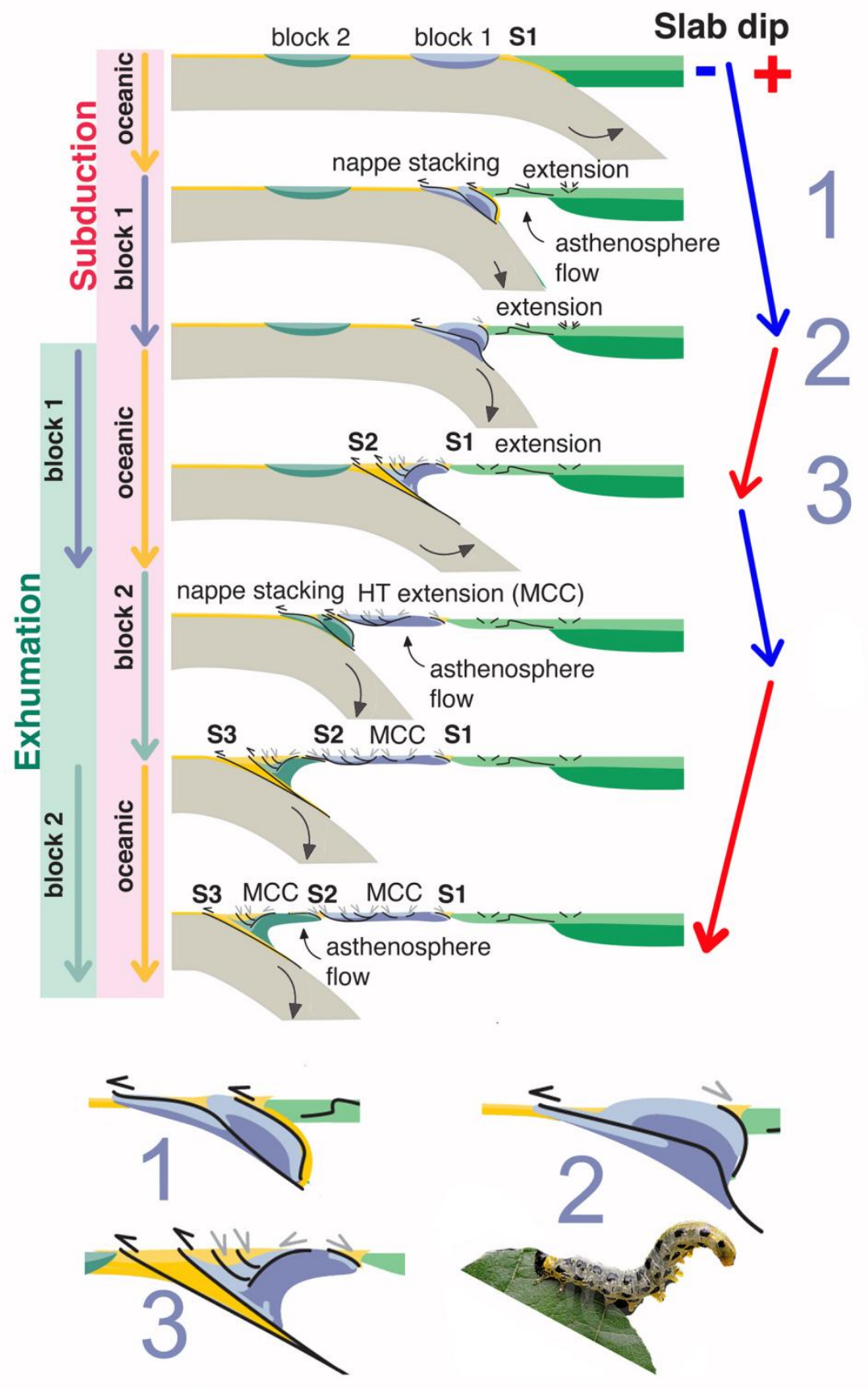

Figure 23 


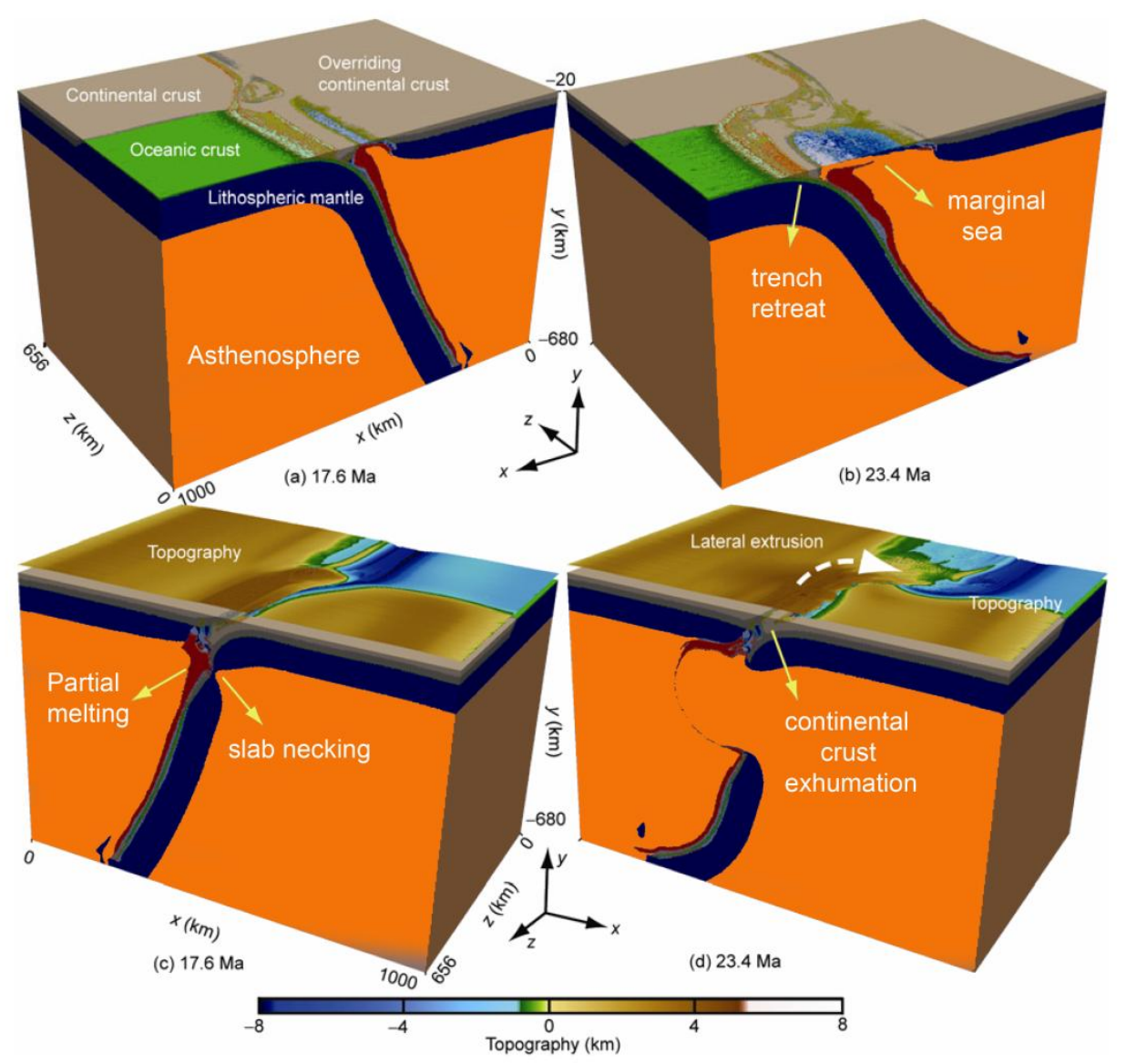

Figure 24 
Highlights

- We study continental subduction and UHP exhumation using advanced numerical models.

- Continental subduction is mainly a transient process requiring strong mantle lithosphere rheology

- During convergence, UHP exhumation occurs at subduction phase.

- UHP exhumation is a poly-phase process driven by viscous buoyancy drag.

- UHP exhumation is favored in slow convergence settings. 